\title{
X-RAY COMPUTED TOMOGRAPHY IMAGE ANALYSIS TO EXPLAIN THE AIRFLOW RESISTANCE DIFFERENCES IN GRAIN BULKS
}

\author{
BY \\ SURESH RAJA NEETHIRAJAN
}

\begin{abstract}
A Thesis Submitted to
the Faculty of Graduate Studies

In Partial Fulfillment of the Requirements for the Degree of

Master of Science
\end{abstract}

Department of Biosystems Engineering

University of Manitoba

Winnipeg, Manitoba

(C) Suresh Raja Neethirajan, March 2005

The Faculty of Graduate Studies

500 University Centre, University of Manitoba

Winnipeg, Manitoba R3T 2N2

Phone: (204) 474 - 9377

Fax: (204) $474-7553$

graduate_studies@umanitoba.ca 
THE UNIVERSITY OF MANITOBA

FACULTY OF GRADUATE STUDIES

$* * * * *$

COPYRIGHT PERMISSION

X-RAY COMPUTED TOMOGRAPHY IMAGE ANALYSIS TO EXPLAIN

THE AIRFLOW RESISTANCE DIFFERENCES IN GRAIN BULKS

BY

SURESH RAJA NEETHIRAJAN

A Thesis/Practicum submitted to the Faculty of Graduate Studies of The University of Manitoba in partial fulfillment of the requirement of the degree

Of

MASTER OF SCIENCE

SURESH RAJA NEETHIRAJAN @ 2005

Permission has been granted to the Library of the University of Manitoba to lend or sell copies of this thesis/practicum, to the National Library of Canada to microfilm this thesis and to lend or sell copies of the film, and to University Microfilms Inc. to publish an abstract of this thesis/practicum.

This reproduction or copy of this thesis has been made available by authority of the copyright owner solely for the purpose of private study and research, and may only be reproduced and copied as permitted by copyright laws or with express written authorization from the copyright owner. 


\begin{abstract}
$\mathrm{X}$-ray Computed Tomography (CT) is a technique that uses X-ray images to reconstruct the internal microstructure of objects. A high resolution X-ray CT system with a resolution of $120 \mu \mathrm{m}$ was used to scan airpaths inside grain bulks. The bulk grains of wheat, barley, flax seed, peas and mustard were scanned along horizontal and vertical directions. The X-ray CT images were analyzed to explain the reported airflow resistance difference along the horizontal and vertical directions of grain bulks. Total airspace, airpath distribution and size of airpaths were determined from the image processing algorithms. Morphological information from the tomographic images showed that the size and number of airpaths vary between horizontal and vertical directions of grain bulks. The number of airpaths and their size were almost double along the horizontal direction than in the vertical direction for wheat, flax seed and barley. However for peas and mustard, the airpath distribution and their sizes were similar $(\mathrm{P}<0.0001)$ along both directions of the grain bulks. The ratio between numbers of airpaths in horizontal and vertical directions is the best predictor of the difference in the airflow resistance in horizontal and vertical directions in the grain bulk.
\end{abstract}




\section{ACKNOWLEDGEMENTS}

I would like to express my gratitude to all those who gave me the possibility to complete this thesis. I am deeply indebted to my advisor, Dr. Digvir Jayas from the Department of Biosystems Engineering (University of Manitoba) for his guidance, stimulating suggestions and encouragement. His company and fatherly treatment will be remembered lifelong.

My sincere thanks are due to $\mathrm{Dr}$. Noel White (Agriculture and Agri-Food Canada) for the help extended to me when I approached him and the valuable discussion that I had with him during the course of research.

Many thanks to Dr. Edward Shwedyk (University of Manitoba) for serving as my committee member and for reviewing my research work. Special thanks are due to Dr. Chithra Karunakaran (University of Manitoba) for extending timely help and sharing her expert knowledge. A generous thank you is owed to Dr. Jitendra Paliwal also from the Department of Biosystems Engineering (University of Manitoba) for his support.

The cooperation I received from other faculty members of the Department of Biosystems Engineering (University of Manitoba) is gratefully acknowledged. I enjoyed my work with the company of the fellow research scholars namely Anand, Aishwarya, Aravind, Fan, Fuji, Govind, Manick, Prabal, Sathya and Vadi. A sincere 
thank you is passed to the technicians and the administrative staff of the Department of Biosystems Engineering for their kind help.

The following industrial and research organizations are gratefully acknowledged for project funding including the Canada Research Chairs (CRC) program and the Natural Sciences and Engineering Research Council (NSERC) of Canada. My gratitude extends to the High Resolution X-ray Computed Tomography Facility at the University of Texas, Austin for providing the X-ray CT images.

I also want to thank my parents, who taught me the value of hard work by their own example. I would like to share this moment of happiness with my brother and sister who rendered me enormous support during the whole tenure of my research.

Finally, I would like to thank all whose direct and indirect support helped me completing my thesis in time. 


\section{TABLE OF CONTENTS}

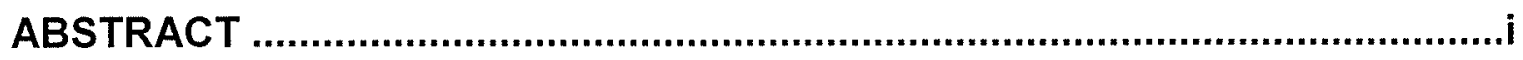

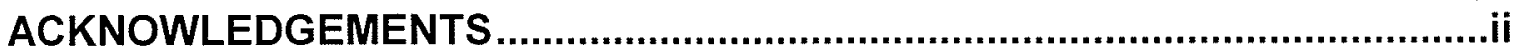

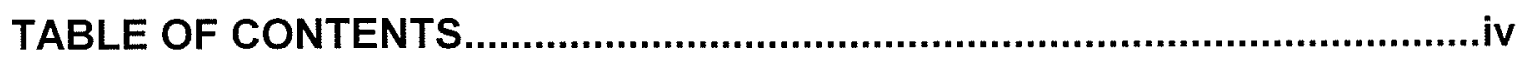

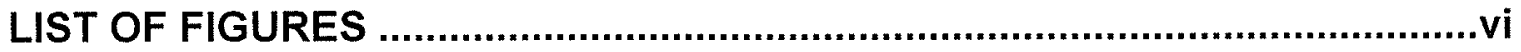

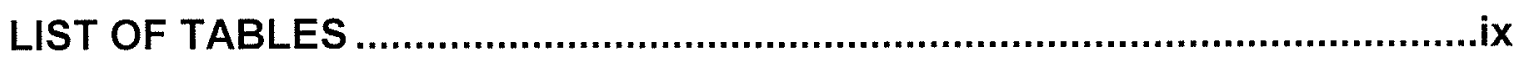

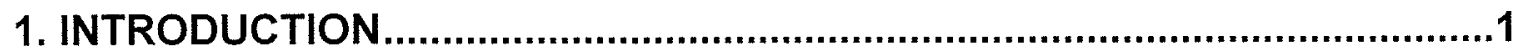

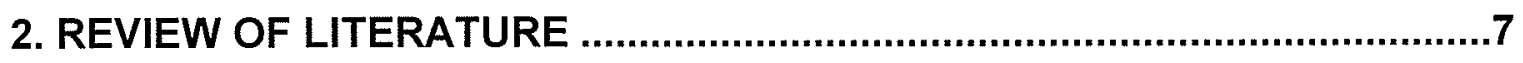

2.1 Effect of airflow direction on resistance of airflow through grain bulks.........7

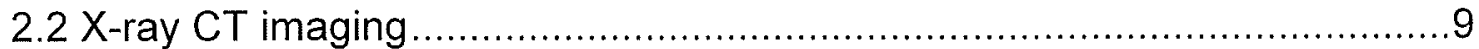

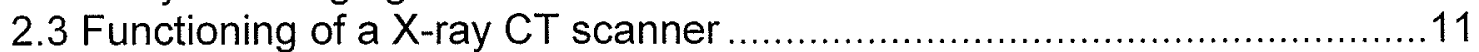

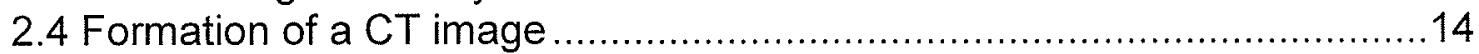

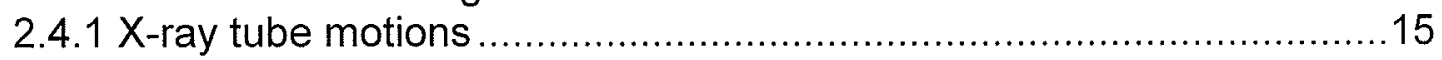

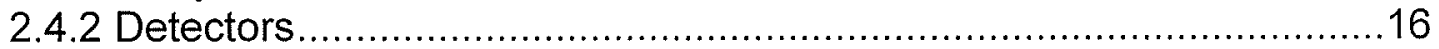

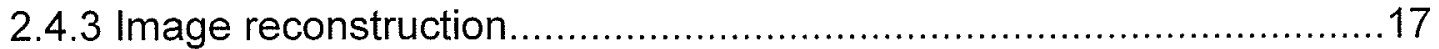

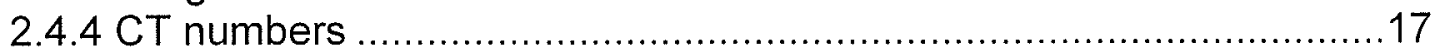

2.4.5 Digital to analog conversion phase ............................................ 18

2.5 Advantages and applications of X-ray CT ..........................................18

2.6 Applications of X-ray CT in the food industry .....................................19

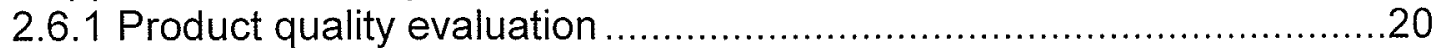

2.6.2 Detection of internal defects in food products ................................24

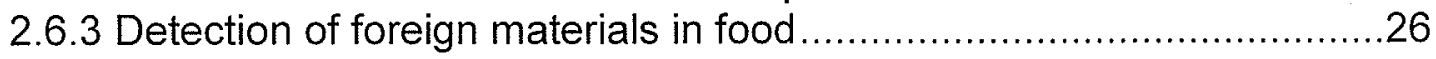

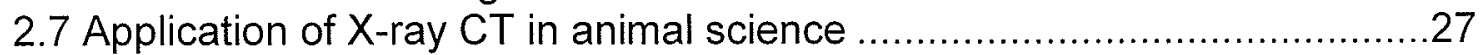

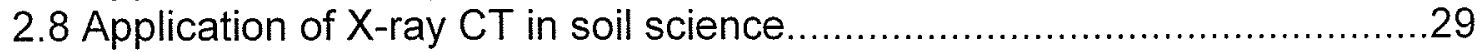

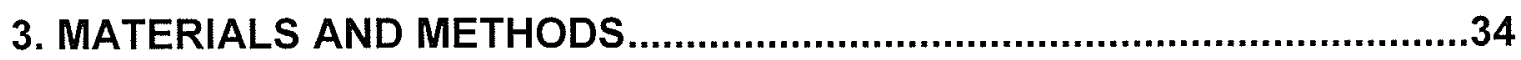

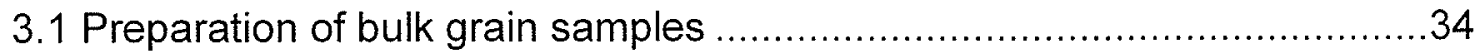

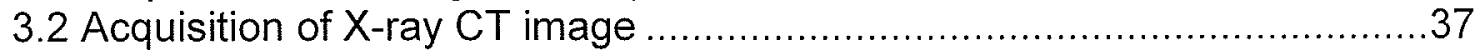

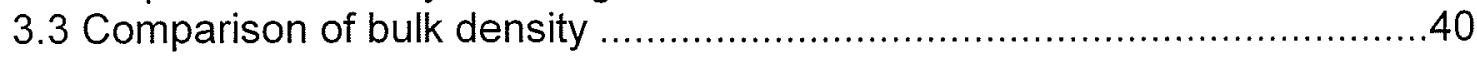

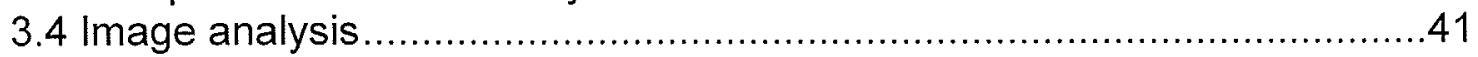

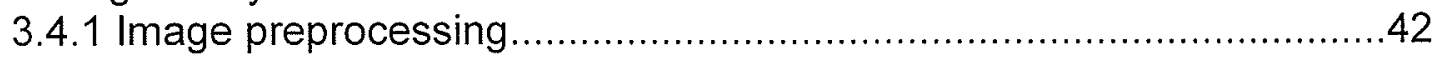

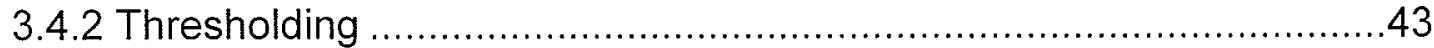

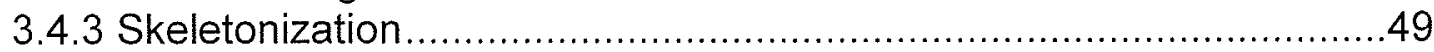

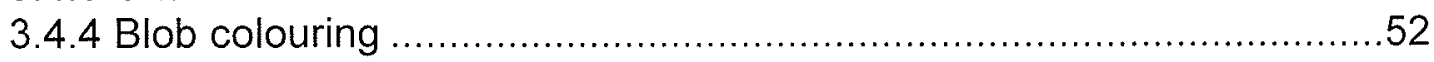

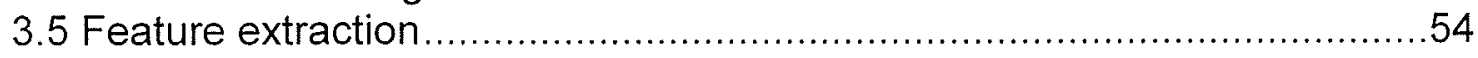

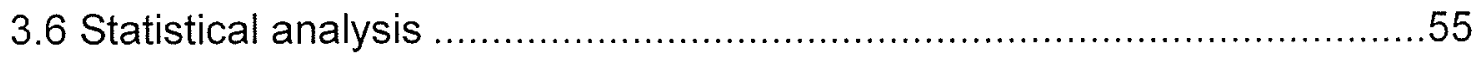




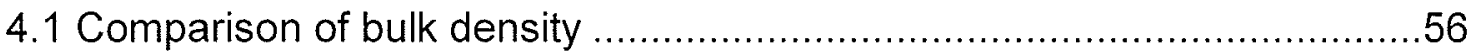

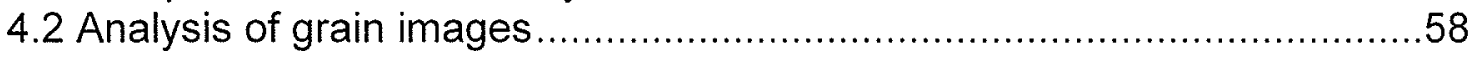

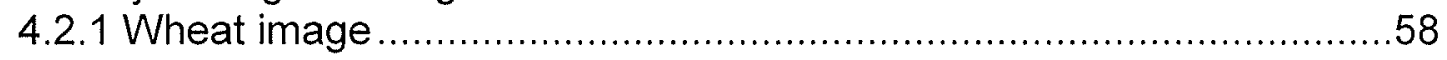

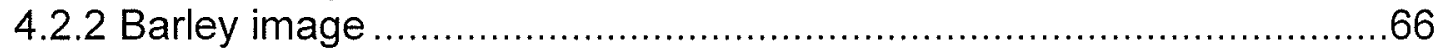

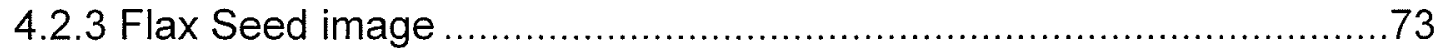

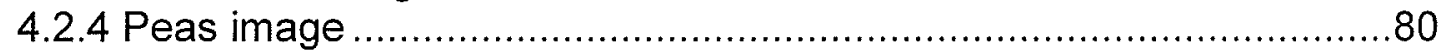

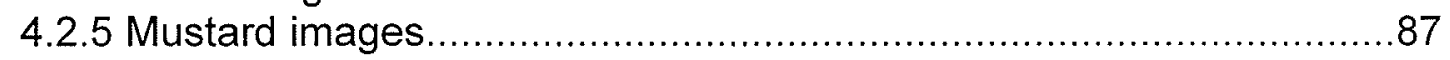

4.3. Comparison of airflow resistance of different grains. ...........................93

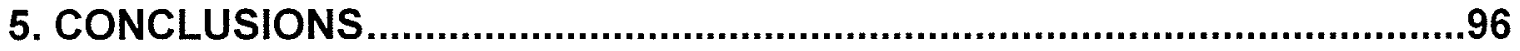

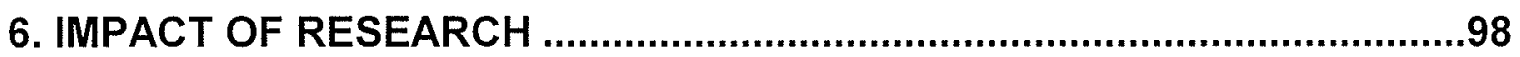

7. REFERENCES 


\section{LIST OF FIGURES}

No.

Title

Page

Fig. 2.1. Photograph of a hospital X-ray CT scanner. 11

Fig. 2.2. Schematic construction of a X-ray CT scanner's gantry. 12

Fig. 2.3. X-ray CT images showing longitudinal internal section of peach (a) fresh b) ripened for 2 weeks.

Fig. 2.4. A CT scan image of a peach fruit and its histogram. The y-axis reflects the CT number and $x$-axis the frequency. 21

Fig. 2.5. X-ray CT scan image of cured ham a).Tomogram showing the overall features of a dry-cured ham, b). Thresholded CT scan image corresponding to a salt content above $4.5 \%$.

Fig. 2.6. A rendered 3D model of aerated chocolate bar numerically cut to show its inner structure.

Fig. 2.7. Reconstructed 2D horizontal X-ray images of aerated confectionary products: a) Marshmallow; b) Chocolate bar.

Fig. 2.8. X-ray CT images of a pear. a) Fresh unaffected pear b) 'Core break down' pear.

Fig. 2.9. X-ray CT scan image showing fat distribution of a fish body .29

Fig. 2.10. X-ray CT image of an undisturbed soil core showing soil macropores.

Fig. 2.11. Three dimensional visualization of a floc of colloidal soil particles. Green represents bacteria while brown represents soil particles. 32

Fig. 2.12. Three dimensional rendering of the macropore network analysed......33

Fig. 3.1. Microscopic images revealing the shapes of grain samples used in this study. a) Barley, b) Wheat, c) Flax Seed, d) Peas, e) Mustard. 36

Fig. 3.2. X-ray CT imaging system. 38

Fig 3.3. Schematic showing the relationship between CT image and airspace...39 
Fig. 3.4. Single slice X-ray CT scan image of a wheat sample a) before cropping b) after cropping.

Fig 3.5.Global thresholdvalues for the horizontal images in a wheat grain bulk. .46

Fig 3.6. Global thresholdvalues for the vertical images in a wheat grain bulk. ....46

Fig. 3.7. Histogram of a single slice of X-ray CT wheat image 48

Fig.3.8. Adaptive thresholded image of the single slice of X-ray CT wheat image. White represents airspace and black represents grain area.

Fig.3.9. A sample of the skeletonised wheat image. White lines represent airflow paths in grain bulk. 51

Fig.3.10. Blob coloured image of a typical X-ray CT wheat image .54

Fig. 4.1. X-ray CT images of a wheat bulk: a) horizontal image (vertical airspace) b) vertical image (horizontal airspace).

Fig 4.2. Blob coloured X-ray CT images of a wheat bulk:a) horizontal image b) vertical image.

Fig 4.3. Distribution of airspace area in different slices of wheat bulk a) horizontal airspace b) vertical airspace. 0 slice corresponds to bottom of the container. ...662

Fig 4.4. Number of airpaths in different slices of wheat bulk images a) horizontal airspace b) vertical airspace

Fig 4.5. Frequency distribution on the length of airpaths in a) horizontal airspace b) vertical airspace of wheat bulk image.

Fig 4.6. X-ray CT images of barley bulk: a) horizontal image (vertical airspace) b) vertical image (horizontal airspace).

Fig 4.7. Blob coloured X-ray CT images of a barley bulk: a) horizontal image b) vertical image.

Fig 4.8. Distribution of airspace area in different slices of a barley bulk a) horizontal airspace b) vertical airspace. 0 slice corresponds to bottom of the container. ....69

Fig 4.9. Number of airpaths in a) horizontal airspace b) vertical airspace of bulk barley images.

Fig 4.10. Frequency distribution of the length of airpaths in a) horizontal airspace

b) vertical airspace of barley bulk image. 72 
Fig 4.11. X-ray CT images of flax seed bulk: a) horizontal image b) vertical image. .73

Fig 4.12. Blob coloured X-ray CT images of bulk flax seed: a) horizontal image b) vertical image. .75

Fig 4.13. Distribution of a) horizontal airspace b) vertical airspace in bulk flax seed images. 0 slice corresponds to bottom of the container. .76

Fig 4.14. Number of airpaths in a) horizontal airspace b) vertical airspace of flax seed bulk images. 78

Fig 4.15. Frequency distribution of the length of airpaths in a) horizontal airspace b) vertical airspace of flax seed bulk images. .79

4.16. X-ray CT images of bulk peas a) horizontal image; b) vertical image.........80

Fig 4.17. Blob coloured X-ray CT images of a pea bulk: a)..... horizontal image b) vertical image.

Fig 4.18. Distribution of a) horizontal airspace b) vertical airspace in bulk pea images. 0 slice corresponds to bottom of the container.

Fig 4.19. Number of airpaths in a) horizontal airspace b) vertical airspace of bulk peas. .85

Fig 4.20. Frequency distribution of the length of airpaths in a) horizontal airspace b) vertical airspace of bulk peas images. 86

4.21. X-ray CT images of mustard bulk: a) horizontal image b) vertical image. ..87

Fig 4.22. Blob coloured X-ray CT images of a mustard bulk: a)horizontal image b) vertical image.

Fig 4.23. Distribution of a) horizontal airspace b) vertical airspace in mustard images. 0 slice corresponds to bottom of the container.

Fig 4.24. Number of airpaths in a) horizontal airspace b) vertical airspace of a mustard bulk image.

Fig 4.25. Frequency distribution of the length of airpaths in a) horizontal airspace

b) vertical airspace of a mustard bulk image. 93 


\section{LIST OF TABLES}

No.

Title

Page

Table 3.1. Summary of image characteristics of different grain bulks 40

Table 4.1. Comparison of calculated bulk densities of grain samples with that of the reported data................................................................ 58

Table 4.2. Comparison of airflow resistance of reported data with the image features

Table 4.3. Statistical analysis on the number of airpaths along the horizontal and vertical airspace of grains 


\section{INTRODUCTION}

Cereals and oilseeds are the major source of food for humans and most domesticated animals throughout the world. Annual world production of the main cereals in millions of metric tonnes are: wheat -554 ; rice -530 ; corn -508 ; barley - 162; and sorghum - 58 (CGC 1998). Annual world production of major oilseed crops in millions of metric tonnes are: soybeans -115 ; cottonseed -33 ; rapeseed (Canola) - 27; sunflower seed - 23; and groundnut - 18 (CGC 1998).

Canada produces a wide variety of grains and oilseeds, which are used for producing breads, pasta, breakfast cereals, vegetable oils, and other food products. Grains include wheat, corn, oats, barley and rye, while oilseeds include canola, soybean, flaxseed, safflower and sunflower seeds (Agriculture and AgriFood Canada 2004). Coarse grains, such as barley and corn are used both for human consumption and as livestock and poultry feed. Canadian farmers are growing more specialty crops such as mustard, lentils, peas, beans, chick peas and canary seed at present than ever before (Agriculture and Agri-Food Canada 2004).

Total production of grains and oilseeds in Canada is $59.6 \mathrm{Mt}$ for the year 2003-2004 (Agriculture and Agri-Food Canada 2004). Wheat is the largest crop in Canada. Canada is the sixth largest producer and the second largest exporter of wheat in the world. Export markets are of major importance to wheat 
producers in Canada because it exports $74 \%$ of its total grain production (CGC 1998).

Farmers normally store grain on their farms in free-standing bins varying in capacity from 25 to $250 \mathrm{t}$. Cylindrical, bolted, corrugated-steel structures on concrete foundations are the most common storage units. Farmers normally have storage capacity for at least one year's production. Throughout the first year and the following year, as demand develops, the grain is delivered by truck to primary elevators (grain handling facilities), processing plants, or fed to the farmer's own livestock.

Stored grains are susceptible to invasion and damage by insects, mites and fungi. The temperature and moisture content of the stored grain are two important non-biological factors that affect the survival, development, and activity of these biological organisms.

During storage, grain is aerated to cool it and to eliminate temperature gradients so that the deterioration processes will cease or be reduced to an acceptable rate (Foster and Tuite 1992). Under some circumstances, aeration is used to warm stored grain in the spring to prevent condensation (Friesen and Huminicki 1987). In western Canada, harvested grain is often stored at high temperature and has different moisture contents. High grain temperature and moisture content can lead to grain spoilage. Cooling or aeration brings the grain 
throughout the bin to a lower and uniform temperature thereby preventing moisture migration due to temperature differences in the bulk, and thus reducing the risk of grain spoilage. Aeration is also used for the removal of odors, reduction of respiration rates and inhibition of molds (Chuma et al.1983).

Keeping the grain cool and dry is the most effective method of ensuring safe storage. To achieve this, air is forced through the grain to dry it or to cool it. Depending on the flow rate and the inlet air conditions, these forced ventilation systems are classified as hot air drying, natural air drying and near-ambient drying (Alagusundaram and Jayas 1990).

The air flow rate through the packed bed determines the rate of drying or cooling. To design grain cooling and drying systems, information on the airflow resistance of grains is needed. The performance of the forced-ventilation processes depends on the uniformity of airflow distribution in different regions of the grain mass. The determination of this resistance is essential for designing an energy efficient forced ventilation system, as well as for choosing the correct fan size (Matthies and Peterson 1974).

The airflow-pressure drop relationships are basic inputs to the mathematical models for predicting the pressure pattern and airflow distribution within the stored grain mass (Brooker et al. 1974; Jayas et al. 1990). Airflow resistance helps to determine static pressure requirements of fans and also to assess filling 
depths in storage bins. The higher the air flow rates, the faster will be the cooling or drying of grain.

The resistance to airflow through grains is affected by several factors such as air velocity and viscosity; moisture content of the grain; shape and size of kernels; grain surface roughness characteristics; configuration of voids; amount, size and distribution of foreign materials; method of filling and direction of airflow. Several researchers have conducted experiments to determine the effect of these parameters on the resistance of grains to airflow (Jayas et al. 1987; Kumar and Muir 1986; Alagusundaram et al. 1992). They also determined that there is a difference in airflow resistance between horizontal and vertical directions in grain bulks.

Until now, no scientific effort has been made to explain why there is a difference in airflow resistance between horizontal and vertical directions of grain bulks. Some plausible explanations have been reported in the literature (Jayas et al. 1987). This new knowledge will help to understand the importance of airflow direction and packing on resistance of grains to airflow.

Methods such as magnetic resonance, ultrasound, and X-ray computer tomography (CT) are well known and useful diagnostic techniques in medicine. These are now used for the non-destructive examination of agricultural products (Dull 1986; Bull 1993; Self et al. 1993; Tollner 1993). X-ray CT has been used to 
determine the maturity of tomatoes, mangoes and head lettuces and to detect the cracked seeds in peaches (Brecht et al. 1991; Thomas et al. 1993).

X-ray CT is a widely used technique to determine a number of physiological as well as pathological processes. Computer tomographic images have been used extensively to quantify features such as macropores in soil and fractures and density of soil samples (Anderson et al.1990; Hopmans et al. 1994). X-ray CT is a promising approach for detecting physical factors relating to voids or structures, desiccation or undesirable fragments such as pits and other foreign materials such as stones, soil, or machinery parts (Tollner 1993).

X-ray CT has the ability to distinguish between objects of different density. It is increasingly being used in geosciences and archaeology for textural analysis and for the geometric description and quantification of porosity and water distribution in rocks and soils (Adderley et al. 2001; Hopmans et al. 1992; Ketcham and Carlson 2001).

The hypothesis of this research is that the analysis of X-ray CT images can be used to explain the difference in airflow resistance in both horizontal and vertical directions in grain bulks. 
The following specific objectives were formulated to validate the hypothesis.

1) to acquire images of grain bulk samples non invasively using $X$-ray $C T$,

2) to develop algorithms to extract airspace, number of airpaths and the length of airpath features from the X-ray CT images, and

3) to use the extracted features to compare the air paths in the vertical and horizontal directions from the X-ray CT images. 


\section{REVIEW OF LITERATURE}

\subsection{Effect of airflow direction on resistance of airflow through grain bulks}

In near-ambient drying and aeration systems, the resistance of airflow through the grain bulks, expressed as pressure drop per unit depth of the product, plays a major role in fan selection and system design.

In most studies the resistance to airflow of agricultural products has been assumed equal in all directions. Resistance to airflow changes with the airflow direction in relation to the orientation of kernels in the grain bulk. Resistance to airflow in both directions can vary because of non uniformity of both porosity and distribution of kernel size of grain that form the bed (Lai 1980). Lamond and Smith (1982) observed the tendency of long kernels of Midas barley to lie with their major axes horizontal and speculated that it is likely that different porosities and pathway configurations are presented horizontally and vertically causing a variation in the airflow resistance in each direction. They supported this speculation with indirect measurements and finite element modeling. Jayas and Sokhansanj (1986) were the first to demonstrate this experimentally in canola in their preliminary study.

Kumar and Muir (1986) compared the pressure drop data of wheat and barley in the vertical and horizontal airflow directions at an arbitrarily chosen air velocity 
of $0.077 \mathrm{~m}^{3} /\left(\mathrm{m}^{2} \mathrm{~s}\right)$. They reported that the airflow resistance of wheat was up to $115 \%$ higher when the airflow direction was vertical as opposed to horizontal.

Resistance to airflow is also significantly affected by bin filling methods (Stephens and Foster 1976; Chang et al. 1983; Jayas and Muir 1991). Mechanical spreaders used in commercial bins caused 100 to $300 \%$ more resistance to airflow than a conventional central spout system. Greenkorn (1983), while discussing airflow through porous media, indicated the importance of porosity, permeability, tortuosity and connectivity for relating pressure drop and superficial velocity for an anisotropic medium. If these parameters are different for each direction, then different airflow resistances may occur.

Jayas et al. (1987) studied horizontal and vertical airflow resistance of canola in the airflow range of $0.0158-0.1709 \mathrm{~m}^{3} /\left(\mathrm{s} \cdot \mathrm{m}^{2}\right)$. They tested clean canola and canola mixed with foreign material. Horizontal airflow resistance varied from 50 to $70 \%$ of vertical airflow resistance. For practical purposes it was suggested to use a value $60 \%$ of the value in vertical direction for the resistance in horizontal direction.

Irvine (1989) found that the resistance of flax seed in the horizontal direction was 0.38 to 0.65 times the resistance in the vertical direction. Alagusundaram et al. (1990) studied the effect of direction of airflow on the resistance of eight different grain legumes and grass seeds, in the airflow range of 0.035 to 0.28 
$\mathrm{m}^{3} /\left(\mathrm{m}^{2} \mathrm{~s}\right)$. They reported that for small seeds the resistance to airflow in the horizontal direction was 0.3 to 0.7 times the resistance to airflow in the vertical direction, and for larger seeds such as beans and peas, the resistance to airflow in both directions was the same. These measurements indicate that nearambient drying and aeration systems designed to facilitate movement of air horizontally would conserve energy during drying and cooling of the grain.

Kay et al. (1989) studied the horizontal and vertical airflow resistance of shelled corn at various bulk densities and found that airflow resistance of shelled corn for horizontal airflow is about 0.58 times that for vertical airflow. They also speculated that differences in air pathway sizes and lengths may cause the airflow resistance differences. They also concluded that larger, shorter and straighter air pathways have less resistance to air flow which was the situation for horizontal airflow.

\section{$2.2 \mathrm{X}$-ray $\mathrm{CT}$ imaging}

The pace of scientific discovery and technological transformation has fundamentally altered almost every aspect of human life. Science and technology today provide powerful instruments for understanding and controlling the world.

Feeding the ever-growing world population is one of the world's emerging challenges. Consumers are placing significant importance on the quality of food 
products that they purchase. Therefore, there is a need to preserve the quality of food products and to inspect them before delivering them to the consumers. Consumer demand has forced the agricultural and food industries to place an increased emphasis on quality monitoring of products in a non-destructive manner. This in turn has stimulated the development of new technologies that can be applied for real time applications.

Modern agricultural and food research needs good data acquisition techniques to evaluate the product quality. The most common internal quality evaluation methods are done by $\mathrm{X}$-ray and X-ray CT methods. X-ray gives two dimensional images while X-ray CT extracts three dimensional information.

A new milestone in the development of radiology was achieved when Godfrey Hounsfield (1972) proposed to get additional anatomical information of a crosssectional plane of a human body from X-ray transmission data. Thus, the idea of X-ray CT was born and the dramatic development of X-ray CT imaging technology began, enhancing efficiency and potential for non-destructive examination of products.

Hounsfield developed computed tomography in 1972. He was awarded the Nobel Prize for his invention in 1979. The word 'tomography' is derived from two Greek words: 'tomo' meaning 'slice' or 'section', and 'graphy' meaning 'to write' or 'to display'. The CT scan enables three-dimensional, non-destructive imaging of 
the internal structure of the object under examination using measurements of the attenuation of a beam of radiation.

\subsection{Functioning of a X-ray CT scanner}

An X-ray CT scanner is comprised of the following components: a scanning gantry, an X-ray generator, detector, central processing unit (CPU), the operator's monitor, and an image storage and production device. Comprehension of each of these parts and their relation to one another is helpful in understanding the overall functioning of a CT scanner (Brooker 1986). Figure 2.1 shows the photograph of a medical X-ray CT scanner.

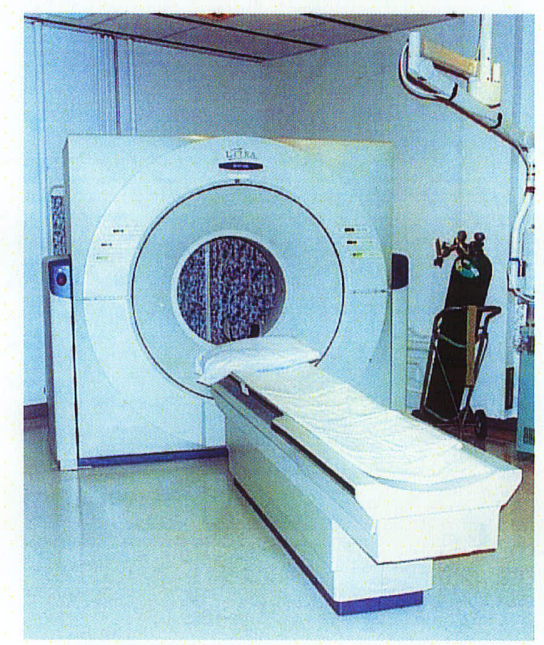

Fig. 2.1. Photograph of a hospital X-ray CT scanner. 
The gantry is a structure that encompasses mechanisms responsible for generating and detecting $\mathrm{X}$-rays. The $\mathrm{X}$-rays produced from the generators are passed through the collimators on the object to be scanned. The X-rays passing through the object are detected by detectors, collecting the X-ray attenuation and diffraction data. The data are processed by a CPU and displayed on the operator's monitor. Concurrently, the image is digitally stored for future reference and comparison. Figure 2.2 shows the schematic diagram of a X-ray CT scanner gantry construction.

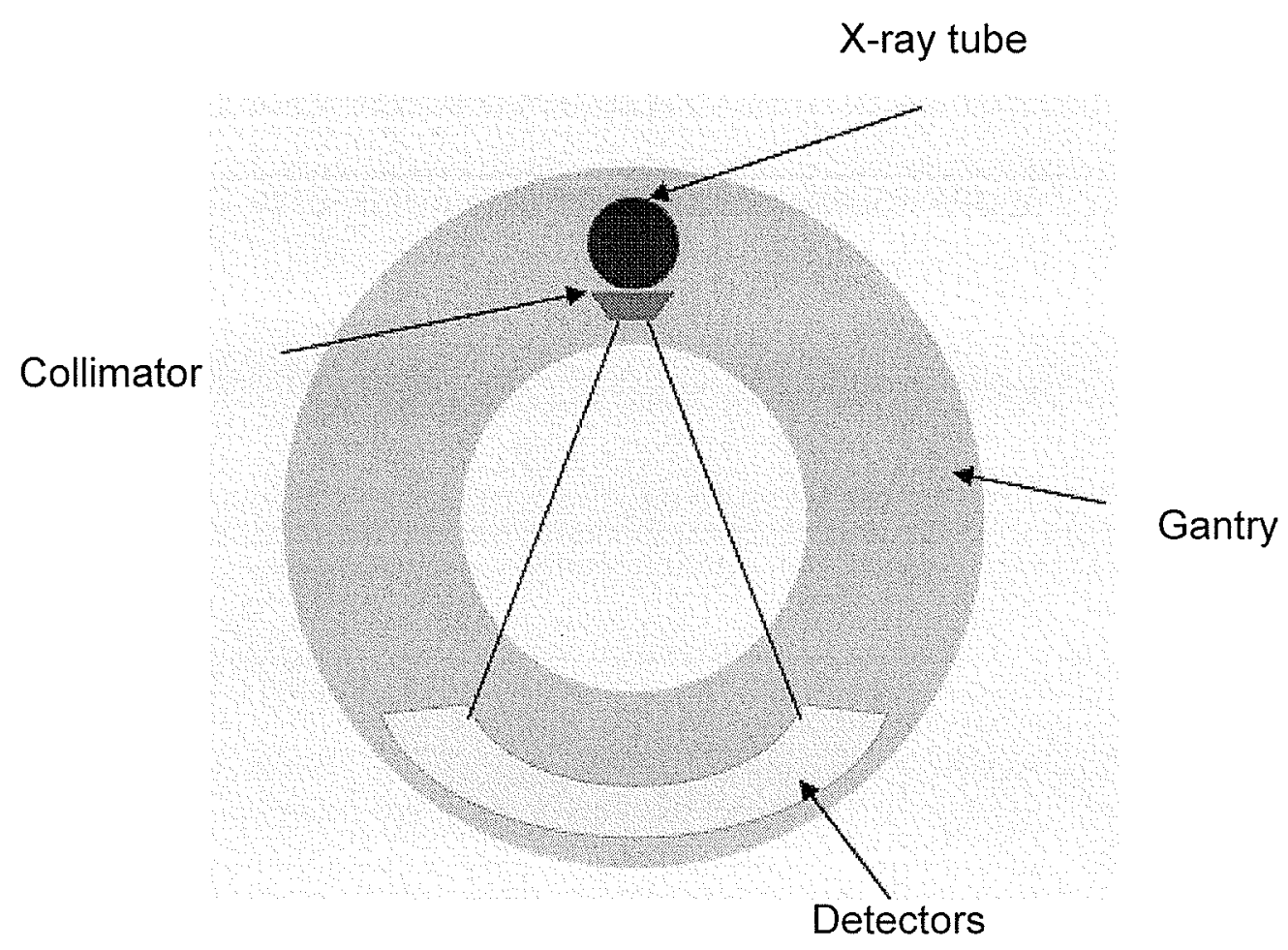

Fig. 2.2. Schematic construction of a X-ray CT scanner's gantry. 
The process of computed tomography begins in the X-ray tube. The metallic filament inside the tube is heated, exciting the valence electrons of the filament. Upon heating, electrons are released and subsequently accelerated toward a tungsten anode. The force propelling the electrons from the filament cathode to the tungsten anode is supplied by the external voltage generator. Impact of the accelerated electrons with the positive tungsten anode yields X-ray energy as well as thermal energy which heats the anode. Advances in computed tomography have led to revolving anodes which function to prevent overheating of the X-ray tube and maintain proper functioning of the CT scanner (Brooker, 1986).

The principal function of a computed tomography device is to produce numerous cross-sectional images and scans in a short period of time. As opposed to a standard X-ray instrument, a CT scanner has a mobile X-ray tube and detecting material that covers the full $360^{\circ}$ of a circle. This enables the scanner to effectively generate cross-sectional images of the object from any angle. By simply adjusting the computer-controlled gantry components, images from opposite perspectives (separated by $180^{\circ}$ ) can then be averaged to obtain a more accurate representation of each "slice" of an object.

From the detector, collected data are instantly processed by the computer. Based on the degree of penetration and the level of attenuation of thousands of X-ray beams, the molecular density of each material present within the object can 
be calculated. The calculated values are then compared to numerous molecular densities registered in a comprehensive database. The collected attenuation data are subsequently converted into a visible image through mathematical algorithms by reconstruction analysis and displayed on the operator's monitor.

\subsection{Formation of a CT image}

The formation of a CT image is a distinct three phase process.

a) The scanning phase produces data, but not an image.

b) The reconstruction phase processes the acquired data and forms a digital image.

c) The displayed analog image (shades of gray) is produced by the digital-to analog conversion phase.

There are adjustable factors associated with each of these phases that can have an effect on the characteristics and quality of the image (Seeram 1996).

During the scanning phase a fan-shaped $\mathrm{X}$-ray beam is scanned around the object. The amount of $\mathrm{X}$-radiation that penetrates the object along each individual ray through the object is measured by the detectors that intercept the X-ray beam after it passes through the object.

The projection of the fan-shaped X-ray beam from one specific X-ray tube focal spot position produces one view. Many views projected from around the object's body are required to acquire the necessary data to reconstruct an image. 
The CT images have five specific image quality characteristics. These are:

1) contrast sensitivity blurring and 2) visibility of detail, 3) visual noise, 4) artifacts, and 5) spatial (tomographic slice or volume views). Each of these characteristics are affected by the selection of protocol factor values that control the imaging process.

A complete scan is formed by rotating the $\mathrm{x}$-ray tube completely around the object body and projecting many views. Each view produces one profile or line of data. The complete scan produces a complete data set that contains sufficient information for the reconstruction of an image. In principle, one scan produces data for one slice image.

The principal objective of CT imaging is to produce a digital image (a matrix of pixels) for a specific slice of tissue. During the image reconstruction process, the slice of tissue is divided into a matrix of voxels (volume elements). A CT number is calculated and displayed for each pixel of the image. The value of the CT number is calculated from the $x$-ray attenuation properties of the corresponding tissue voxel.

\subsubsection{X-ray tube motions}

There are two distinct motions of the $\mathrm{x}$-ray beam relative to the object during CT imaging. One motion is the rotation (scanning) of the beam around the object. The other motion is the movement of the beam along the length of the object. 
The motions are achieved by moving the object through the beam while it is rotating around.

\subsubsection{Detectors}

The radiation detectors are very small elements that are arranged in rows that span and intercept one view. The function of the detector is to measure the quantity of $\mathrm{x}$-rays transmitted through the object along a direct path from the $\mathrm{x}$ ray tube. Measurements are taken many times per second as the $x$-ray tube rotates around the object. These measurements, in the form of electrical signals, are digitized and stored in a powerful computer.

A specific CT machine can be designed to have either a single row of detectors or multiple rows. There are advantages in having multiple rows. An object section can generally be scanned faster with a multiple row detector system because there are multiple fan beams scanning simultaneously. This is especially significant when covering a relatively large object section with thin beams for the purpose of producing thin, high-detail slice images or $3 \mathrm{D}$ volume images.

A volume data set can be used to reconstruct 3-D images. A general requirement for good-quality 3-D images is that the data set should have good details in the axis direction. This is achieved by scanning with thin beams. 


\subsubsection{Image reconstruction}

Image reconstruction is the phase in which the scanned data set is processed to produce an image. The image is digital and consist of a matrix of pixels. Filtered back projection is the reconstruction method used in CT for image reconstruction. 'Filtered' refers to the use of the digital image processing algorithms that are used to improve image quality or change certain image quality characteristics, such as detail and noise. 'Back projection' is the actual process used to produce or "reconstruct" the image.

\subsubsection{CT numbers}

The CT numbers are calculated from the $\mathrm{X}$-ray linear attenuation coefficient values for each individual tissue voxel. The attenuation coefficient is first calculated by the reconstruction process and then it is used to calculate the CT number values.

Water is the reference material for CT numbers and has an assigned value of zero. Tissues or materials with attenuation (density) greater than water will have positive CT numbers. Those that are less dense will have negative CT numbers. The X-ray attenuation depends on both the density and atomic number $(Z)$ of materials and the energy of the $\mathrm{x}$-ray photons. For CT imaging a high voltage (in the range of 120-140 kV) and heavy beam filtration are used. This minimizes the photoelectric interactions that are influenced by the $Z$ of a material. 
Therefore, CT numbers are determined by the density of the tissues or materials. The CT numbers are in Hounsfield Units.

\subsubsection{Digital to analog conversion phase}

In this phase the digital image, consisting of a matrix of pixels with each pixel having a CT number, is converted into a visible image represented by different shades of gray or brightness levels.

\subsection{Advantages and applications of X-ray CT}

The principal advantage of $\mathrm{CT}$ is that it non destructively provides quantitative densitometric (density and geometry) images of thin cross sections through an object. Dimensional inspections and absolute density determinations can be made very accurately with proper calibration.

Uses of CT scanners have received wide application. The CT scanner provides detailed, two-dimensional images with great clarity. This method provides higher quality images of many types of tissue. It is also very sensitive, simple, fast, accurate and non-invasive. It can distinguish normal from abnormal structures accurately. It can also make three dimensional images with sufficient resolution to enable detailed studies of objects. The X-ray CT can provide the density distribution and the internal structure of the object of interest. 
CT scanning has been a popular diagnostic tool in medicine since 1980. X-ray CT is typically used in three fields: scientific research, industry, and medicine. It has been used to produce enlarged images of molecular and atomic structures. It is used in airports to inspect luggage. The technique has been particularly helpful in diagnosing diseases such as cancer, tumours, haemorrhages, head injuries, and bone abnormalities. The application of this technique in the attenuation of $X$ rays allowed advances in medical diagnostic capabilities and benefited the medical profession greatly by reducing the need for exploratory surgery to examine the internal structures of the human body.

$X$-ray CT scanning is currently used non-medically in research applications. $X$ ray imaging is a developing technique of detecting strongly attenuating materials and has been applied to a number of inspection applications within the agricultural and food industries. In agriculture, a need exists for non-destructive experimental techniques having millimeter or sub-millimeter resolution capable of investigating the intricacies of the many processes occurring in food products.

\subsection{Applications of X-ray CT in the food industry}

$\mathrm{X}$-ray CT is a very powerful technique from a research point of view. $\mathrm{X}$-ray CT has been explored in several studies to determine the interior qualities of agricultural and horticultural produce. X-ray CT allows one to characterize relative $\mathrm{X}$-ray absorption properties of solid objects with much greater detail than is possible with conventional X-rays (Tollner et al. 1992). 


\subsubsection{Product quality evaluation}

Product quality evaluations are extremely important in current agricultural production and food processing. The decisions concerning harvesting, maturity, ripeness and other quality evaluations are based mostly on the visual inspection of the fruit's external appearance. Quality of fruit is mostly based on shape, size, colour, flavour, firmness, texture, and freedom from defects and foreign materials. Numerous techniques for evaluating the external quality factors are available now commercially. Internal quality factors such as sugar, acidity and tissue breakdown are more difficult to evaluate. Methods such as nuclear magnetic resonance, ultrasound, and X-ray CT are used for the non-destructive examination of the tissues and internal quality of food products (Dull 1986; Bull 1993; Self et al. 1993; Tollner 1993).

X-ray CT has been used to determine maturity in green tomatoes (Brecht et al. 1991) and in papaya fruit (Suzuki et al. 1994). For green tomatoes CT can make a clear distinction between mature and immature fruits based on formation of a gel in the carpel area of the fruit. In papaya, changes in pericarp density are exploited to observe maturation.

Barcelon et al. (1999a) used X-ray absorption as an index in the CT image to detect the quality of mango based on its relationship with density, moisture content, soluble solids, titratable acidity and $\mathrm{pH}$. They determined that CT 
number can be used as a non-destructive indicator of the quality of mango. Barcelon et al. (1999b) studied the potential of X-ray CT to measure the internal quality of peaches at different physiological maturity. They determined the effect of maturity and ripening of the peach fruit using CT numbers. Figure 2.3 shows the longitudinal internal section of a fresh and ripened peach fruit. Figure 2.4 shows the CT number histogram of peach at a particular maturity level.

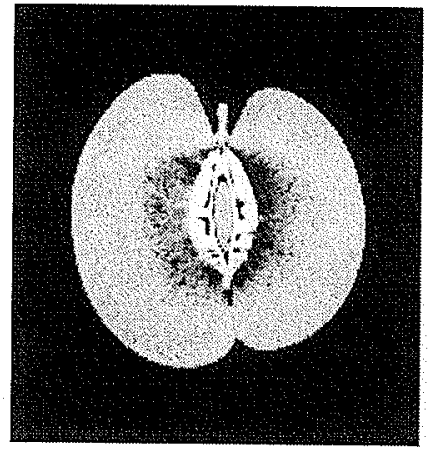

a)

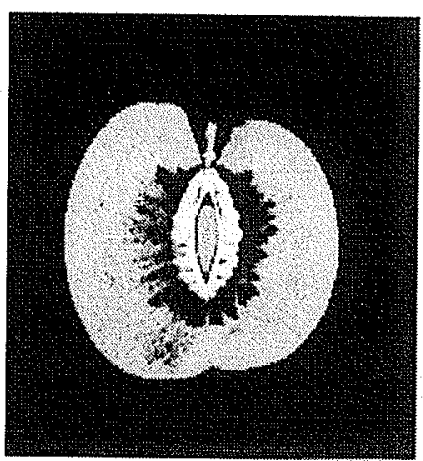

b)

Fig. 2.3. X-ray CT images showing longitudinal internal section of peach. (a) fresh b) ripened for 2 weeks. Source: Barcelon et al. (1999b).

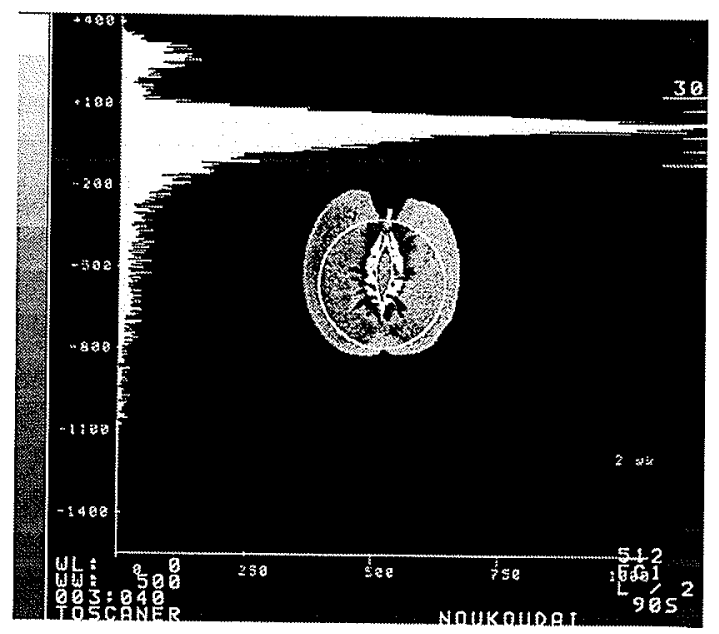

Fig. 2.4. A CT scan image of a peach fruit and its histogram. The $y$-axis reflects the $C T$ number and $x$-axis the frequency.

Source: Barcelon et al. (1999b). 
Curing (salting) of meat is an important processing operation in the meat industry. The knowledge of optimal meat curing is based on centuries of empirical knowledge, but scientifically little research has been done. This is due to several features making the process difficult to study. As salt penetrates the meat by diffusion, osmotic changes cause water to flow in the opposite direction. As X-ray attenuation is linearly related to tissue density as influenced by the degree of curing, computed tomography images of cured meat clearly revealed a number of curing features (Froystein et al. 1989). Figure 2.5 shows the cured ham with bones in it.

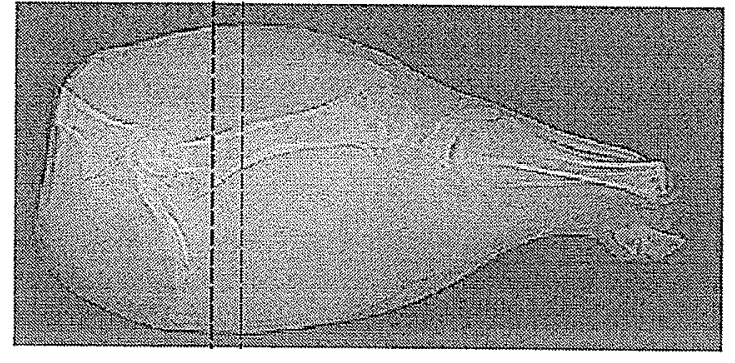

(a)

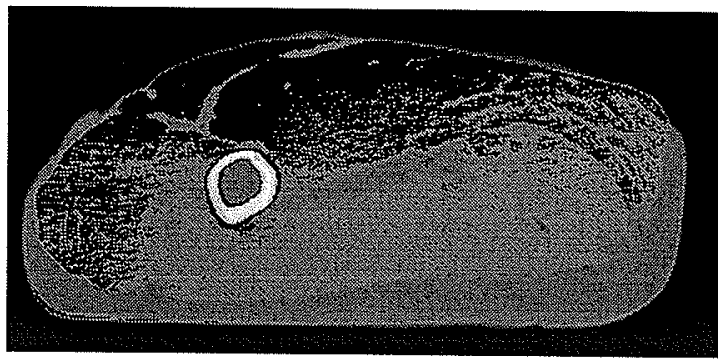

(b)

Fig. 2.5. X-ray CT scan image of cured ham a).Tomogram showing the overall features of a dry-cured ham, b).Thresholded CT scan image corresponding to a salt content above $4.5 \%$.

Source: Froystein et al. (1989).

$\mathrm{X}$-ray $\mathrm{CT}$ is the best quantitative method and a successful imaging technology for accurately characterising the microstructure of food products. X-ray CT helps to determine the mechanical and aesthetic properties of the cellular food products. Air cells of chocolate bars and marshmallows were observed by Lim and Barigou (2004) using X-ray micro computed tomography. They determined two dimensional quantitative information such as air cell count, total cell area and 
also three dimensional parameters such as air cell volume fraction, cell wall thickness and index of connectivity by using the X-ray CT images. Figure 2.6 shows the rendered three dimensional model of aerated chocolate bar. Figure 2.7 shows the reconstructed two dimensional horizontal X-ray images of aerated marshmallow and chocolate bar.

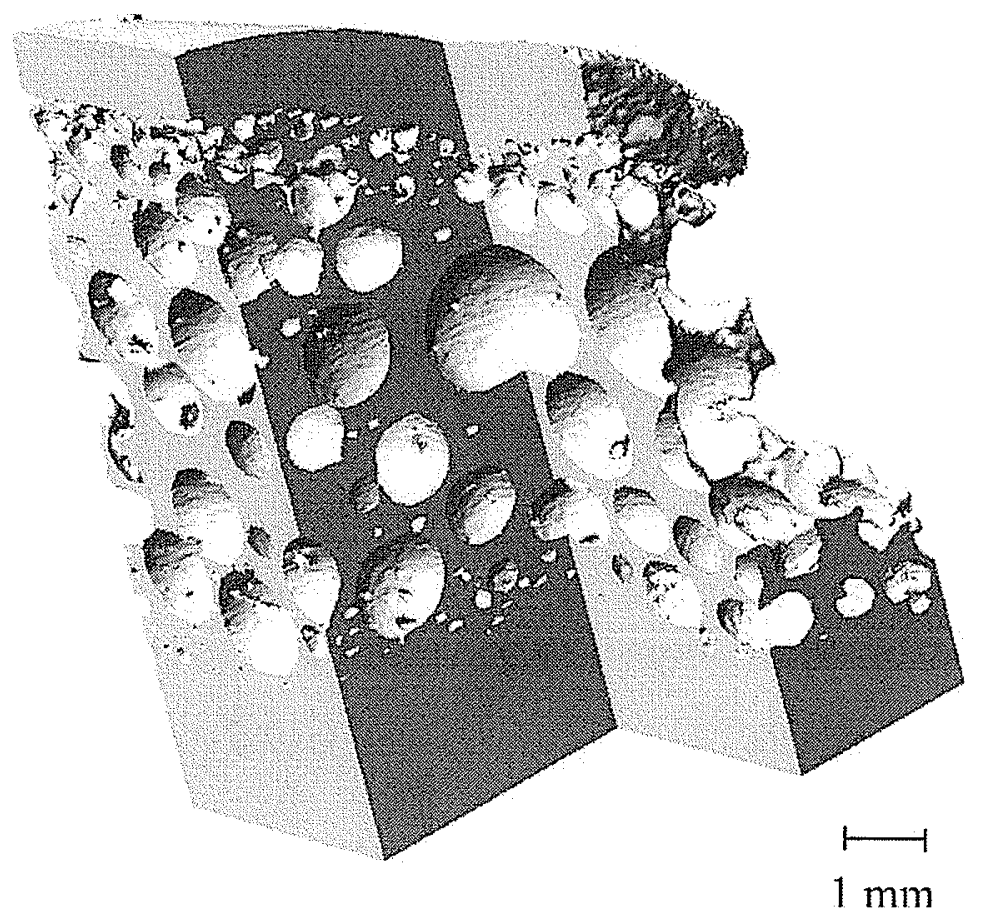

Fig. 2.6. A rendered 3D model of aerated chocolate bar numerically cut to show its inner structure. Source: Lim and Barigou (2004). 


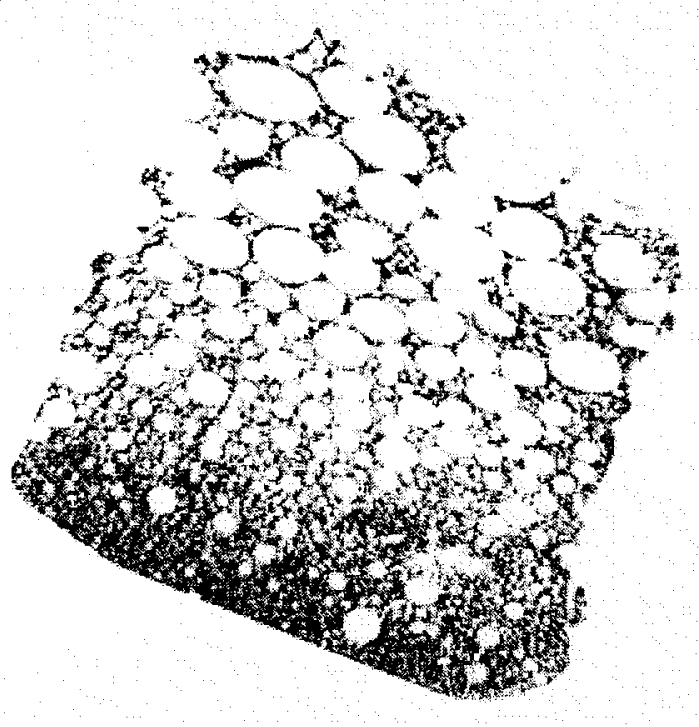

(a)

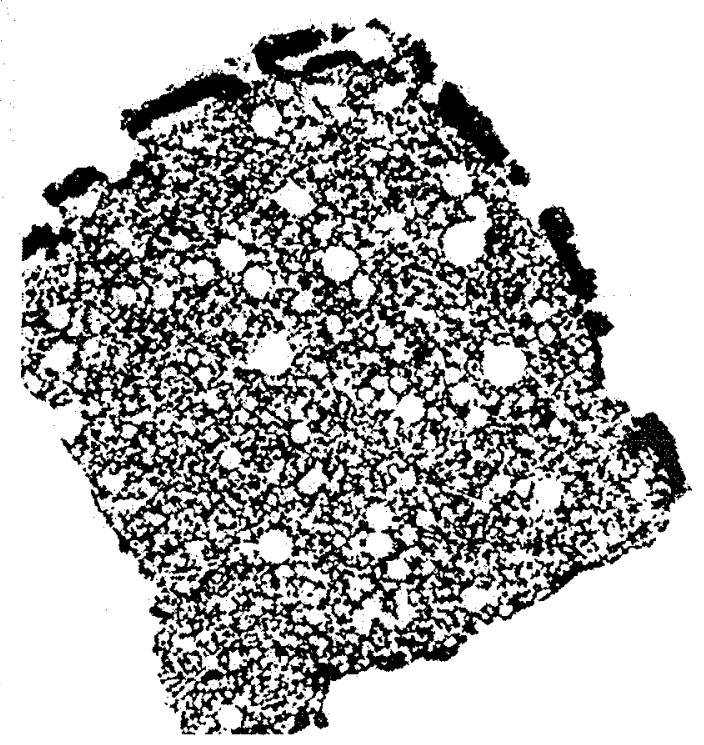

(b)

Fig. 2.7. Reconstructed 2D horizontal X-ray images of aerated confectionary products:

a) Marshmallow; b) Chocolate bar. Source: Lim and Barigou (2004).

\subsubsection{Detection of internal defects in food products}

In X-ray CT scanners, the intensity of the energy exiting the product depends upon the incident energy, atomic number, absorption or attenuation coefficient, density of the product and sample thickness. Due to the high moisture content in fruits and vegetables, water dominates X-ray absorption (Abbott 1999). Most internal disorders like woolliness in nectarines, hollow heart in potatoes, spongy tissue in mangoes affect the density measurements (Tollner et al. 1992; Thomas et al. 1993; Schatzki et al. 1997; Barcelon at al. 1999a).

Sonego et al. (1995) used X-ray CT and NMR (nuclear magnetic resonance) to monitor the development of woolliness in nectarines and they determined the 
changes in water mobility and texture of the flesh induced by the disease. They determined that NMR could not detect the presence of gas inclusions and concluded that only X-ray CT provided a direct confirmation of woolly structure involving numerous gas inclusions.

Seeds, seed cavity and any occurrence of internal breakdown in watermelon and cantaloupes can be observed by CT (Tollner 1993). Halloran et al. (1999) demonstrated the value of using computed tomography for making a nondestructive determination of tissue collapse due to mechanical injury in melon fruit. Damage caused to fruit which has been heat-treated for the purposes of storage or to mitigate the effects of chilling injury can also be determined by CT.

Healthy 'Alphonso' mango fruit is noted by the appearance of a light gray appearance while unwanted spongy tissues appear as dark-gray areas in the CT X-ray image (Thomas et al. 1993). X-ray CT was used to detect seeds in oranges and pomelos (Sarig et al., 1992) and stones in apricots (Zwiggelaar et al. 1997).

Tollner et al. (1992) determined a relation between the distribution of the volumetric water content in an apple and the internal differences in X-ray absorption of apples. Schatzki et al. (1997) applied X-ray CT for internal defect detection in apples. 
Lammertyn et al. (2003a) measured the core breakdown disorder in nectarines and pears. Lammertyn et al. (2003b) compared quantitatively and qualitatively X-ray CT scans and MRI (magnetic resonance imaging) slices to detect core breakdown in pears. They determined that both techniques were suited to detect brown discoloured tissue and cavities in affected pears. The Xray $C T$ measures the attenuation of incident $X$-rays by the tissue, while MRI measures the proton density and mobility. The core breakdown in pears was characterized by the gray level difference in the pixels and by the threshold function which separated the affected and unaffected tissue. Figure 2.8 shows the X-ray CT images of fresh and core break down pears.

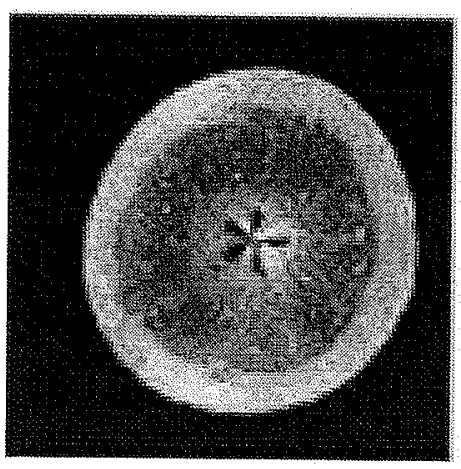

a)

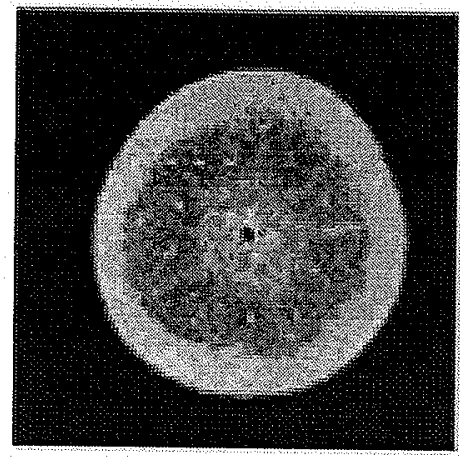

b)

Fig. 2.8. X-ray CT images of a pear. a) Fresh unaffected pear b) 'Core break down' pear. Source: Lammertyn et al. (2002)

\subsubsection{Detection of foreign materials in food}

It is necessary for food and agricultural products to have high quality and stringent quality control. It is especially important for food products to have a high degree of safety. The type of foreign materials and their locations in the food 
product are usually unknown; there are no fixed physical inspection methods for the detection of metallic foreign materials (Sakou 1989 cited by Ogawa et al. 1998).

One-dimensional and two-dimensional image analysis using video images are commonly used to detect foreign materials in food (Shinohara 1995 cited by Ogawa et al. 1998). X-ray CT can be used for three-dimensional feature measurements of food products (Fuji and Uyama 1994 cited by Ogawa et al. 1998).

Ogawa et al. (1998) used a X-ray CT scanner to detect foreign materials in food based on density difference. They detected human hair and a glass tip in hamburger patties by threshold values based on CT numbers.

\subsection{Application of X-ray CT in animal science}

Applications of X-ray CT on live animals were initiated in Norway in 1980 (Skerjvold et al. 1981). X-ray CT is the only non-invasive method for the determination of body composition of animals.

X-ray CT has been used for detailed measurement of body components and fat distribution on live animals (Kolstad et al. 1996; Vangen and Thompson 1992). The CT can locate fat and protein deposits in all parts of the animal body (Vangen and Thompson 1992). Kolstad (2001) used the X-ray CT scan images 
for measuring the body composition of pigs. Vangen and Kolstad (1986) estimated the amount of chemical fat and protein in pigs with high accuracy. They determined that CT numbers gave $96-98 \%$ accuracy in measuring the fat and $70-74 \%$ accuracy in measuring protein while the ultrasonic method gave only $42 \%$ of the accuracy in protein and $24 \%$ accuracy in fat. Thus X-ray CT is a method which exactly describes carcass composition of live pigs and is far superior compared to ultrasonics.

Sorenson (1992) determined that computer tomography was a valuable tool for in vivo measurement to predict body fat and energy content of goats. The Xray $\mathrm{CT}$ scan of the goat body gave a wide range of $\mathrm{CT}$ values due to the mixture of solids, water and air in the goat body. The difference in CT values helped to determine the body fat and energy of the goat.

Computer tomography offers great potential as a non-destructive method for monitoring dynamic changes without interfering with the process at study. As such CT has been used to study fat and lean tissue changes in pigs during fasting, water shift in stress- susceptible pigs during halothane induced malignant hyperthermia (Vangen et al. 1985).

The fat content of farmed fish species is an important trait in fish production, both from the point of view of feeding costs and consumer acceptance. In vivo methods to predict body composition of live fish have primary importance in 
nutritional and physiological investigations, where body composition is traditionally determined by comparative slaughtering followed by chemical analysis (Schwarz and Kirchgessner 1993; Oberle et al. 1997). Non-invasive methods that enable the number of animals sacrificed to be reduced, without any loss of precision. X-ray CT is the best method for carcass determination of fish. Romvari et al. (2002) measured fillet composition of fish species by using computed tomography. They determined the volume of fat tissue of the fish body from the pixel density data. Figure 2.9 shows the fat distribution of the fish body in the X-ray CT image.

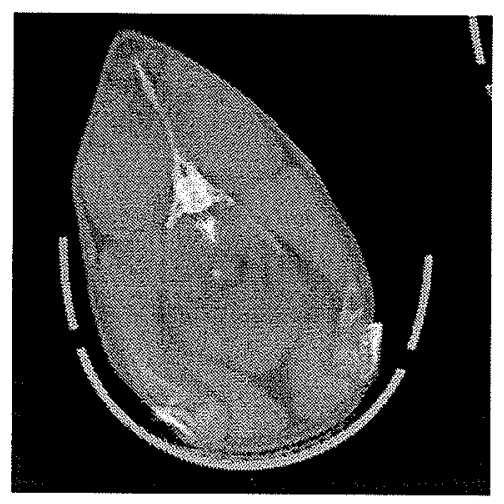

Fig. 2.9. X-ray CT scan image showing fat distribution of a fish body. Source: Romvari et al. (2002).

\subsection{Application of X-ray CT in soil science}

Tomographic imaging can be achieved using several different methods, i.e. $\gamma$ ray or X-ray tomography, or magnetic resonance imaging (MRI) (Aylmore 1993; Asseng et al. 1999). For a highly attenuating ferrous-rich environment such as soil, the low flux available from $\gamma$-radiation sources, and the paramagnetic nature 
of the soil which renders MRI useless, makes X-ray tomography the ideal solution.

Many encouraging attempts have been made to apply the CT scanning techniques in soil science studies, particularly for investigating soil macropores (Anderson et al. 1988; Warner et al. 1989; Peyton et al. 1992). The CT technique has also been used to investigate soil water content and solute transport in soil columns (Anderson et al. 1988).

Petrovic et al. (1982) demonstrated the possibility of using X-ray CT to measure soil bulk density. Application of CT methodology in soil science has proven advantageous when compared to other classical methods such as gravimetry or $\mathrm{y}$ ray direct transmission (Crestana et al. 1986). Unlike $\mathrm{y}$ ray transmitted images, CT image measures local heterogeneity within the soil at pixel resolution or soil bulk density and water content pixel by pixel. It also non invasively helps to obtain two and three-dimensional measurement of soil physical parameters such as bulk density and water content which is an important task in modeling and analyzing soil science problems. X-ray CT images have been used to investigate processes such as soil compaction, root penetrations, crusting, seedling cracking and swelling, wetting and drying or thawing and freezing cycles, miscible and immiscible displacement of nutrients in the presence of roots, and preferential flow of pollutants in fractured porous media (Cruvinel et al. 1990). 
Modeling and monitoring solute transport in soil is necessary to properly characterise the macroporous structure of the soil. Knowledge of active transport zones in the soil matrix provides a better understanding of the role and relative importance of macroporous channels in the transport process. X-ray computer tomography of soil scans has been used to characterize large biopores in unexposed interior portions of undisturbed soil samples (Ringrose-Voase 1996; Peyton et al. 1992; Peyton et al. 1994). The method is able to non-destructively measure macropore-scale density in undisturbed soil cores and visualise threedimensional flow patterns for solutes. Hole porosity and equivalent hole perimeters and diameters to a resolution of $0.5 \mathrm{~mm}$ can also be identified by this method. Figure 2.10 shows a magnified section of soil with clearly marked macropores.

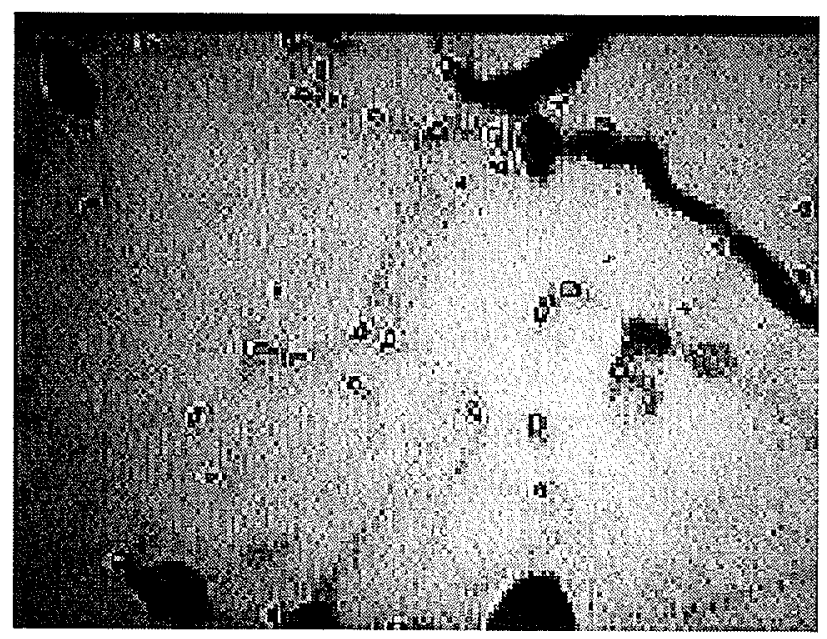

Fig. 2.10. X-ray CT image of an undisturbed soil core showing soil macropores. Source: Peyton et al. (1994).

A study was conducted to clarify the availability of pore system nutrients for microorganisms in soils (Thieme et al. 2003). They used X-ray CT based on X- 
ray microscopy images. They concluded that $\mathrm{X}$-ray nano tomography is a very powerful tool for examining the three-dimensional structure of flocs of colloidal particles. Figure 2.11 shows the $3 \mathrm{D}$ visualization of a floc of colloidal soil particles.

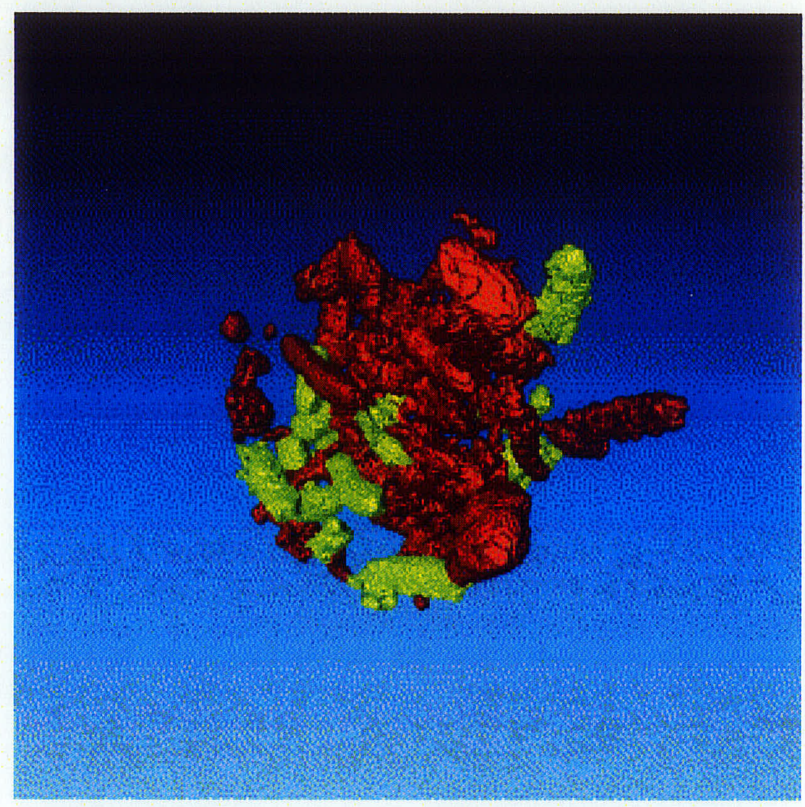

Fig. 2.11. Three dimensional visualization of a floc of colloidal soil particles. Green represents bacteria while brown represents soill particles. Source: Thieme et al. (2003).

X-ray CT is a very promising tool for characterization of porosity and morphology of granules, compacts, and tablets. Farber et al. (2003) determined the porosity and pore size distribution of granular objects by using X-ray CT. To study the effect of soil macropores on root growth, X-ray CT images of a set of soil macropores were scanned by Pierret et al. (2002). Their detailed study was effective in visualising and quantifying the $3 D$ attributes of the soil macropore 
networks. Figure 2.12 shows three dimensional rendering of the macropore networks.

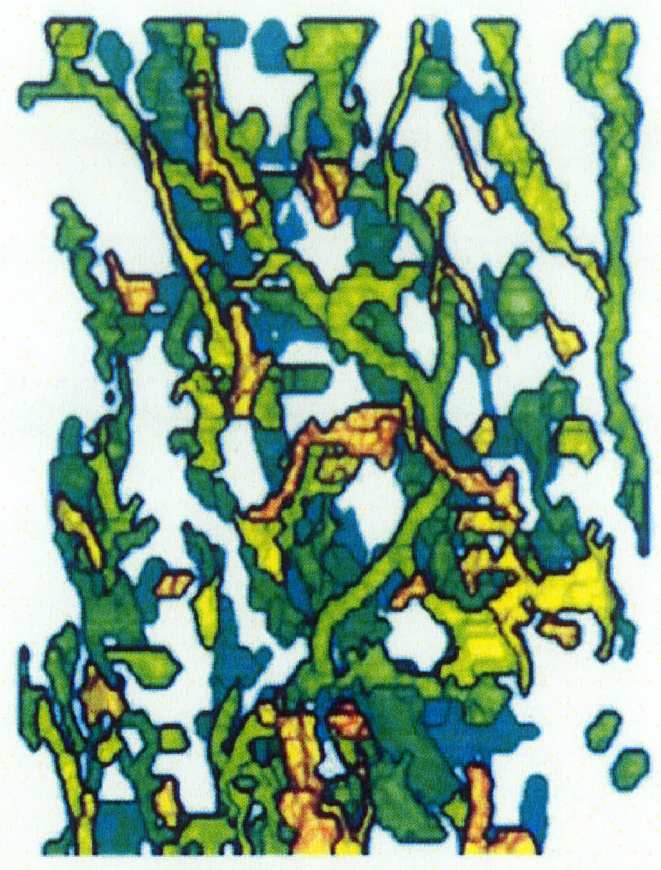

Fig. 2.12. Three dimensional rendering of the macropore network analysed. Source: Pierret at al. (2002).

Because of the ability of CT scanner to give quantitative densitometric images and its usage in soil science research for pore related studies, it is hoped that the X-ray CT scanner is the best tool for studying air flow resistance difference in grain bulks. 


\section{MATERIALS AND METHODS}

The different processes involved in determining airflow paths in bulk grain using X-ray CT image analysis are:

i) preparation of grain samples,

ii) acquisition of $\mathrm{X}$-ray CT images of grain bulks,

iii) comparing bulk density of images with bulk density of grain bulks,

iv) analysis of $\mathrm{X}$-ray CT images,

v) feature extraction from the images, and

vi) statistical analysis.

\subsection{Preparation of bulk grain samples}

Five types of grains were selected for X-ray scanning based on their shape to give potentially different paths of airflow. These were barley, hard red winter wheat (referred to as wheat, hereinafter), flax seed, peas and mustard. Of these samples wheat, barley and flax seed are oblong in shape while peas and mustard are almost spherical. All the grain samples were further sifted manually to remove stone, straw and chaff particles. 
The sample containers were made of acrylic material, which is radiometrically translucent for the X-ray energies. The resolution of the X-ray CT image depends on the size of the sample. For smaller seeds like flax seed and mustard, the resolution of the image must be higher to get a clear image. Hence, two sizes of sample containers were used for scanning. Wheat, barley and peas were filled in 3 separate $15 \mathrm{~cm}$ side cubic acrylic containers while flax seed and mustard were filled in two, $7.5 \mathrm{~cm}$ side cubic containers. The grains were filled from the top of the individual containers. The orientation of grain kernels inside the container should not change while scanning in the vertical direction. Hence, after the sample containers were filled with grain, the containers were shaken well for compaction. Cotton was placed on the top of each sample container before covering with the lid to avoid movement of grain kernels inside the container. The samples were scanned at both the horizontal and vertical direction of packed grain bulks. Samples were scanned only at the middle of the container for a 25 $\mathrm{mm}$ thickness to avoid wall effects. Figure 3.1 shows the microscopic images of different grain samples used in this study. 


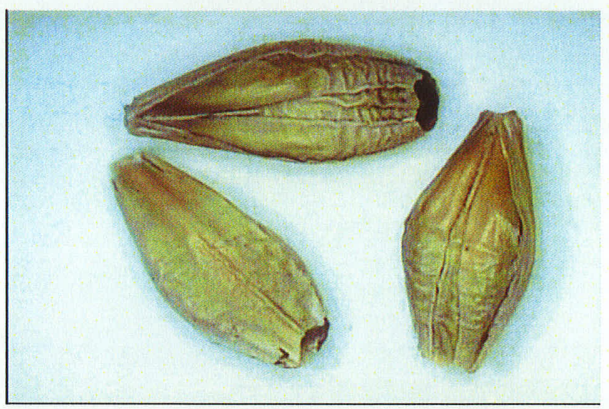

a)

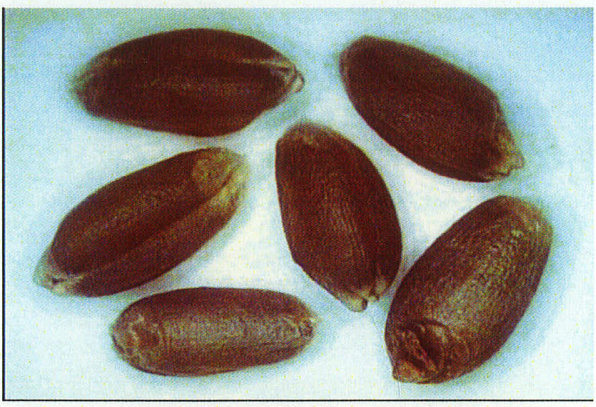

b)

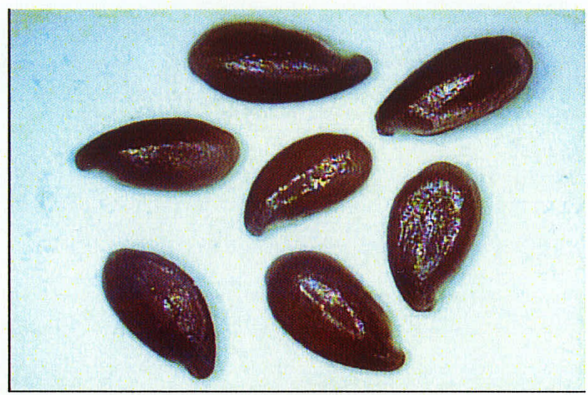

c)

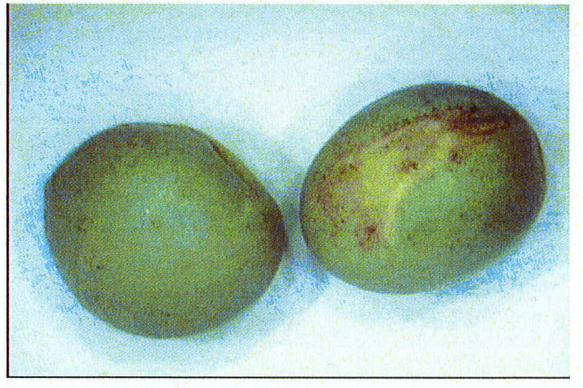

d)

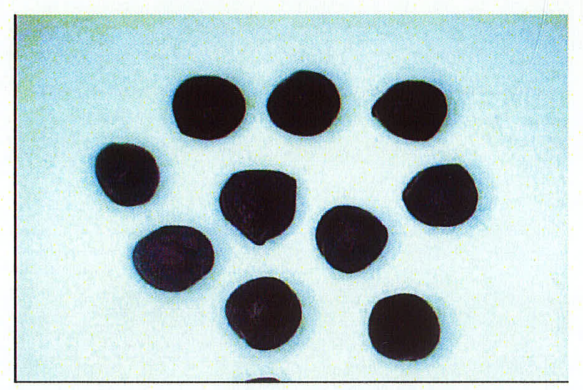

e)

Fig. 3.1. Microscopic images revealing the shapes of grain samples used in this study. a) Barley, b) Wheat, c) Flax seed, d) Peas, e) Mustard. 


\subsection{Acquisition of X-ray CT image}

The X-ray CT images used in this study were obtained at the High-Resolution X-Ray Computed Tomography Facility, the University of Texas, Austin. X-ray tomography was performed using the Bio-imaging Research X-ray CT scanner that has a resolution of better than $4 \mu \mathrm{m}$.

The X-ray source was operated at $420 \mathrm{kV}$ and $1.8 \mathrm{~mA}$. Figure 3.2 shows the parts of the Bio-imaging Research X-ray CT scanner. There is a difference between the Bio-imaging Research CT scanner and the hospital X-ray CT scanner. In the hospital X-ray CT scanner, the sample bed slides in and out while the $\mathrm{X}$-ray production unit and the detectors move around the sample making a circular path. But in the Bio-imaging Research X-ray CT scanner, the X-ray production unit and the detectors move up and down while scanning the sample.

The sample holder holds the sample container for scanning. The sample was scanned along the horizontal direction first and then the container was rotated at $90^{\circ}$ for vertical scanning. The images taken along the horizontal direction of the sample container gives the horizontal images. The images taken along the vertical direction of the sample container gives the vertical images of the grain bulk. But the horizontal image represents the vertical airspace while the vertical image represents the horizontal airspace in the grain bulk (Fig. 3.3). From now onwards, the discussion will be carried out by using the 'airspace' term and not 
the direction of the images. Table 3.2.1 shows the summary of image characteristics of different grain bulks.

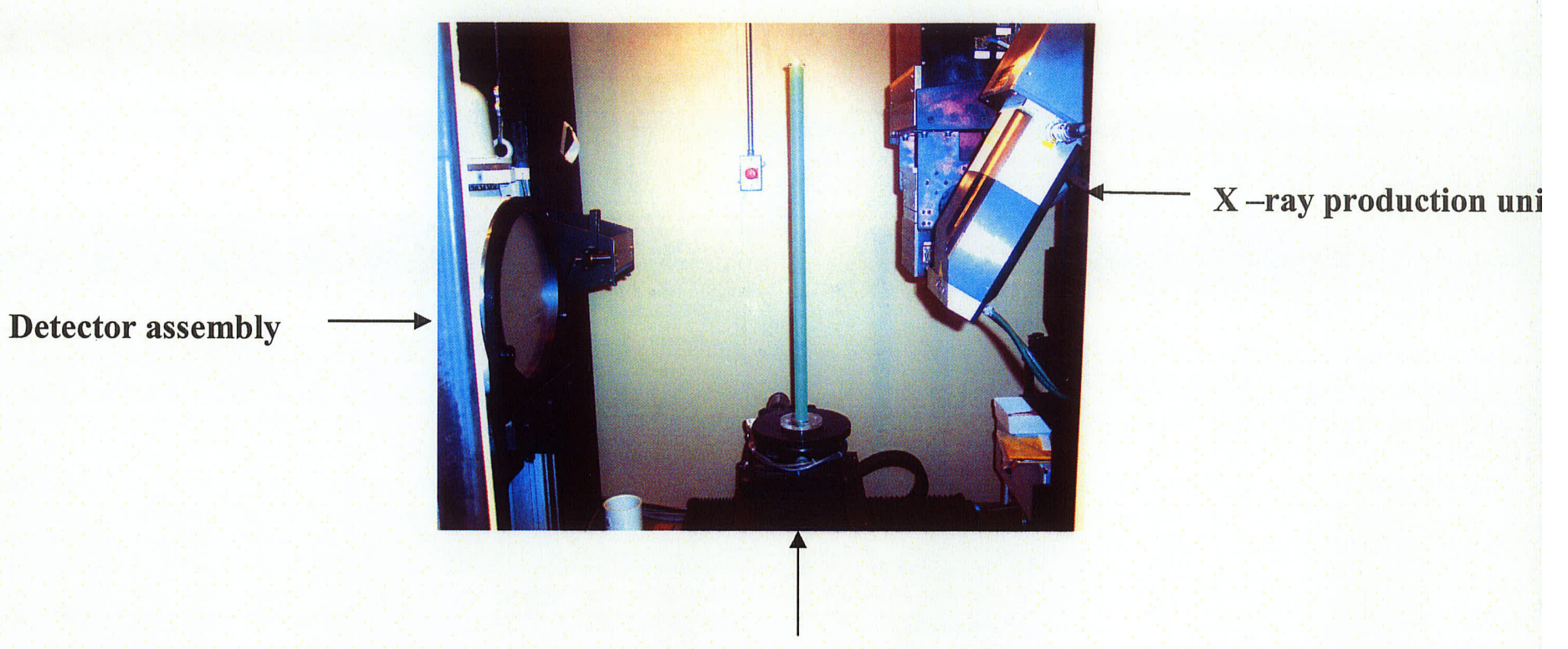

Sample holder

Fig. 3.2. X-ray CT imaging system. 


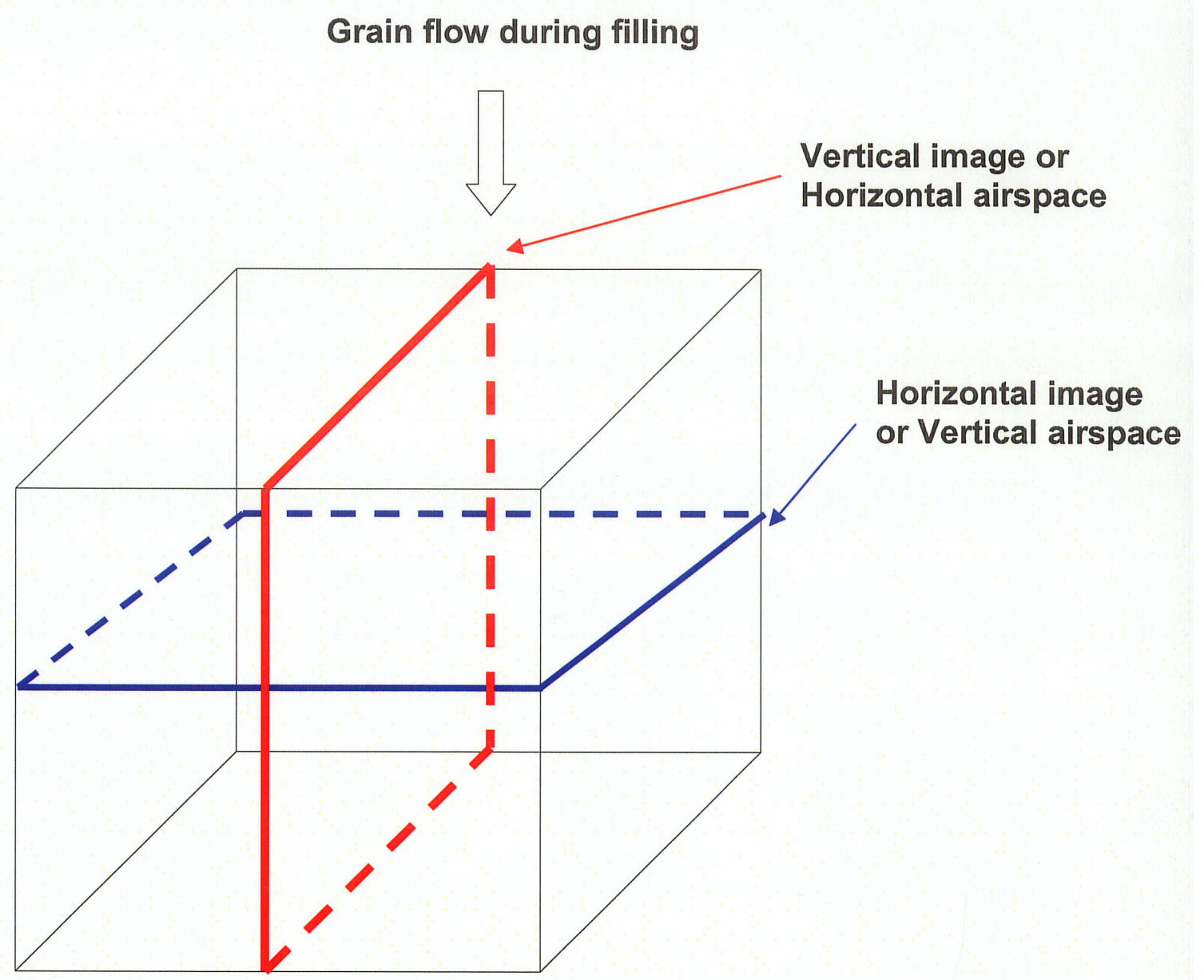

Fig 3.3. Schematic showing the relationship between CT image and airspace. 
Table 3.1. Summary of image characteristics of different grain bulks.

\begin{tabular}{llcc}
\hline Grain Type & $\begin{array}{l}\text { Image Resolution } \\
\text { along } \\
\text { direction }(\mu \mathrm{m})\end{array}$ & $\begin{array}{c}\text { Slice thickness } \\
(\mathrm{mm})\end{array}$ & Number of slices \\
\hline Barley & 200 & 0.25 & 200 \\
Wheat & 200 & 0.25 & 200 \\
Peas & 200 & 0.25 & 200 \\
Flax seed & 120 & 0.125 & 350 \\
Mustard & 120 & 0.125 & 350 \\
\hline
\end{tabular}

\subsection{Comparison of bulk density}

The bulk density of the grains calculated from the images has to be equivalent to the reported bulk density of the grains. This will prove that the grain samples used for this study are a good representation of the bulk grain.

To prove this objective, the bulk density of the grain sample from the image was calculated and compared with the reported bulk density of the grain. The following calculations were done to determine the bulk density of the grain sample from the image. 

Mass of grain $(g), \quad M_{g} \quad$ = Total mass of the container with grain - Mass of the container

Volume of the grain from image, $V_{g}=x \cdot y \cdot r^{2} \cdot z \cdot t$

Where

$$
\begin{aligned}
& x=\text { number of pixels in } x \text { direction of the image } \\
& y=\text { number of pixels in } y \text { direction of the image } \\
& z=\text { slice thickness of the image } \\
& r=\text { image resolution }(\mu) \\
& t=\text { total number of slices in the image stack }
\end{aligned}
$$

Bulk density from the image, $B D_{i}=M_{g} / V_{g}$

\subsection{Image analysis}

Algorithms were developed in MATLAB (version 6.5, The Mathworks Inc, Natick, MA.) to analyze the images and to determine the airflow paths. The following image processing techniques were used to quantify the airflow paths inside the grain bulks,:

i) image preprocessing, to select the region of interest;

ii) thresholding, to remove grain from the air space;

iii) skeletonization, to determine the length of air flow paths;

iv) blob colouring to identify different air paths; and

v) feature extraction of each airflow path to determine their characteristics. 


\subsubsection{Image preprocessing}

Image preprocessing is an essential step in computer vision and automatic pattern recognition processes for image analysis of foods, as subsequent extracted data are highly dependent on the accuracy of this operation. The automated segmentation or the preprocessing is one of the most difficult tasks in image analysis (Gonzalez and Wintz 1991), because a false segmentation will cause degradation of the measurement process and therefore the interpretation may fail.

Each slice of the image was $1024 \times 1024$ pixels in size. This original size of the image includes the CT ring and the walls of the container. But the region of interest for this study is only the grain and the air surface. To remove the CT ring artifact and the sample container wall from the image, each slice of the original image was cropped and a square sub-image was selected. The sub-image consisted of the maximum number of pixels excluding the rings of scanner and the container wall in the image. Figure 3.4., shows the X-ray CT image before cropping and the sub image of a wheat sample after cropping. The sub image sizes of wheat, peas and barley were $635 \times 635$ pixels, while the sub image sizes of flax seed and mustard were $575 \times 575$ pixels. 


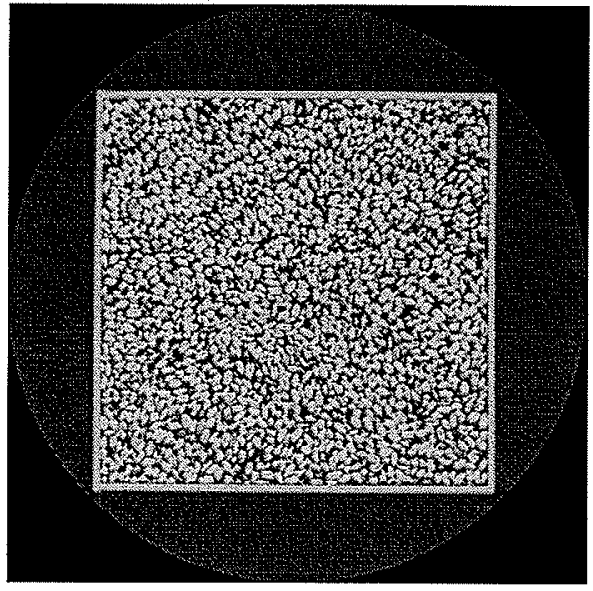

a)

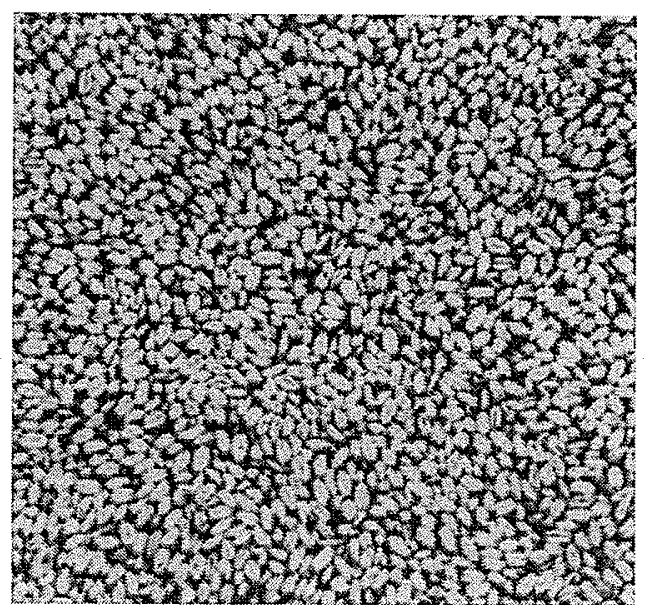

b)

Fig. 3.4. Single slice $X$-ray CT scan image of a wheat sample a) before cropping b) after cropping.

\subsubsection{Thresholding}

The simplest way to segment objects of interest in an image is thresholding (Sahoo et al. 1997; Gonzalez and Woods 2003). Thresholding is one of the most important techniques in image segmentation. Segmentation involves separating an image into regions corresponding to objects. Usually image segmentation is done by identifying common properties of an image. The simplest property that pixels in a region share, is intensity. Hence a natural way to segment such regions is through thresholding, the separation of bright objects against dark backgrounds or vice versa. 
Thresholding creates binary images from grey-level images by turning all pixels below some threshold to zero and all pixels about that threshold to one. The conventional thresholding is global thresholding which uses a global threshold for all pixels.

Thresholding methods can be classified into two general categories: global methods and local methods (Sahasrabudhe and Gupta 1992).

\subsubsection{Problems with global thresholding}

A global thresholding technique segments an entire image with a single threshold value corresponding to the valley point in the bimodal histogram (Brink 1992; Yang et al. 1996). Global thresholding is easily implemented, and it requires less complex computations.

The major problem with global thresholding is that the importance is given only to the intensity but not to the relationship between pixels. There is no guarantee that the pixels identified by the global thresholding process are contiguous.

There are chances to include extraneous pixels that are not part of the desired region which will lead to missing isolated pixels in the region especially near the boundaries of the region. This is because the pixel intensity does not 
represent the normal intensity in the region. Global thresholding is not recommended as there are chances to lose information from the image or to have unwanted background information. Global thresholding cannot be applied for images with uneven illumination. Global thresholding uses a fixed threshold for all pixels in the image and therefore works only if the intensity histogram of the input image contains neatly separated peaks corresponding to the desired object and background.

All of the global thresholding methods can be viewed as using a horizontal plane to segment the intensity surface of an image. But when the background is uneven as a result of poor or non-uniform illumination conditions, such a fixed grey level threshold will not segment the image correctly. Image segmentation using global thresholding is not applicable for inspection of grain images because of the wide range of the pixel intensity between grain surface and air surface. Moreover the range of gray level intensity varies for both horizontal and vertical images of a grain bulk.

Figures 3.5 and Figure 3.6 show the global threshold values for the horizontal and vertical images of a wheat grain bulk, respectively. For the horizontal images, if the mean threshold value is selected to be 31200 , it will affect the images in slices 1 to slices 20 . At the same time, the global threshold value for the vertical image is 31350 . If this value is used as a mean threshold value, the 
resulting thresholded image will not be accurate. The images from slice 1 to slice 80 and from slice 120 to slice 200 greatly deviates from the mean.

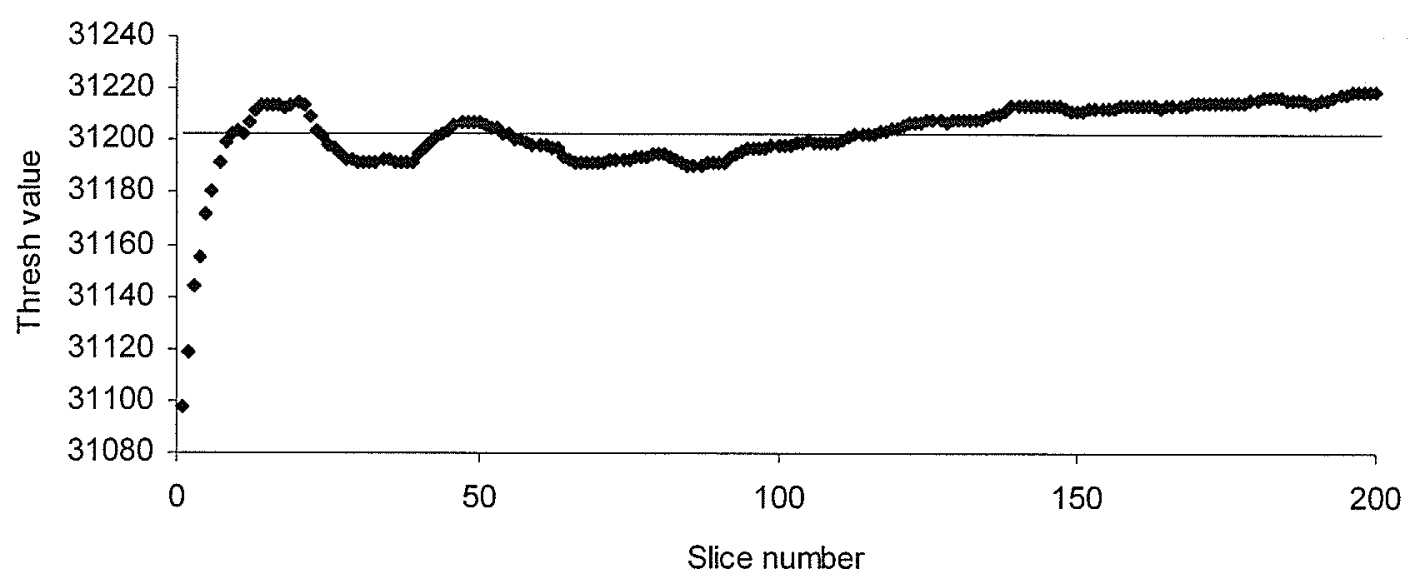

Fig 3.5.Global thresholdvalues for the horizontal images in a wheat grain bulk.

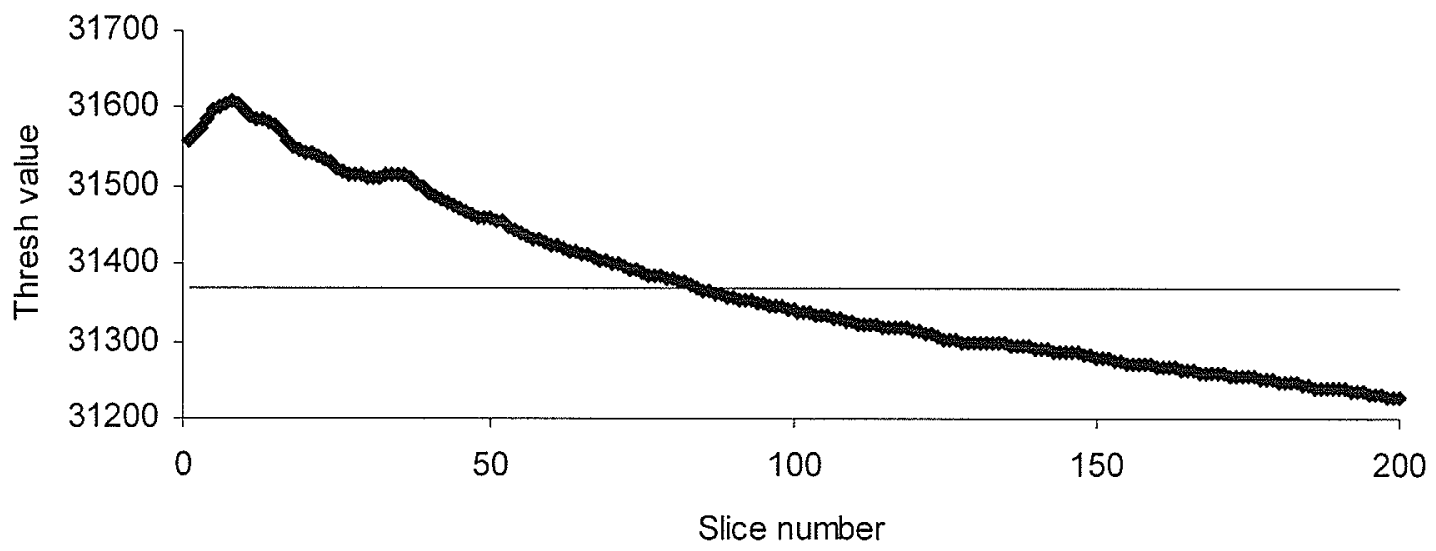

Fig 3.6. Global thresholdvalues for the vertical images in a wheat grain bulk. 
One solution to this problem is to use local adaptive thresholding. An adaptive thresholding which takes into account the local conditions and hence effectively varies spatially in the image gives good and consistent results.

\subsubsection{Adaptive thresholding}

The most popular method of adaptive thresholding is the Otsu method (Yang et al. 1996). It uses discriminant analysis to divide foreground and background by maximizing the discriminant measure variable. The procedure is simple because it only utilizes the zeroth- and the first-order cumulative moments of the gray level histogram, but it is a quite good threshold method. In the X-ray CT grain bulk image, we have two groups of pixels, one with maximum range of pixel values (foreground object) and the other with minimum range of pixel values (background). It is difficult to define a threshold as these ranges are overlapping. This overlapping is shown in Figure 3.6.

It is understood that the place of overlap, the place where the misclassified areas of the distribution of the pixel intensities are equal is not necessarily where the valley occurs in the combined histogram. This occurs when one cluster has a wide distribution and the other a narrow one.

Otsu's method helps to adjust the threshold by increasing the spread of pixels in one way and decreasing the spread of the other range. The goal then is to 
select the threshold that minimizes the combined spread. This method models two clusters of Gaussian distribution of the pixels, one for the background and the other for the foreground region. The optimal threshold value is found by minimizing the weighted sum of within-class variance of the two classes of pixels.

The basic idea of the Otsu's method is to divide the image histogram into two groups of pixels and then calculate a t-test to determine the probability that the two sets of grey values are different. The algorithm selects the point that maximizes that probability.

The histogram and the thresholded images are shown in Figures 3.7 and 3.8. In this work the images were thresholded by using Otsu's adaptive technique to remove the grain. The resulting white pixels in the image had only the airflow paths.

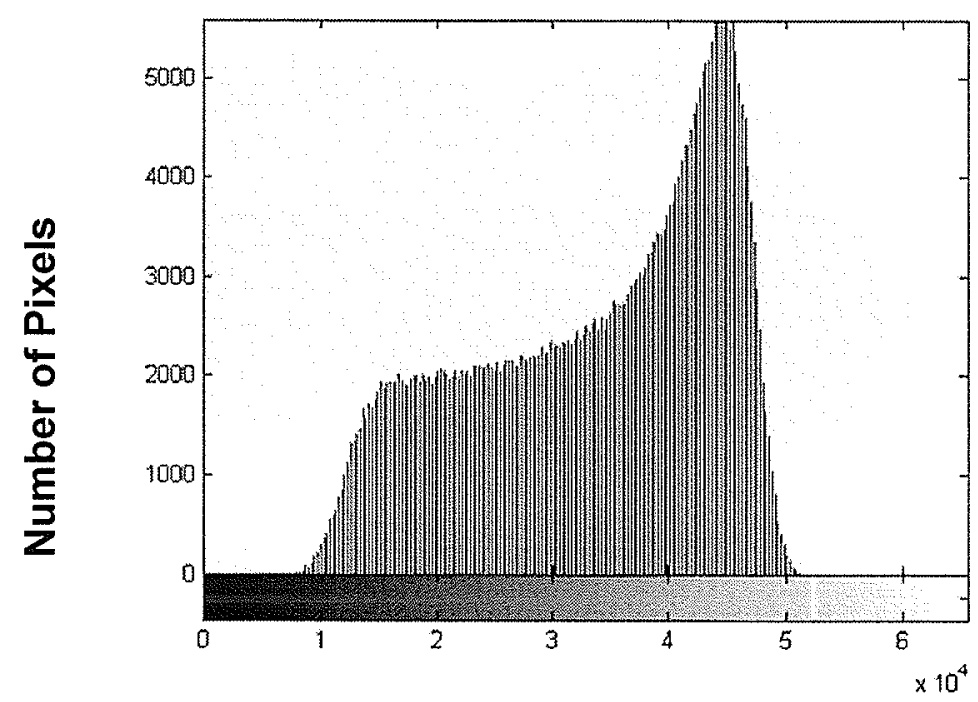

Grey value

Fig. 3.7. Histogram of a single slice of X-ray $C T$ wheat image. 


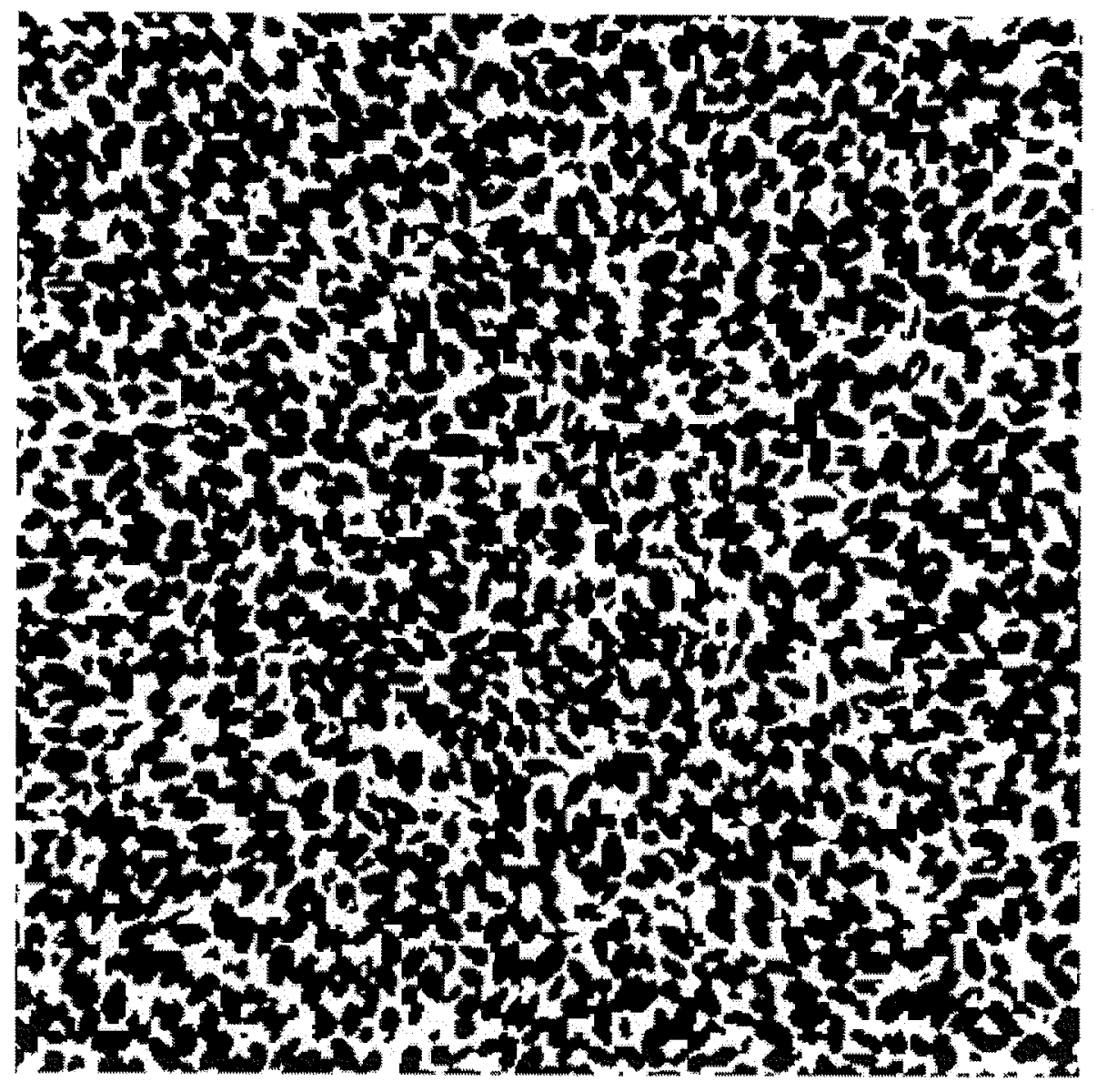

Fig.3.8. Adaptive thresholded image of the single slice of X-ray CT wheat image. White represents airspace and black represents grain area.

\subsubsection{Skeletonization}

A skeleton is a powerful analog concept that may be employed for the analysis and description of shapes in binary images. Skeletonization is a process for reducing foreground regions in the binary image to a skeletal remnant that largely 
preserves the extent and connectivity of the original region while throwing away most of the original foreground pixels.

The skeleton of the X-ray CT image is produced by a morphological thinning algorithm. The algorithm was written in MATLAB that successively eroded away pixels from the boundary while preserving the end points of line segments. This erosion was done until no more thinning was possible, at which point what was left approximated the skeleton.

Thinning is an iterative deleting process that transforms a discrete structure to a lower dimension. The developed thinning algorithm contains a set of deletion conditions which are applied iteratively to delete object elements (1's) to change to background elements (0's). Geometry preservation is a major concern of thinning algorithms. To preserve the geometry of the original image, the thinning algorithm contains the preserving condition to preserve the endpoints of a unit width.

A skeleton is defined as a connected set of medial lines along the limbs of a figure. The skeleton is useful because it provides a simple and compact representation of a shape that preserves many of the topological and size characteristics of the original shape of airpaths inside grain bulks. The length of the airflow path inside grain bulks was measured by the sum of the pixels in that skeleton. The skeleton of the X-ray CT wheat image is shown in Fig. 3.9. 
The obtained skeleton image was a single-stranded subset of the original binary image. It was further processed to determine structure properties, such as the number of branches and the length of each branch.

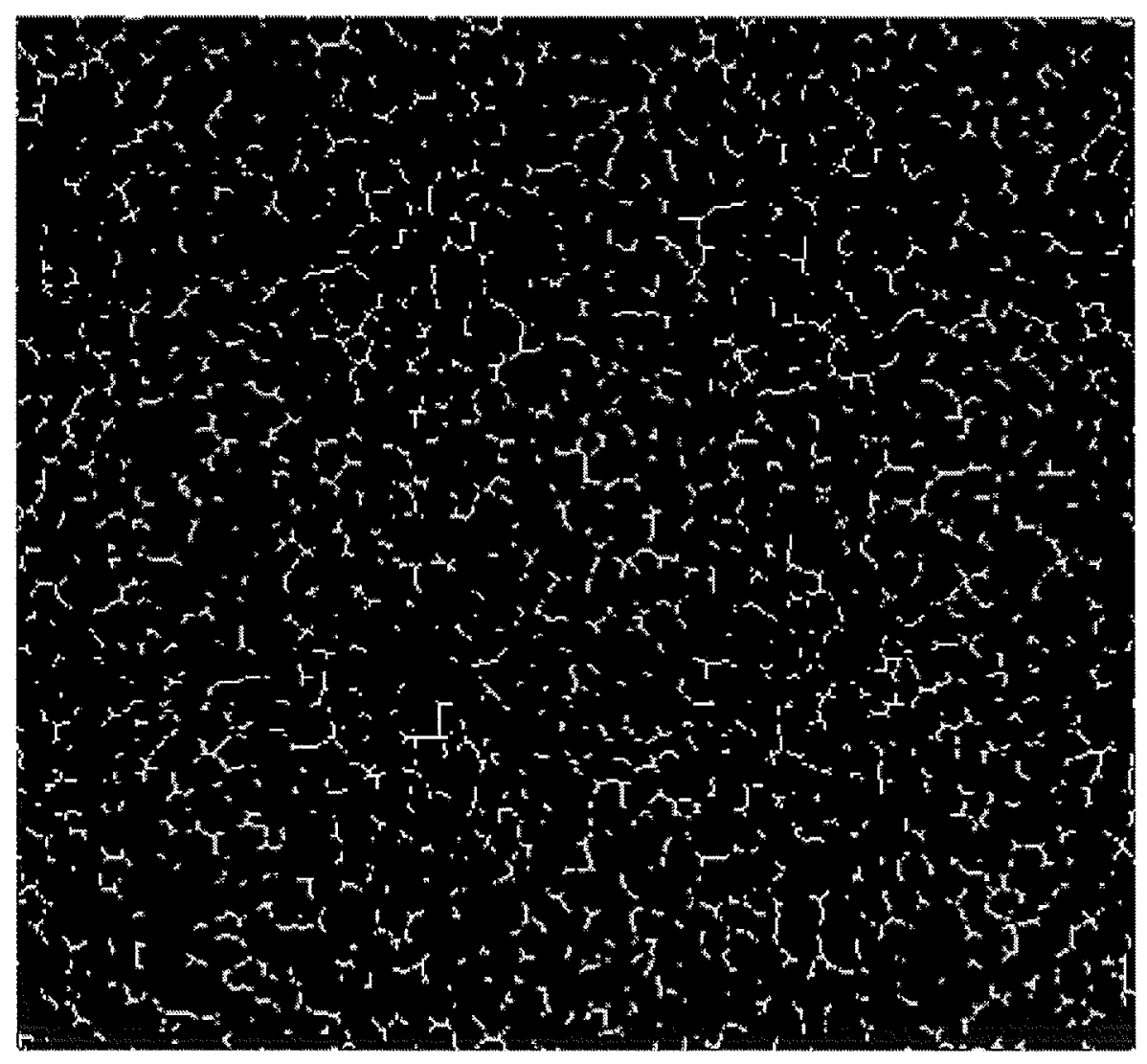

Fig.3.9. A sample of the skeletonised wheat image. White lines represent airflow paths in grain bulk. 


\subsubsection{Blob colouring}

The thresholded image was blob coloured for studying the distribution and size of airflow paths. A connected component labeling algorithm was written for blob analysis of the X-ray CT image. This algorithm has to be implemented only on the thresholded image. Component labeling algorithm joins neighbouring pixels into connected regions. It is better to work with this tool after image preprocessing (binarization, segmentation or classification), because original (noisy) images have many one-pixel distinct regions.

Connected components labeling algorithm scans the X-ray CT image and groups its pixels into components based on pixel connectivity. All pixels in a connected component share similar pixel intensity values and are in some way connected with each other. Once all groups have been determined, each pixel is labeled with a color according to the component it was assigned to. This is called blob colouring.

Extracting and labeling of various disjoint and connected components in an image is central to many automated image analysis applications. Connected component labeling works by scanning an image, pixel-by-pixel (from top to bottom and left to right) in order to identify connected pixels which share the same set of intensity values $V$. (For a binary image $V=\{1\}$; however, in a graylevel image $V$ will take on a range of values, between 1 to 255 . 
Connected component labeling algorithm works on both binary and gray level images. However, the algorithm was written assuming binary input images and 4 - connectivity. The connected components labeling operator scans the image by moving along a row until it comes to a point $p$ (where $p$ denotes the pixel to be labeled at any stage in the scanning process) for which $V=\{1\}$. When this is true, it examines the four neighbors of $p$ which have already been encountered in the scan (i.e. the neighbors, to the left of $p$, above it, and the two upper diagonal pixels). Based on this information, the labeling of $p$ occurs as follows:

- If all four neighbors are 0 , assign a new label to $p$, else

- if only one neighbor has $V=\{1\}$, assign its label to $p$, else

- if one or more of the neighbors have $V=\{1\}$, assign one of the labels to $p$ and make a note of the equivalences.

After completing the scan, the equivalent label pairs are sorted into equivalence classes and a unique label is assigned to each class. As a final step, a second scan is made through the image, during which each label is replaced by the label assigned to its equivalence classes. For display, the labels might be different colours. The total number of individual airflow paths was measured based on the number of blob-colours in the image. Different colour objects in the image represented different airpaths. A blobbed image of the X-ray CT wheat image is shown in Figure 3.9. 


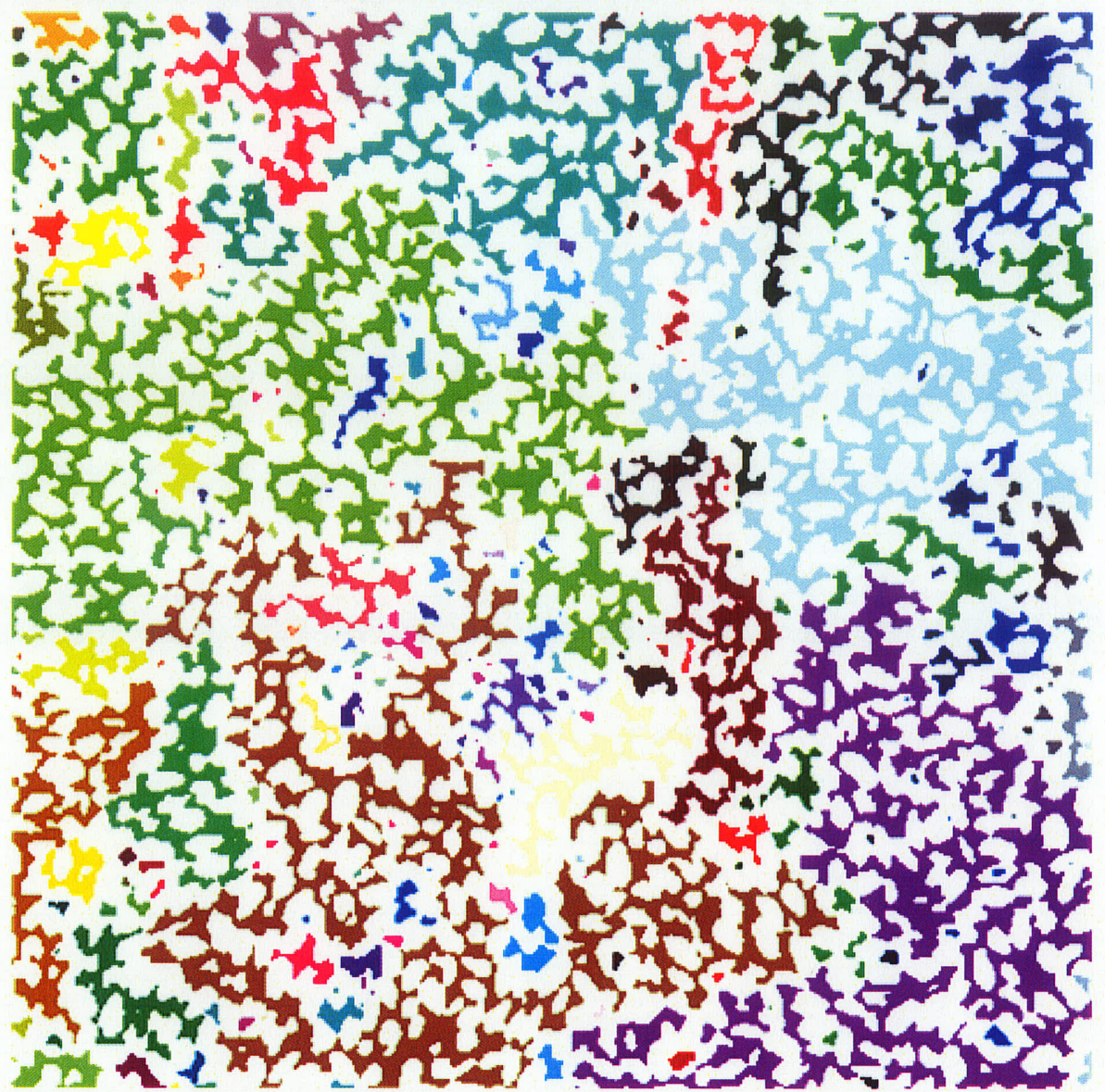

Fig.3.10. Blob coloured image of a typical X-ray CT wheat image.

\subsection{Feature extraction}

The following features were extracted from the X-ray CT grain images:

i) total grain surface area from the thresholded image;

ii) total air surface area from the thresholded image;

iii) total number of airflow paths from the blob coloured image;

iv) areas of the individual airflow paths from the blob coloured image; and

v) lengths of the individual airflow paths from the skeletonised image. 
The total number of individual airflow paths was determined based on the number of components in the blob coloured image. The area of the individual airflow path was determined by calculating the area of the different colours in the blob coloured image. The length of individual airflow path was calculated by the sum of the pixels in the skeleton.

The grain sample images for all five grains were analysed by using the above image processing techniques and features for each grain bulk were extracted for both the horizontal and vertical images.

\subsection{Statistical analysis}

An independent group t-test was done to check the difference between the means of area of airflow paths and the number of airflow paths in both horizontal and vertical images for all grains (SAS version 8.2 software, Statistical Analysis Systems, Cary, NC). 


\section{RESULTS AND DISCUSSION}

\subsection{Comparison of bulk density}

The size of the sample container was of $75 \mathrm{~mm} \times 75 \mathrm{~mm} \times 75 \mathrm{~mm}$ for mustard. Excluding the cotton on the surface of the grain bulk, the scan was done for $70 \mathrm{~mm}$ on vertical and horizontal sides of the cubic container. Because the slice thickness was $0.12 \mathrm{~mm}$, the total number of slices in the sample container was $70 \mathrm{~mm} / 0.12 \mathrm{~mm}=583$.

The following calculations were done to determine the bulk density of the mustard from the image using the equation in section 3.3.

Total mass of the container with grain $=448.92 \mathrm{~g}$

Mass of the container

$=148.24 \mathrm{~g}$

Mass of grain, $M_{g}$ $=448.92-148.24$

$=300.68 \mathrm{~g}$

$x=$ number of pixles along $x$ direction of the image $=667$

$y=$ number of pixels along $y$ direction of the image $=667$

$z=$ slice thickness of the image $=0.12 \mathrm{~mm}=0.012 \mathrm{~cm}$

$r=$ image resolution along $x$ and $y$ direction $=120 \mu \mathrm{m}=0.12 \times 10^{-5} \mathrm{~cm}$

$t=$ total number of slices $=583$

Note: The image was cropped to remove the container and the cotton. 
Substituting the above values in Eq (1),

Volume of the grain from image, $V_{g}=667 \times 667 \times 0.12 \times 10^{-5} \times 0.12 \times 10^{-5} \times$

$0.012 \times 583$

$=448.19 \mathrm{~cm}^{3}$

Bulk density from the image, $\mathrm{BD}_{\mathrm{i}}=\mathrm{M}_{\mathrm{g}} / \mathrm{V}_{\mathrm{g}}$

$=300.68 / 448.19$

$=0.67 \mathrm{~g} / \mathrm{cm}^{3}$

Bulk density of mustard from published data $=0.69 \mathrm{~g} / \mathrm{cm}^{3} \quad$ (Velasco 1998).

The calculated bulk density of mustard from the image was similar to the reported bulk density of mustard. Similarly bulk densities of other grains were determined from the images and were compared with reported bulk densities and were found to be equivalent (Table 4.1). This proves that the samples used for this study are the representative of the bulk grain. 
Table 4.1 Comparison of calculated bulk densities of grain samples with the reported values.

\begin{tabular}{lccl}
\hline Grain type & $\begin{array}{l}\text { Calculated bulk } \\
\text { density from the } \\
\text { image }\left(\mathrm{kg} / \mathrm{m}^{3}\right)\end{array}$ & $\begin{array}{l}\text { Calculated bulk } \\
\text { density from } \\
\text { the sample } \\
\left(\mathrm{kg} / \mathrm{m}^{3}\right)\end{array}$ & $\begin{array}{l}\text { Published bulk } \\
\text { density }\left(\mathrm{kg} / \mathrm{m}^{3}\right)\end{array}$ \\
\hline Barley & 590 & 603 & 610 (Kumar and Muir 1986) \\
Wheat & 750 & 760 & 772 (Kumar and Muir 1986) \\
Peas & 364 & 375 & 379 (Alagusundaram et al. 1992) \\
Flax seed & 625 & 637 & 642 (Irvine 1989) \\
Mustard & 670 & 684 & 690 (Velasco 1998) \\
\hline
\end{tabular}

\subsection{Analysis of grain images}

\subsubsection{Wheat image}

The cropped horizontal and vertical images of a wheat grain bulk are shown in Figure 4.1. 


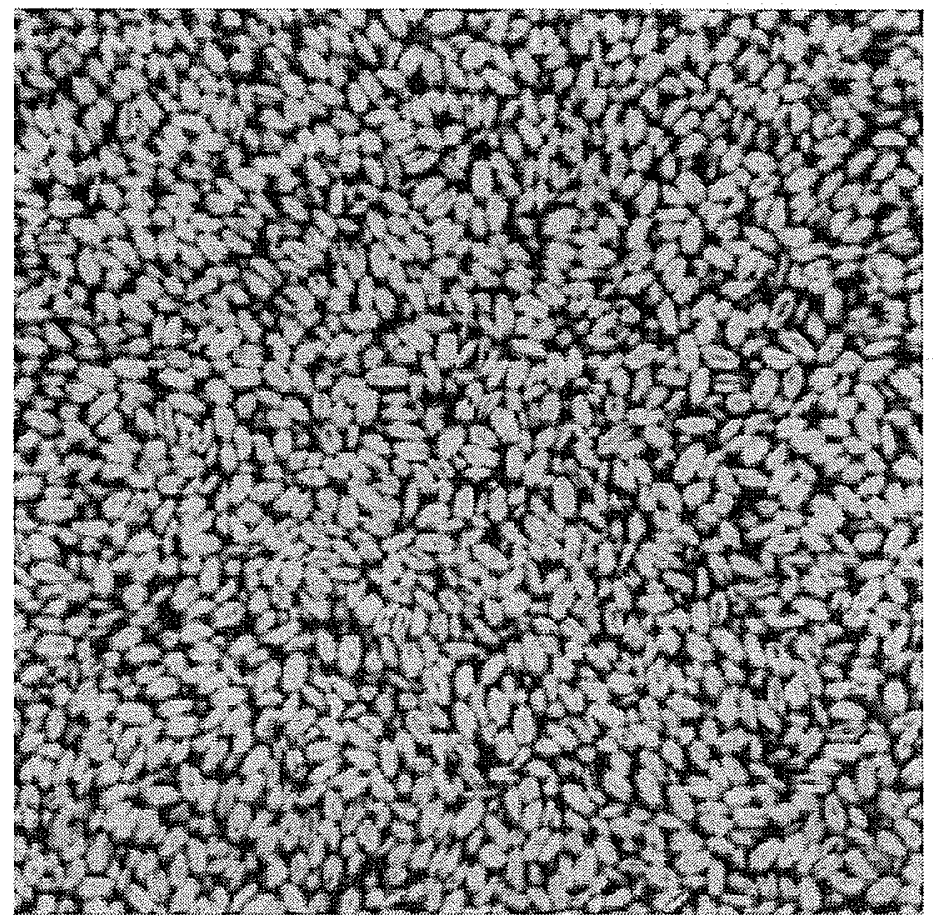

a)

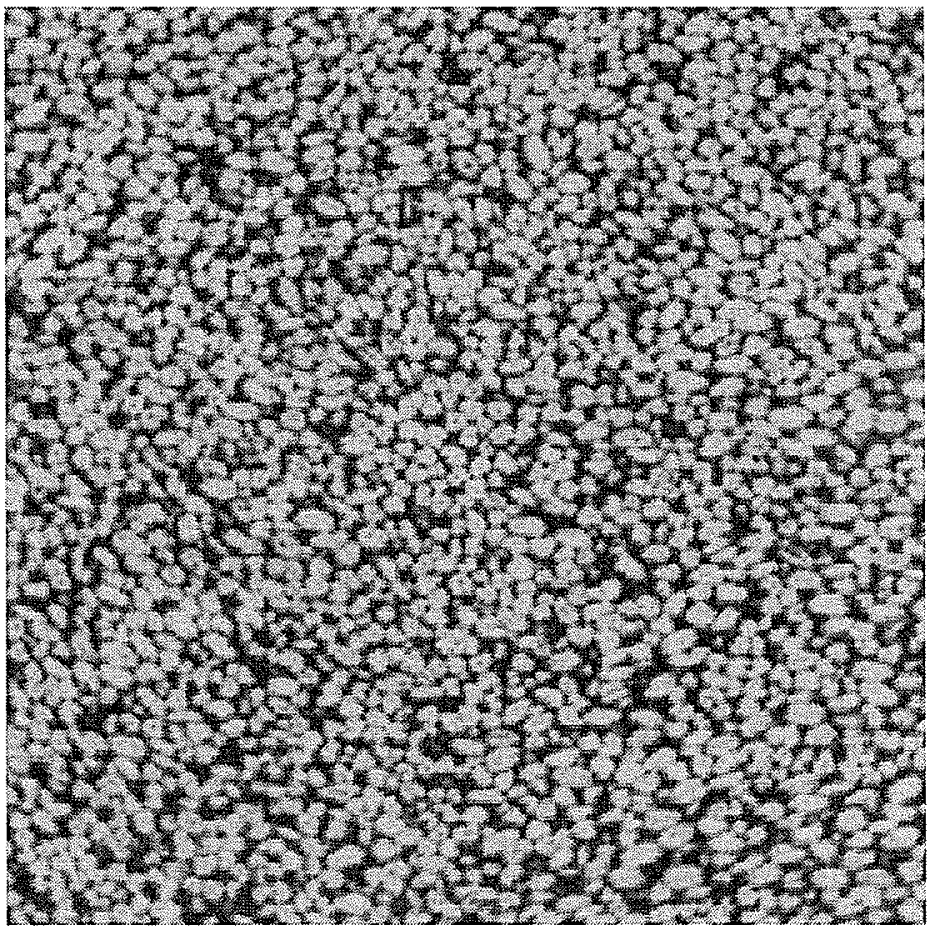

b)

Fig. 4.1. X-ray CT images of a wheat bulk: a) horizontal image (vertical airspace) b) vertical image (horizontal airspace). 
From the horizontal image (Fig. 4.1a), it is obvious that most of the grain kernels lie with their major axes horizontal. The chopped grain kernels are clearly seen from the vertical image (Fig.4.1b).

From the thresholded image, the total air space area in each slice is measured by the total number of the white pixels. The blob coloured horizontal and vertical wheat images are shown in Figure 4.2. The blob coloured image shows that the number of airflow paths and the area of airflow paths are more in horizontal airspace than in the vertical airspace. The distribution of horizontal and vertical airspace in different slices of the wheat bulk is shown in Figure 4.3.

The mean value of the horizontal airspace area in a wheat bulk is 159000 pixels which is less than the mean area of 163000 pixels. From Figure $4.3(b)$, it is observed that there is compaction of grain from the bottom to the top of the sample container as the airspace area is increasing from slice 1 to slice 200 . This trend is not observed for the horizontal airspace. The airspace area varied between 158000 pixels to 162000 pixels in the horizontal airspace while in the vertical airspace, the airspace area varied between 158000 pixels to 166000 pixels.

The airspace area is uniformly distributed in the horizontal airspace of the wheat bulk with a standard deviation of 1705 . But in the vertical airspace of the wheat bulk, the airspace area is distributed with a higher standard deviation of 
2307. Independent group $\mathrm{t}$ - test between means of airflow path areas of horizontal and vertical airspaces of wheat bulk showed that they were statistically different.

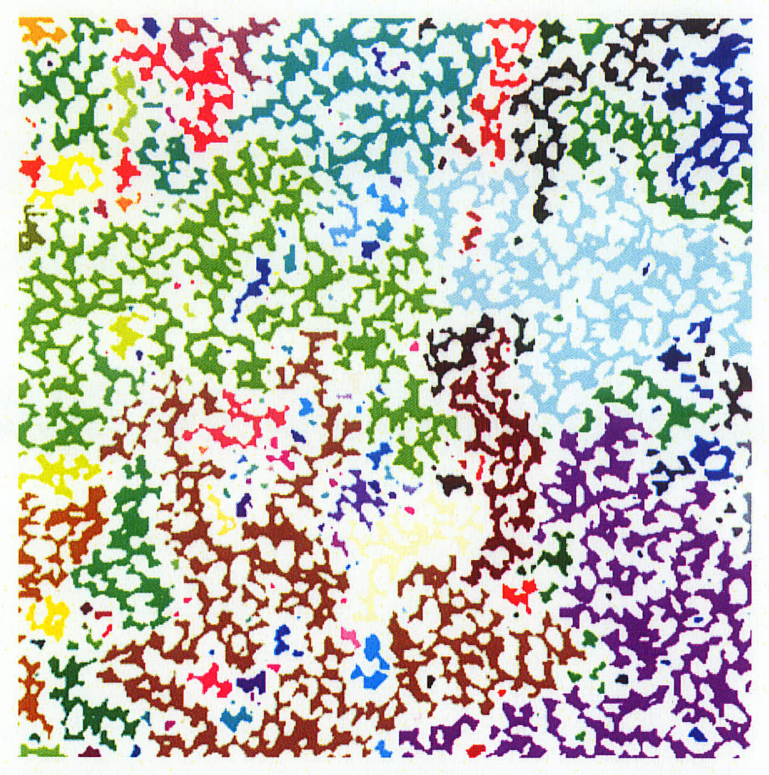

a)

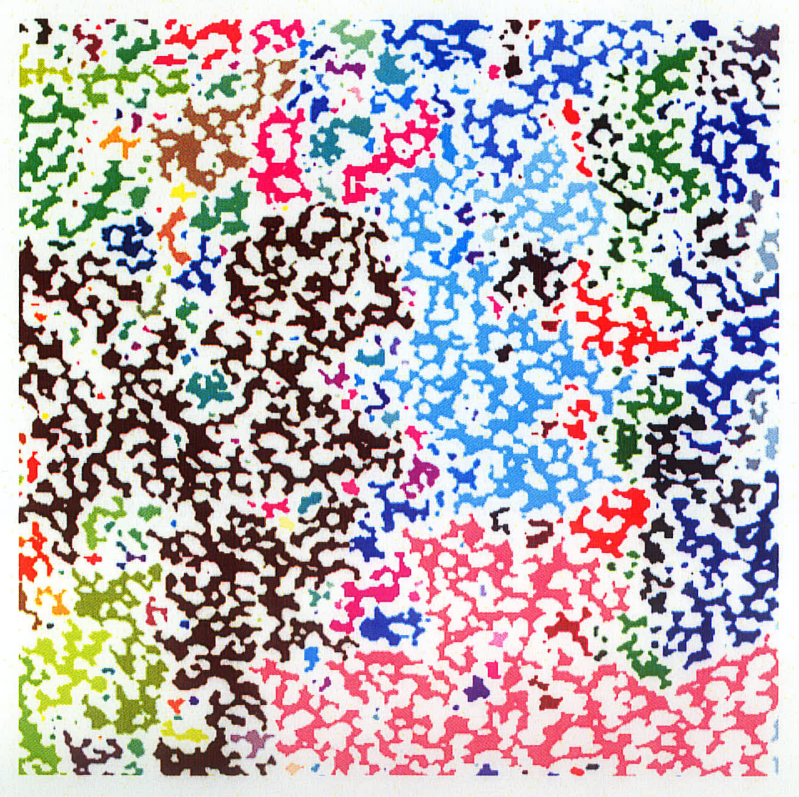

b)

Fig 4.2. Blob coloured X-ray CT images of a wheat bulk:

a) horizontal image b) vertical image. 


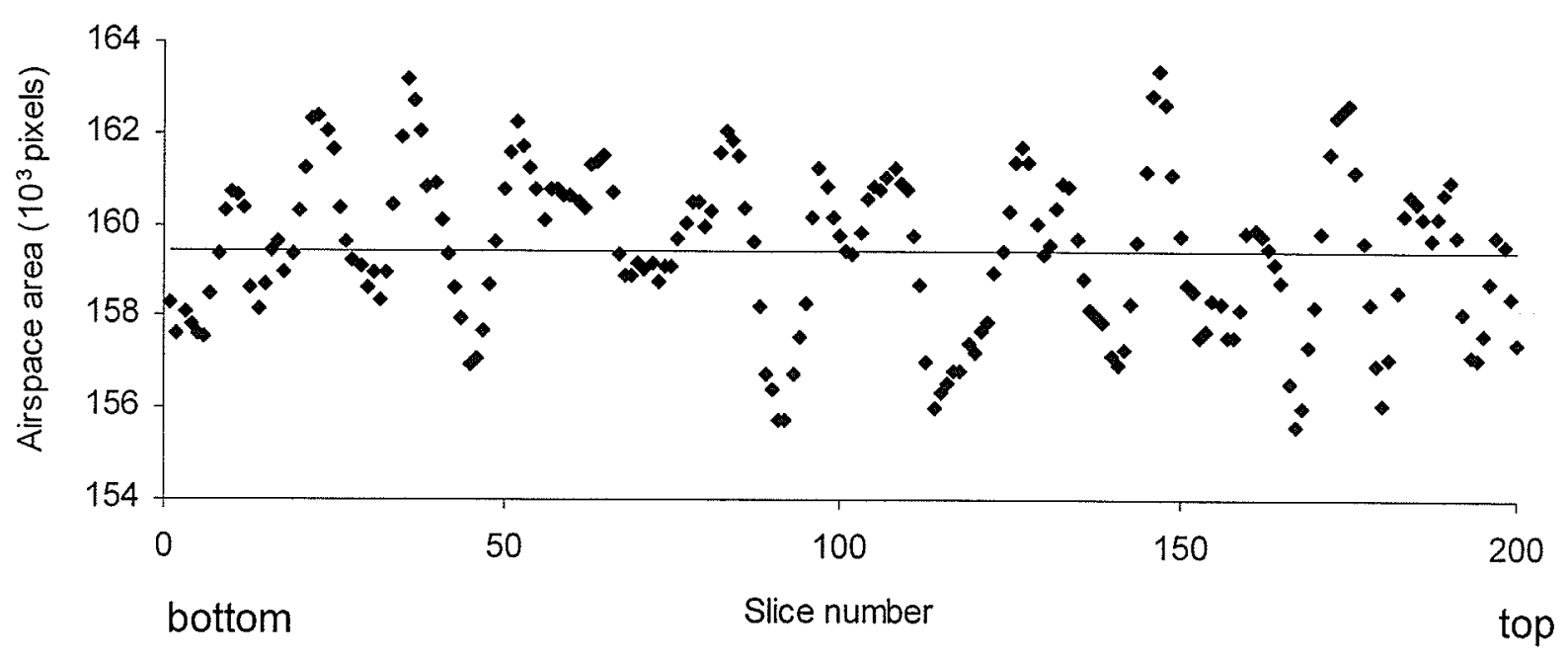

a)

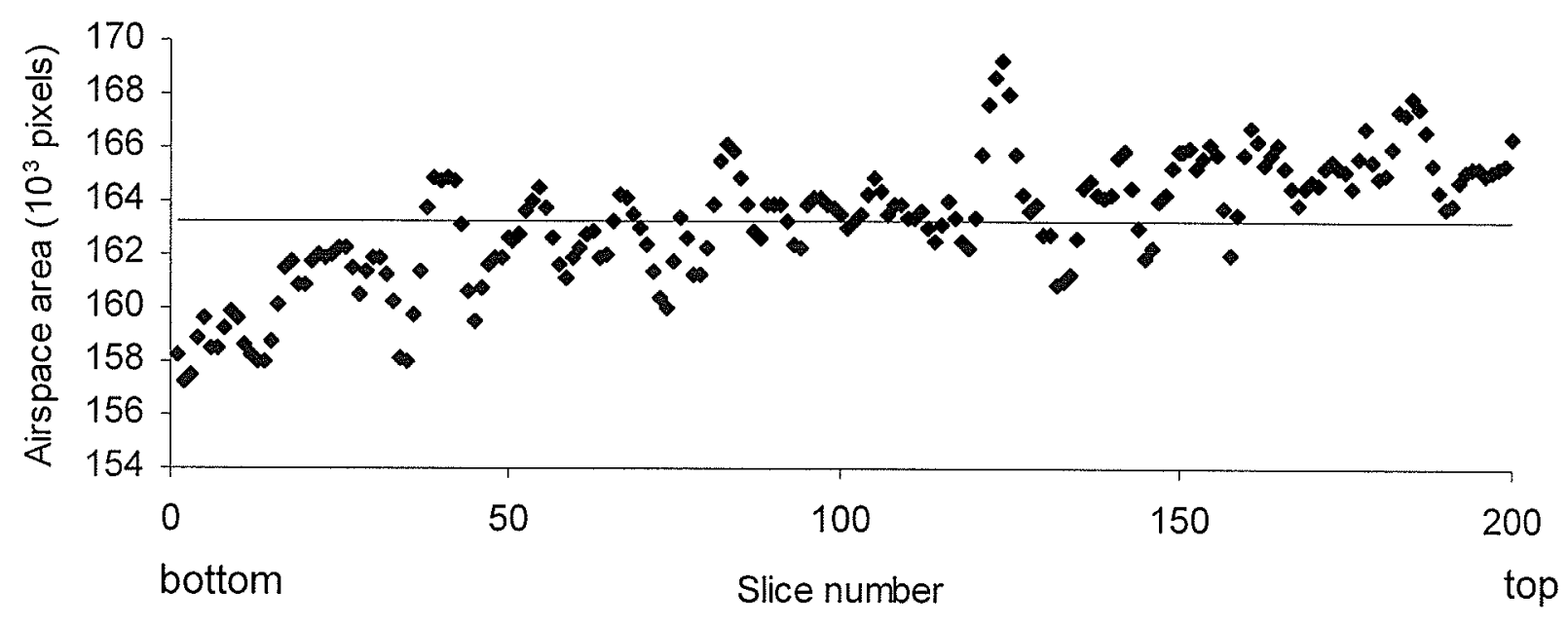

b)

Fig 4.3. Distribution of airspace area in different slices of wheat bulk a) horizontal airspace b) vertical airspace. 0 slice corresponds to bottom of the container. 
The number of airpaths in horizontal and vertical airspaces of a wheat bulk is shown in Figure 4.4. The number of airpaths is almost double in the horizontal airspace than in the vertical airspace of wheat bulk. Because there are more chopped grains in the horizontal airspace, there are more airpaths in the horizontal airspace compared to the vertical airspace in the wheat bulk. This is clearly seen from the blob coloured images (Figure 4.2).

The length of airpaths in horizontal and vertical airspaces of wheat was also measured (Figure 4.5). The number of same length airpaths in the horizontal airspace is almost double that in the vertical airspace of wheat bulk. For example, in the horizontal airspace of wheat (Figure 4.5a), airpaths with 10 pixel length are 130 in number whereas in the vertical airspace of bulk wheat (Figure 4.5b), the number was only 60 . There are more airflow paths in the horizontal airspace and the air can pass through the grain bulk with less resistance than in the vertical direction of the grain bulk. This is the reason for the lower aifflow resistance in the horizontal direction than in the vertical direction of the airflow in the grain bulk. There are more shorter airpaths and they are distributed more uniformly in the horizontal airspace than in the vertical airspace. 


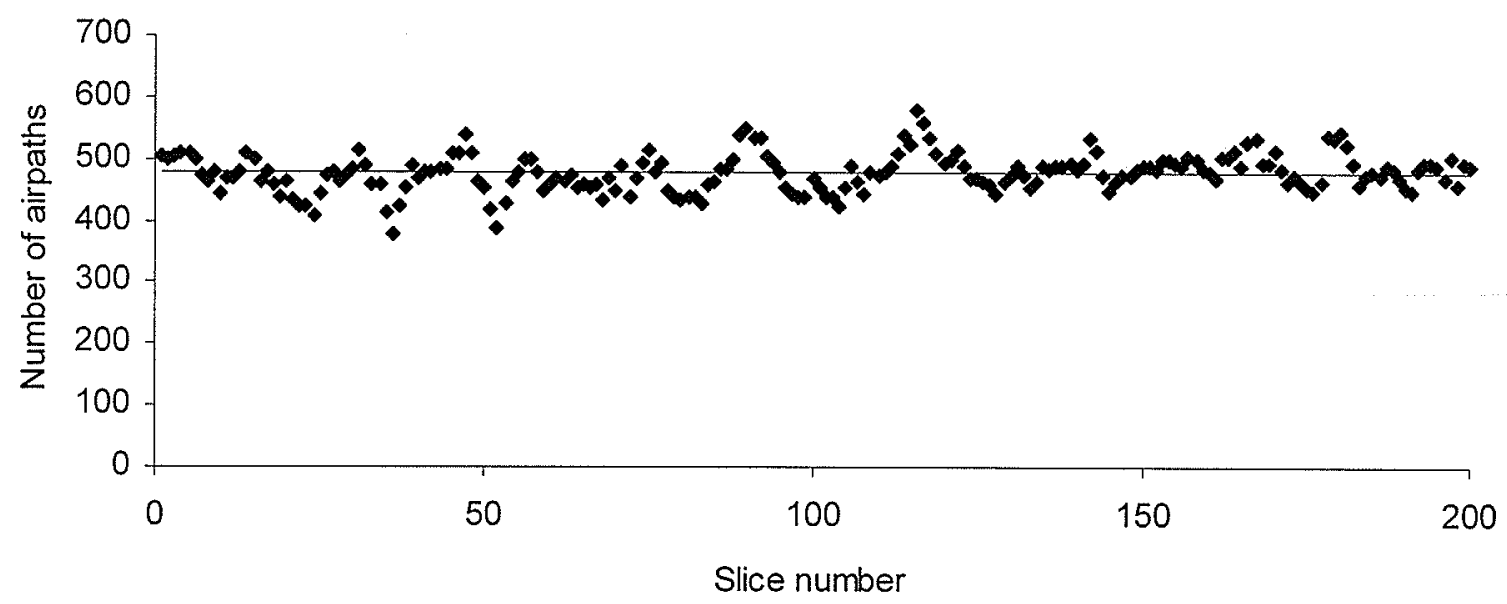

a)

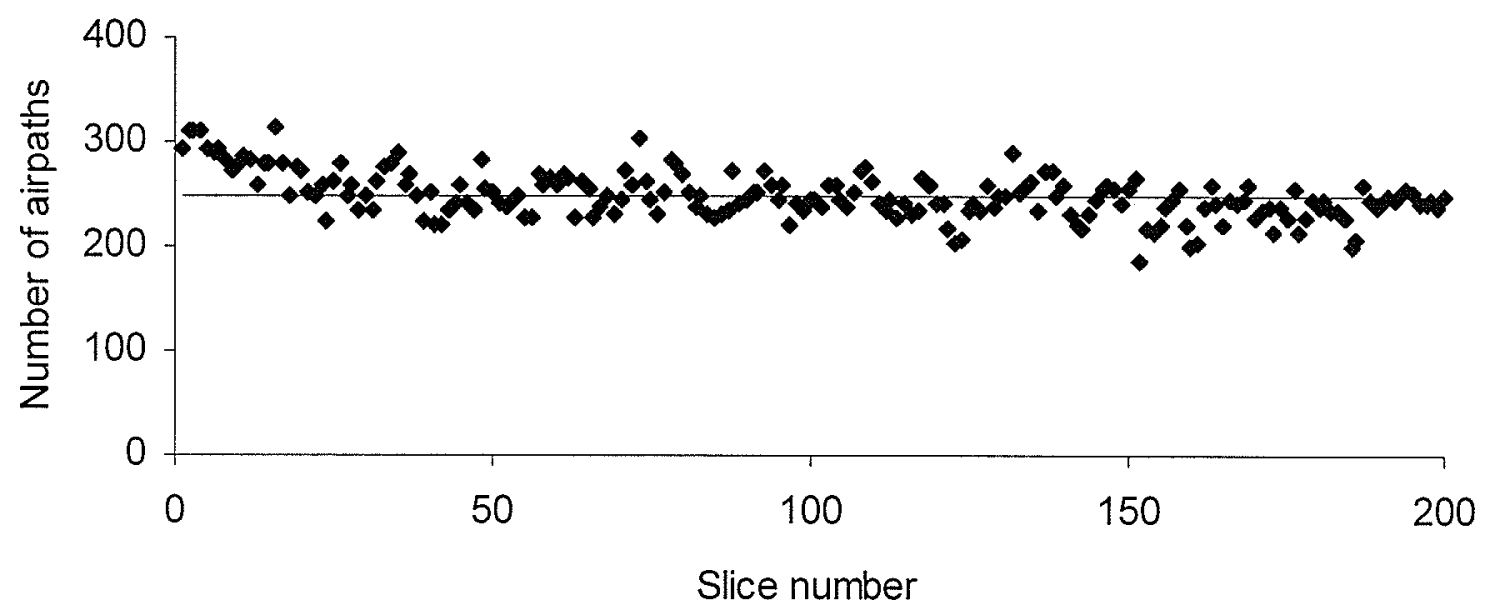

b)

Fig 4.4. Number of airpaths in different slices of wheat bulk images a) horizontal airspace b) vertical airspace. 


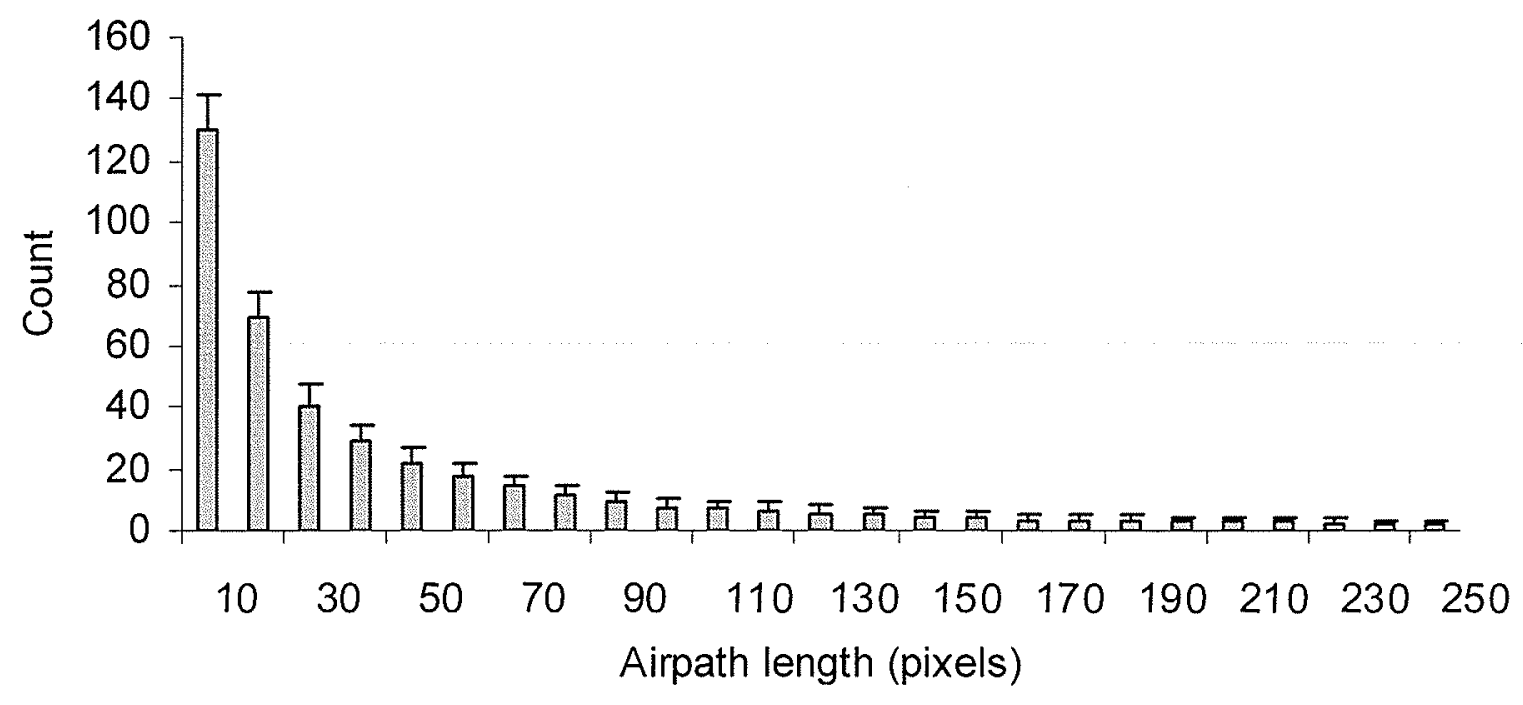

a)

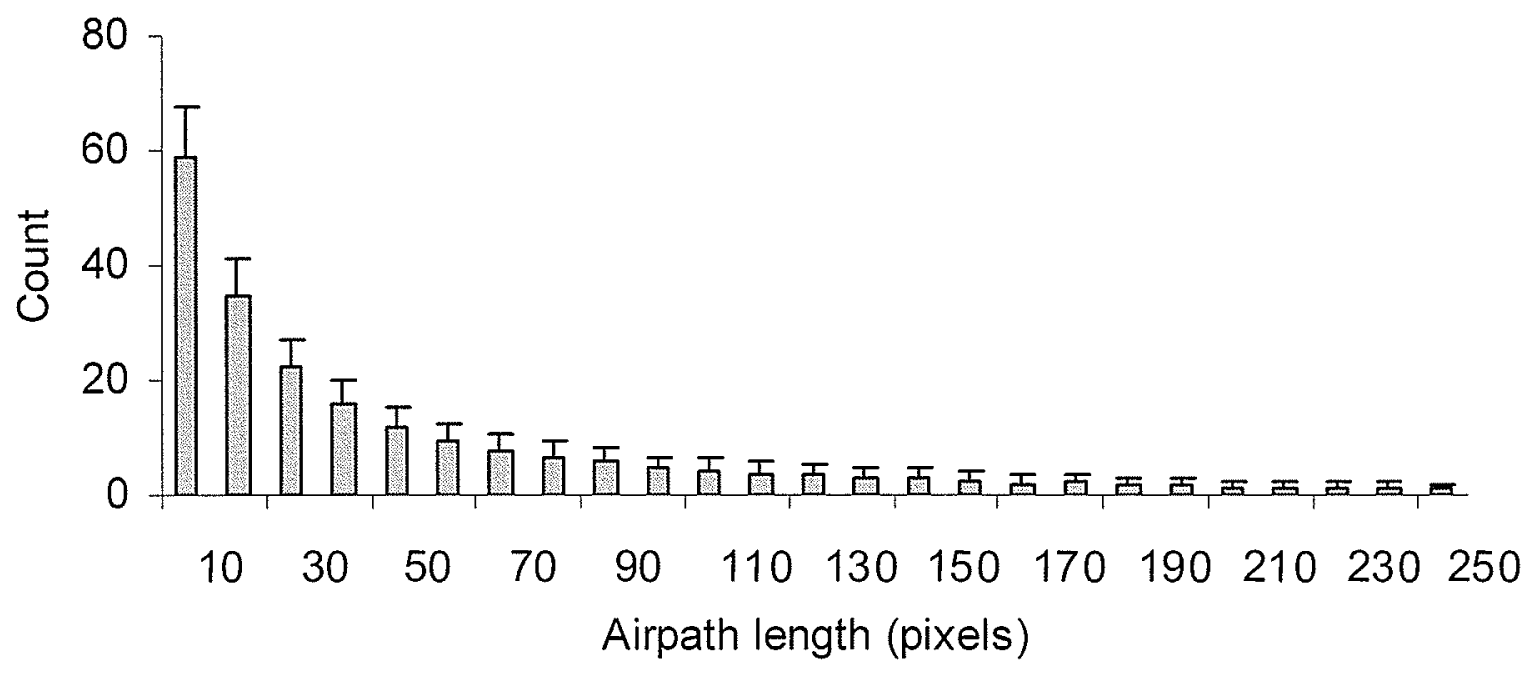

b)

Fig 4.5. Frequency distribution on the length of airpaths in a) horizontal airspace b) vertical airspace of wheat bulk image. 


\subsubsection{Barley image}

The cropped horizontal and vertical images of barley bulk are shown in Figure 4.6.

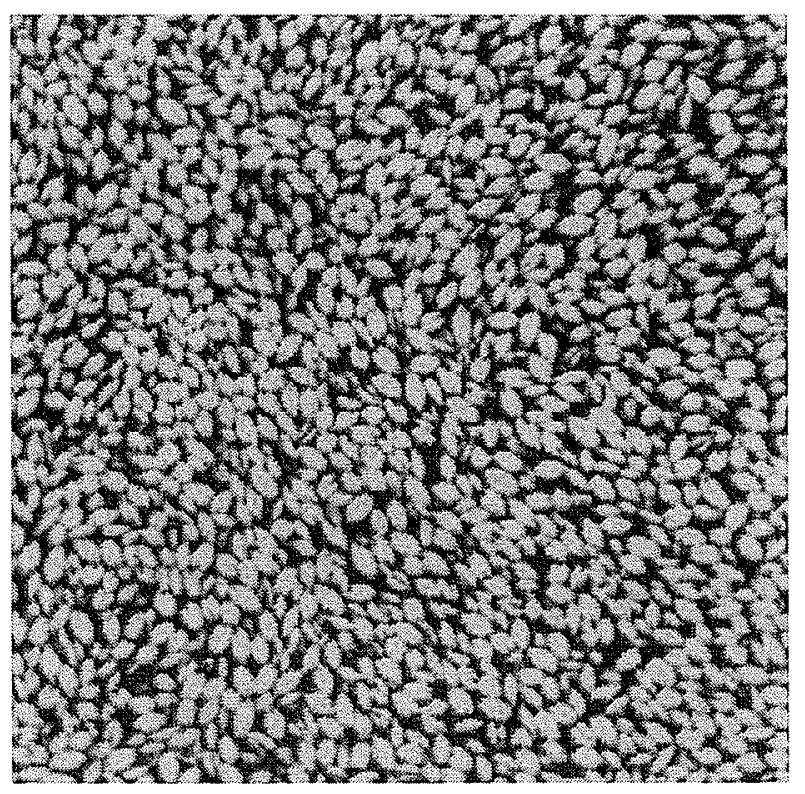

a)

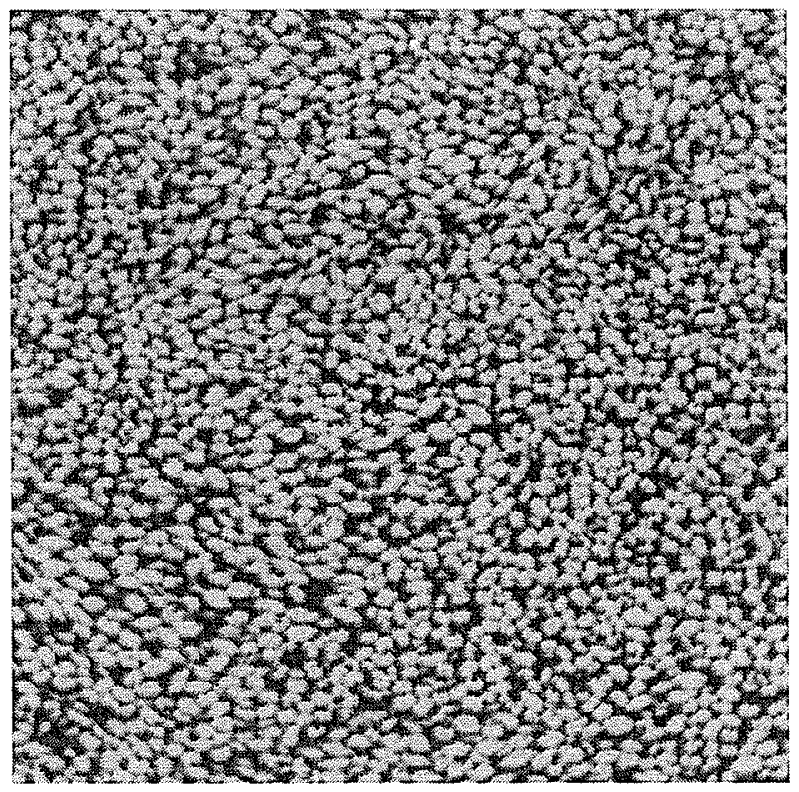

b)

4.6. X-ray CT images of barley bulk: a) horizontal image (vertical airspace) b)vertical image (horizontal airspace). 
The blob coloured horizontal and vertical barley images are shown in Figure 4.7. The blob coloured image shows that there are more airflow paths and more area of airflow paths in the vertical image (horizontal airspace) than in the horizontal image (vertical airspace).

The distribution of horizontal and vertical airspace in a barley bulk is shown in Figure 4.8. The mean value of the horizontal airspace area in a barley bulk is 164000 pixels which is less than the mean area of 170000 pixels. Also, as was the case for wheat, for barley, there is compaction of grain towards the bottom of the sample container as the airspace area is increasing from slice 1 to 200 (Fig.4.8 b). The airspace area varied between 160000 pixels to 165000 pixels in the horizontal airspace while in the vertical airspace, the airspace area varied between 165000 pixels to 175000 pixels.

The airspace area is uniformly distributed in the horizontal airspace of the barley bulk with a standard deviation of 1938. But in the vertical airspace of the barley bulk, the airspace area was distributed with a standard deviation of 2632 .

The number of airpaths in horizontal and vertical airspaces of barley bulk images is shown in Figure 4.9. The number of airpaths is almost double in horizontal airspace than in vertical airspace of a barley bulk. As there are more chopped grains in the horizontal airspace, there are more airpaths in the 
horizontal airspace compared to the vertical airspace in a barley bulk. This is clearly seen from the blob coloured images (Figure 4.7).

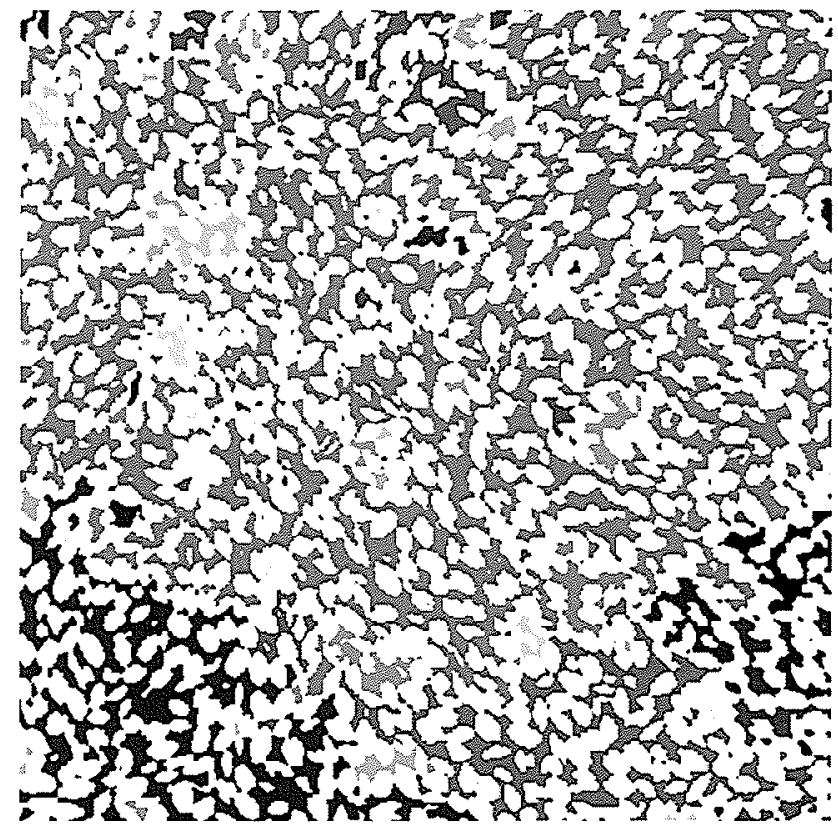

a)

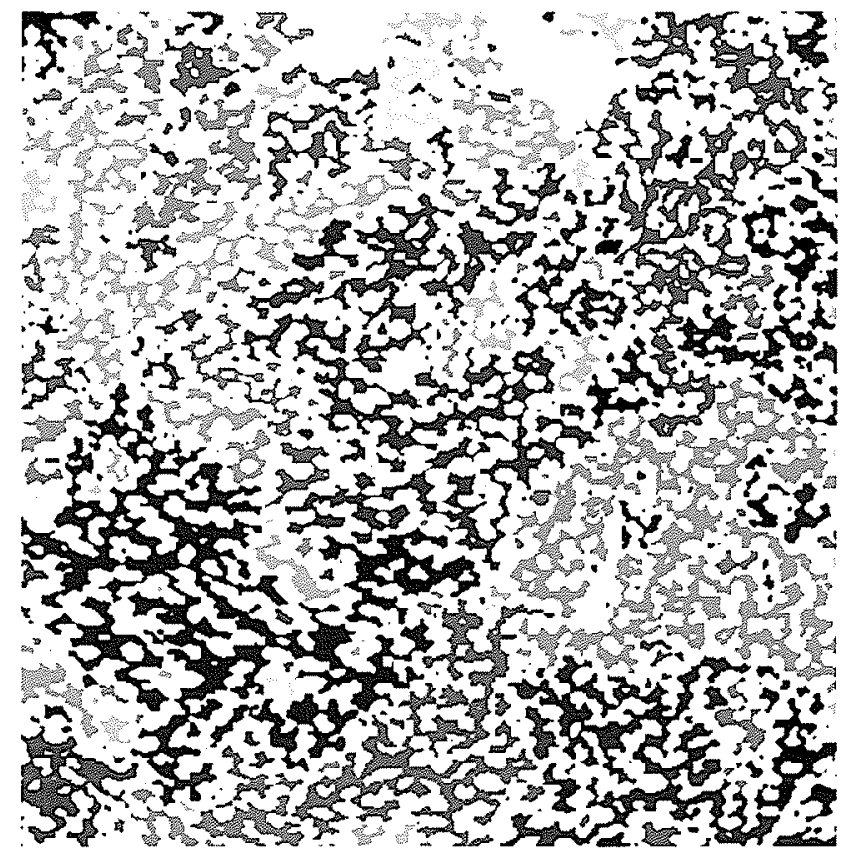

b)

Fig 4.7. Blob coloured X-ray CT images of a barley bulk:

a) horizontal image b) vertical image. 


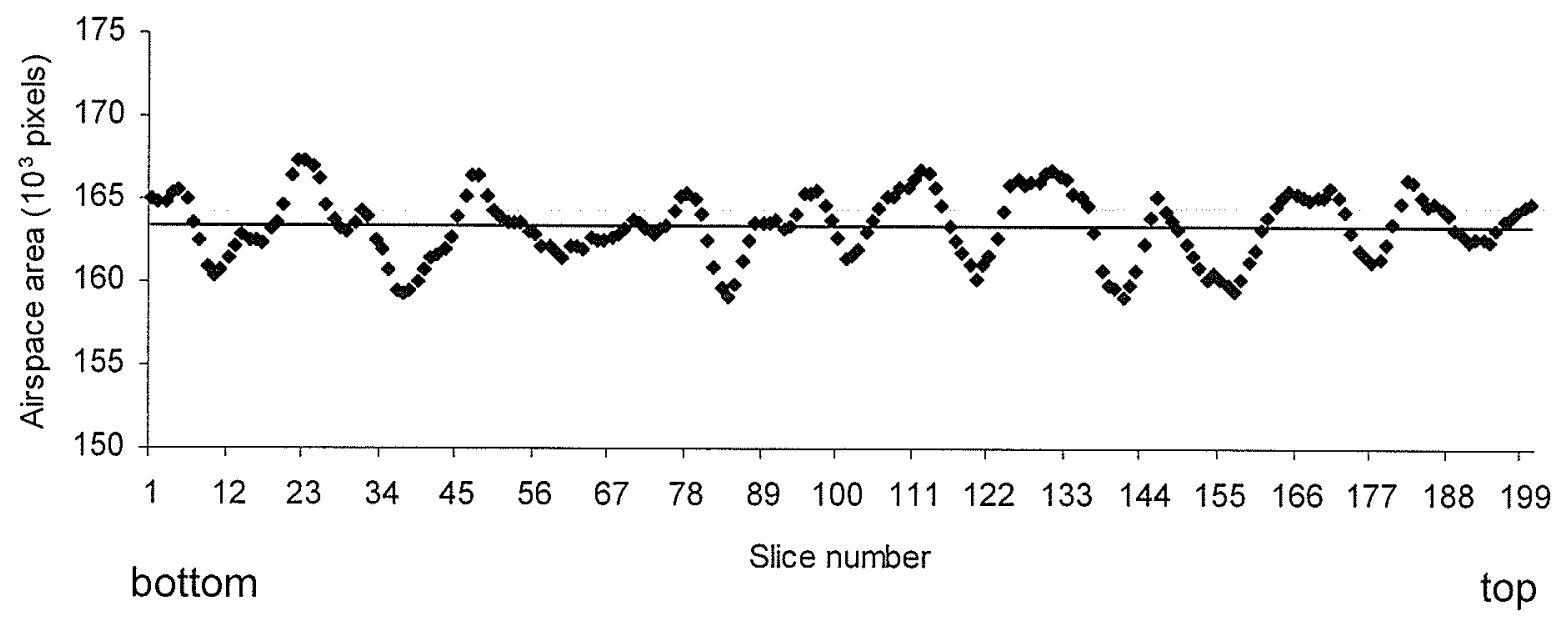

a)

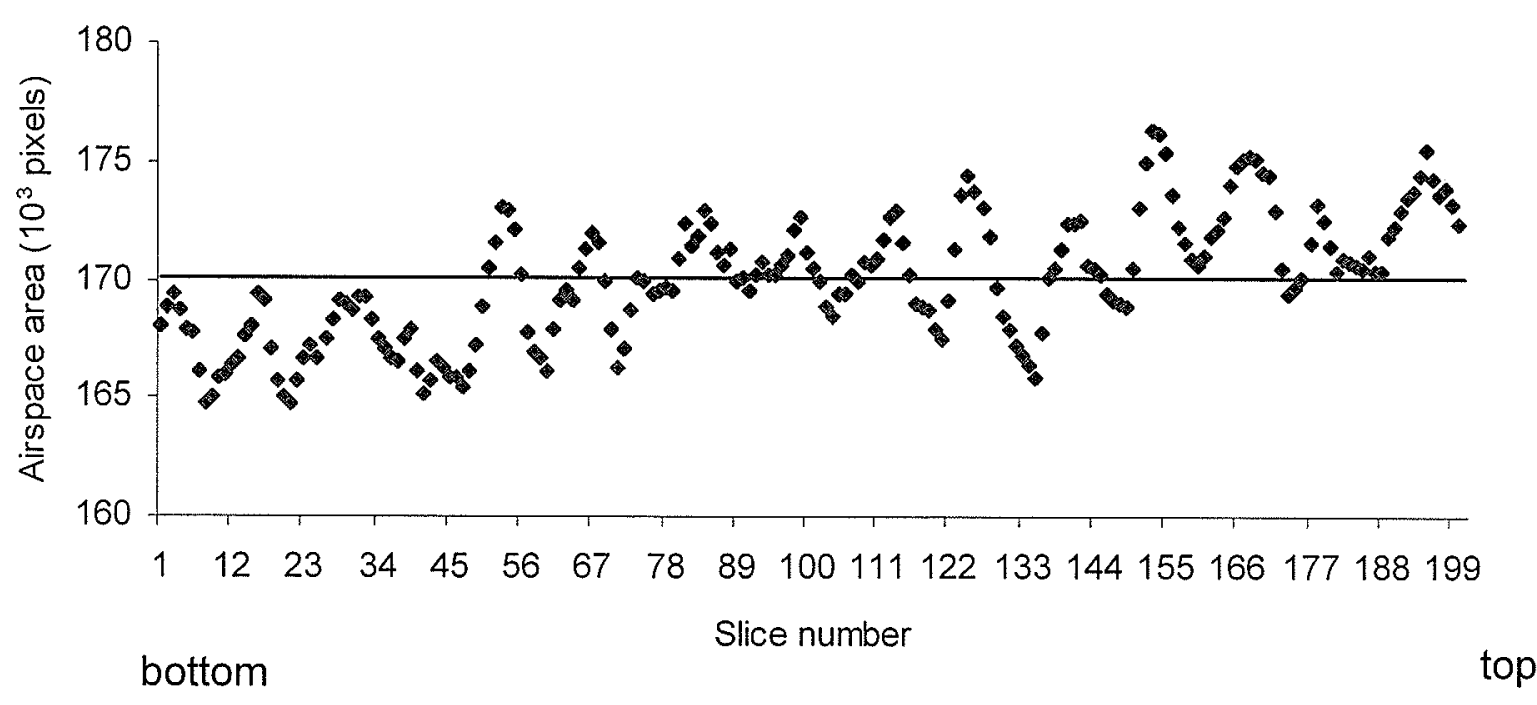

b)

Fig 4.8. Distribution of airspace area in different slices of a barley bulk a) horizontal airspace b) vertical airspace. 0 slice corresponds to bottom of the container. 


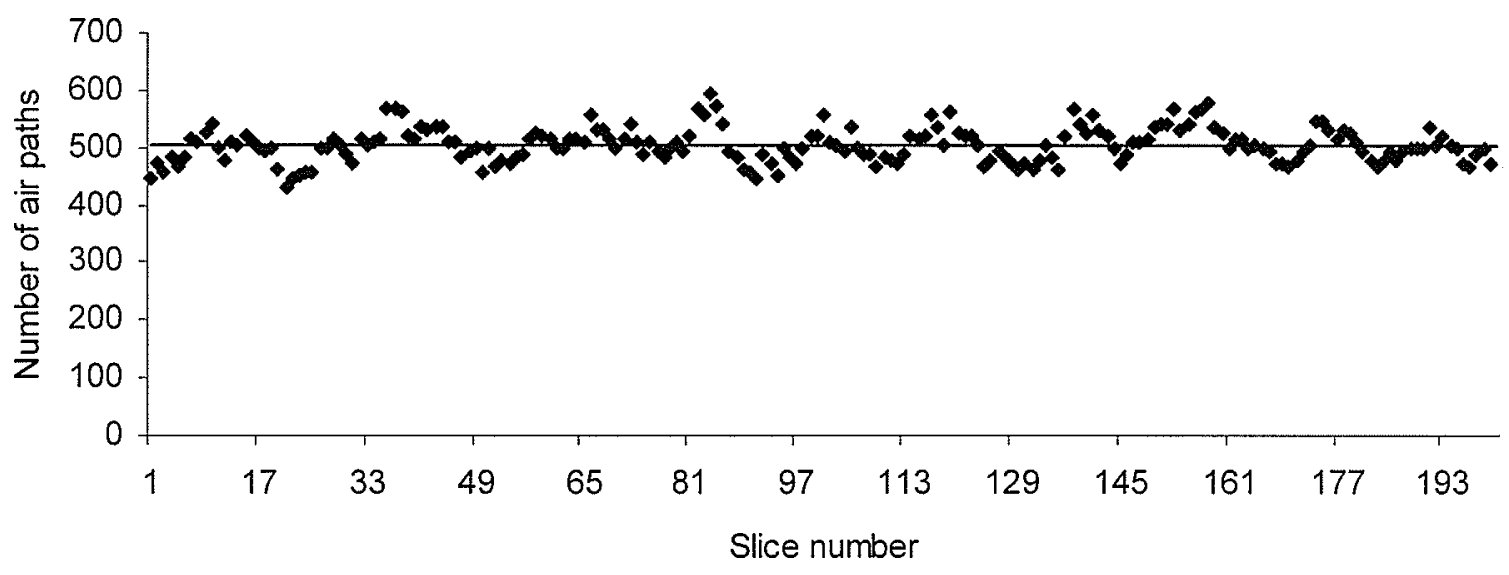

a)

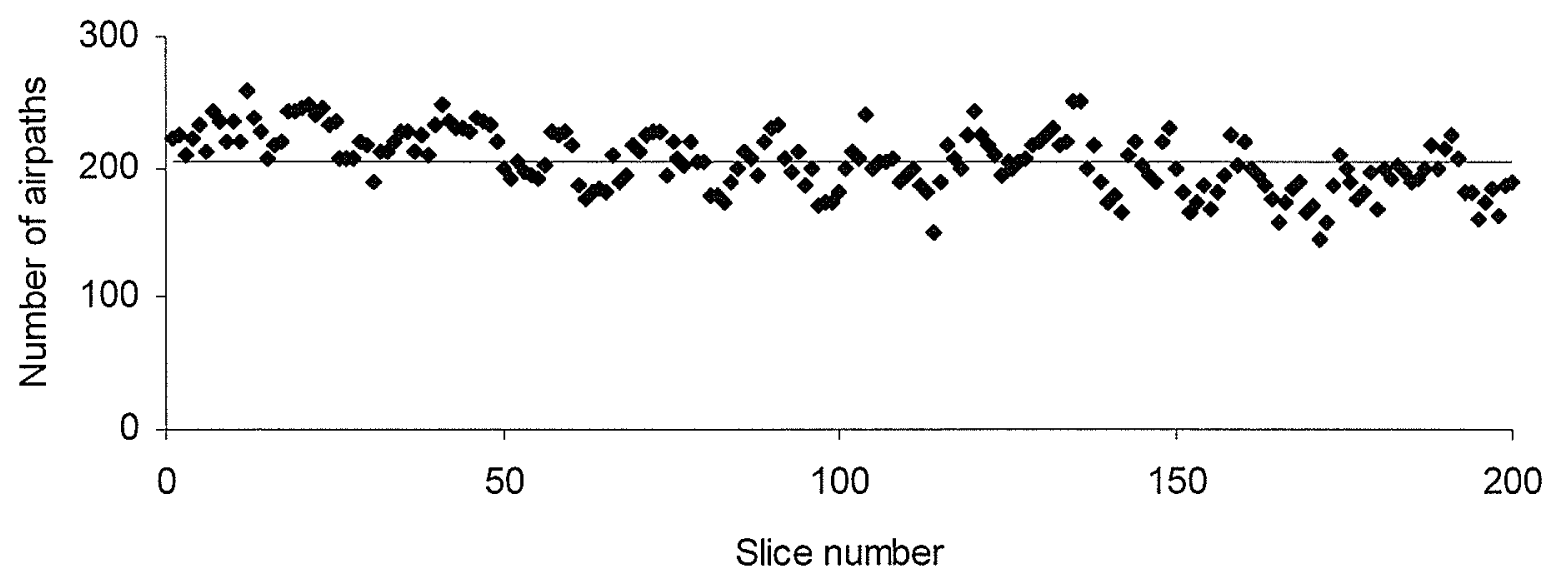

b)

Fig 4.9. Number of airpaths in a) horizontal airspace b) vertical airspace of bulk barley images. 
The length of airpaths in horizontal and vertical airspaces of barley was also measured (Figure 4.10). The number of same length airpaths in the horizontal airspace is more than double those in the vertical airspace of barley bulk images. For example, in the horizontal airspace of barley (Figure $4.10 \mathrm{a}$ ), a 10 pixel width of airflow path length are 125 in number, whereas in the vertical airspace of bulk barley (Figure 4.10, b), the number was only 45 .

Independent group $\mathrm{t}$ - tests between means of airflow path areas of horizontal and vertical airspaces of bulk barley bulk showed that they were statistically different. As there are more airflow paths in the horizontal airspace, the air can pass through the grain bulk with less resistance than in the vertical direction of the grain bulk. This is the reason for the lower airflow resistance in the horizontal direction than in the vertical direction for airflow in the grain bulk. There are more shorter airpaths and they are distributed uniformly in the horizontal airspace than there are in the vertical airspace of bulk barley. 


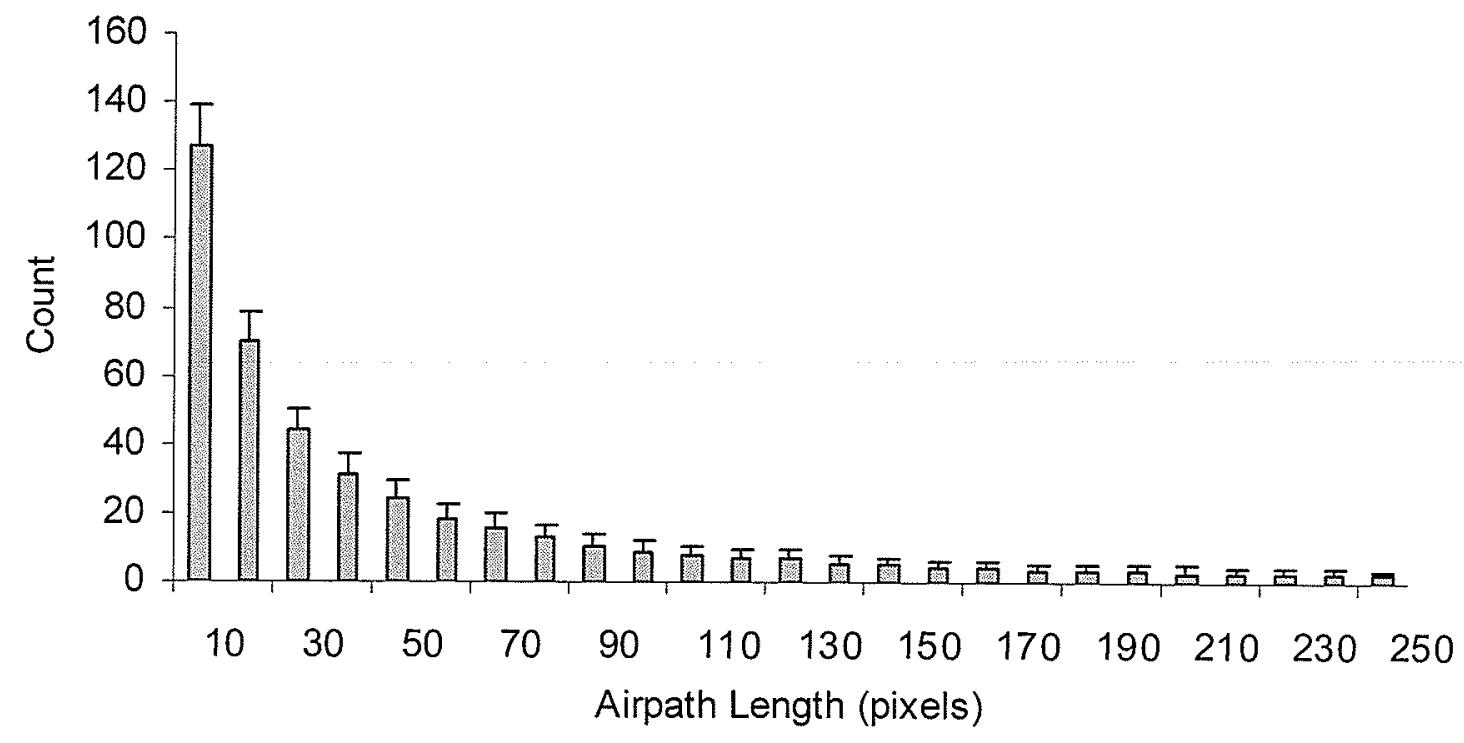

a)

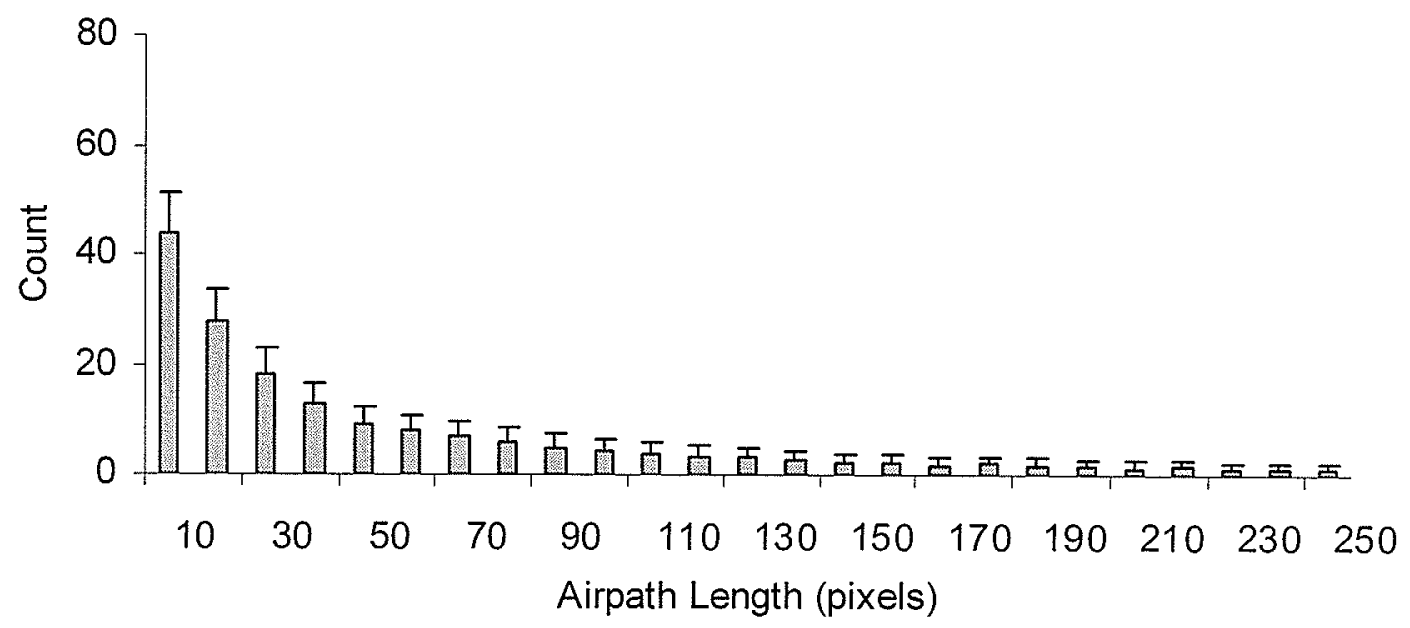

b)

Fig 4.10. Frequency distribution of the length of airpaths in a) horizontal airspace b) vertical airspace of barley bulk image. 


\subsubsection{Flax seed image}

The cropped horizontal and vertical images of flax seed bulk are shown in Figure 4.11.

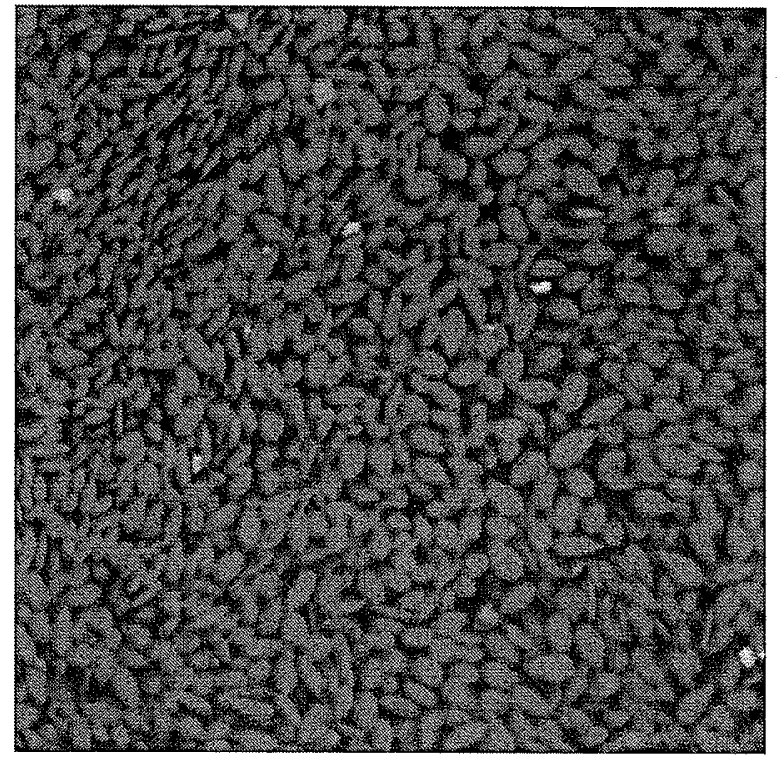

a)

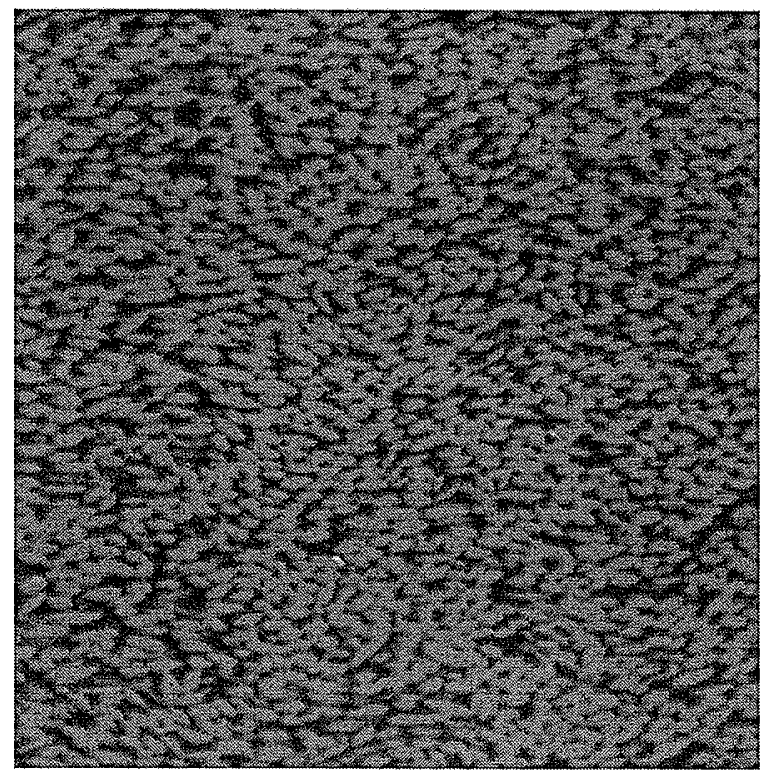

b)

4.11. X-ray CT images of flax seed bulk: a) horizontal image

b) vertical image. 
The blob coloured horizontal and vertical flax seed images are shown in Figure 4.12. The blob coloured images show that the number of airflow paths and the area of airflow paths are more common in the vertical image than in the horizontal image.

The distribution of horizontal and vertical airspace in a flax seed bulk is shown in Figure 4.13. The mean value of the horizontal airspace in a flax seed bulk is 115000 which is less than the mean airspace area of 137000 . From Figure 4.13 $b$, it is observed that there is compaction of grain from the bottom to the top of the sample container as the airspace area is increasing from slice 1 to 200 . The airspace area varies between 105000 pixels to 130000 pixels in the horizontal airspace while in the vertical airspace, the airspace area varies between 125000 pixels to 145000 pixels.

The airspace area is uniformly distributed in the horizontal airspace compared to the vertical airspace of the flax seed bulk. Independent group $\mathrm{t}$ - test between means of airflow path area between horizontal and vertical airspace of a flax seed bulk showed that they were statistically different when $p<0.05$. 


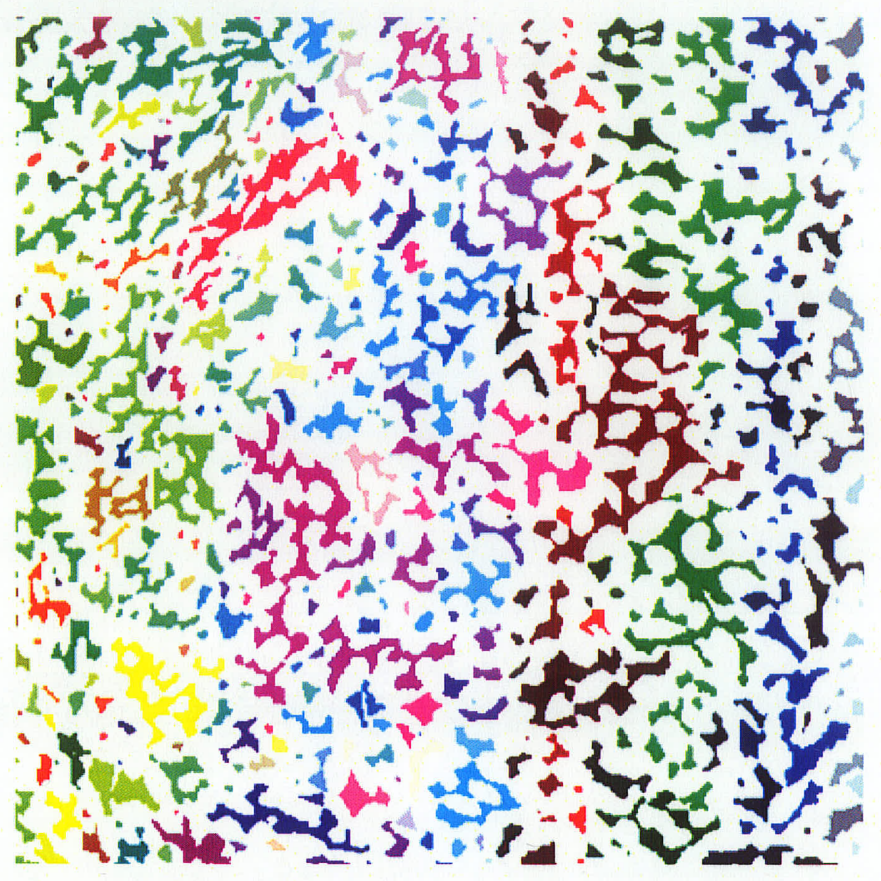

a)

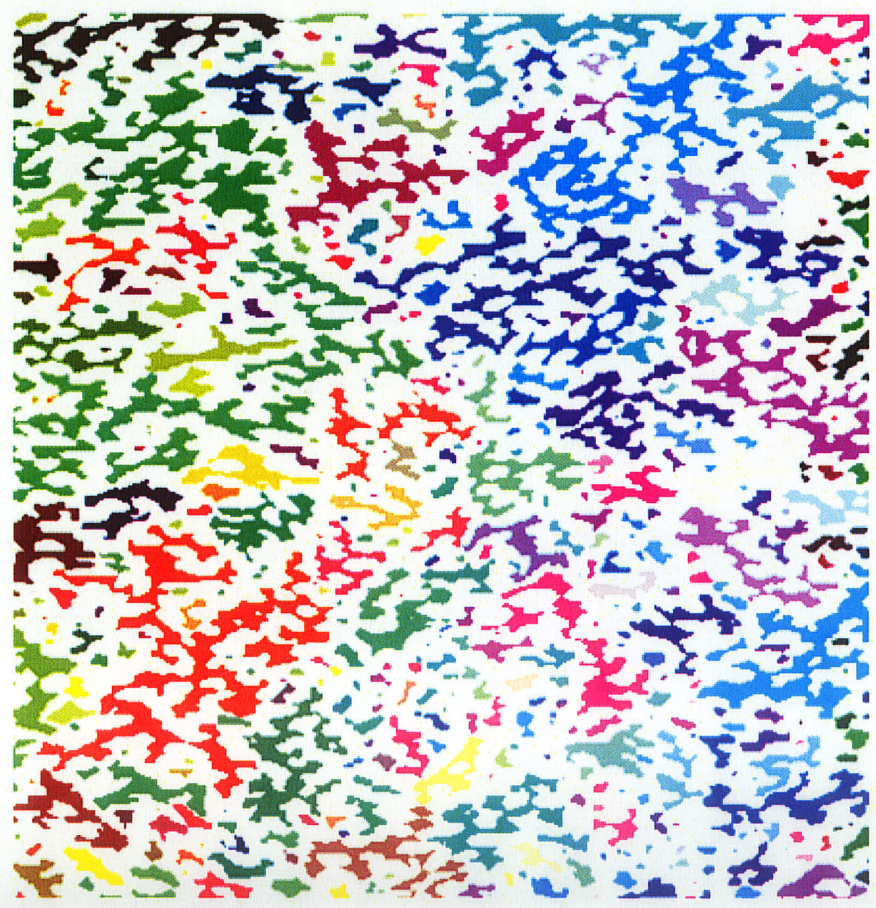

b)

Fig 4.12. Blob coloured X-ray CT images of bulk flax seed:

a) horizontal image b) vertical image. 


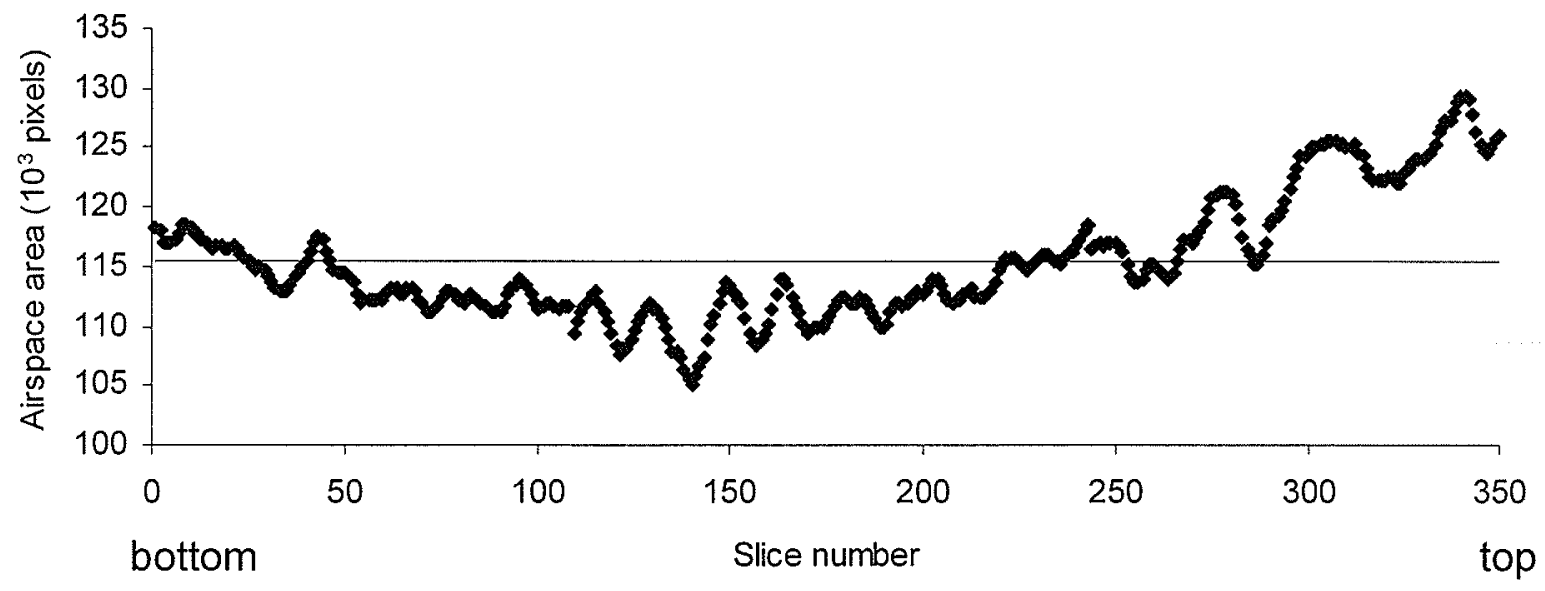

a)

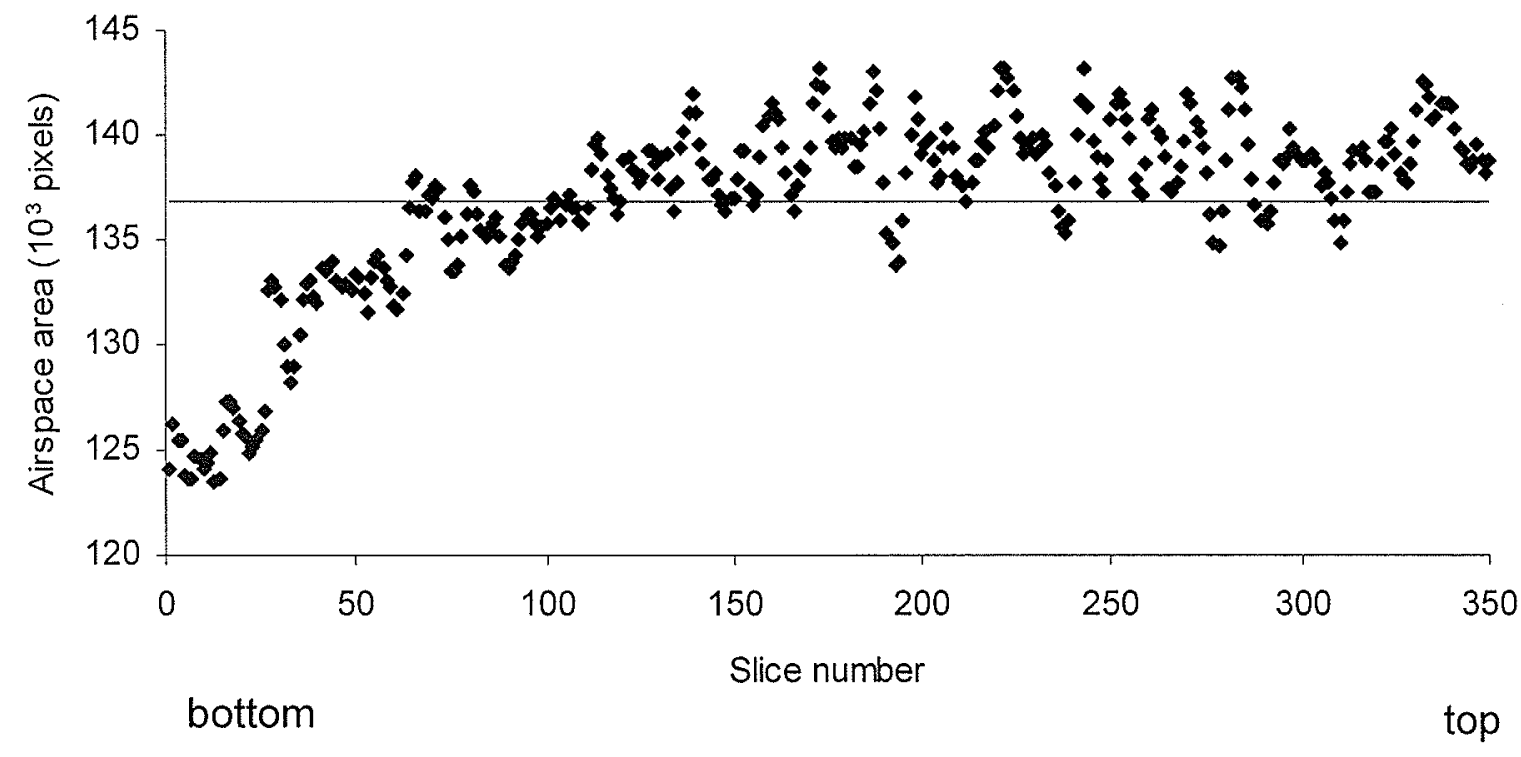

b)

Fig 4.13. Distribution of a) horizontal airspace b) vertical airspace in bulk flax seed images. 0 slice corresponds to bottom of the container. 
The number of airpaths in the horizontal and vertical airspace of a flax seed bulk images is shown in Figure 4.14. The number of airpaths is almost double in the horizontal airspace than in the vertical airspace of flax seed bulk. As there are more chopped grains in the horizontal airspace, there are more airpaths in the horizontal airspace compared to the vertical airspace in a flax seed bulk (Figure 4.12).

The length of airpaths in horizontal and vertical airspace of bulk flax seed was also measured (Figure 4.15). The number of the same length airpaths in the horizontal airspace is almost three times more than in the vertical airspace of flax seed bulk images. For example, in the horizontal airspace of flax seed (Figure $4.15,(a)), 10$ pixel width of airflow path lengths are 110 in number whereas in the vertical airspace of bulk flax seed (Figure 4.15, (b)), there were only 30 pixels. As there are more airflow paths in the horizontal airspace, the air can pass through the grain bulk with less resistance than in the vertical direction in the grain bulk. This is the reason for the lower airflow resistance in the horizontal direction than in the vertical direction of the airflow in the grain bulk. There are more shorter airpaths and they are distributed more uniformly in the horizontal airspace than in the vertical airspace. 


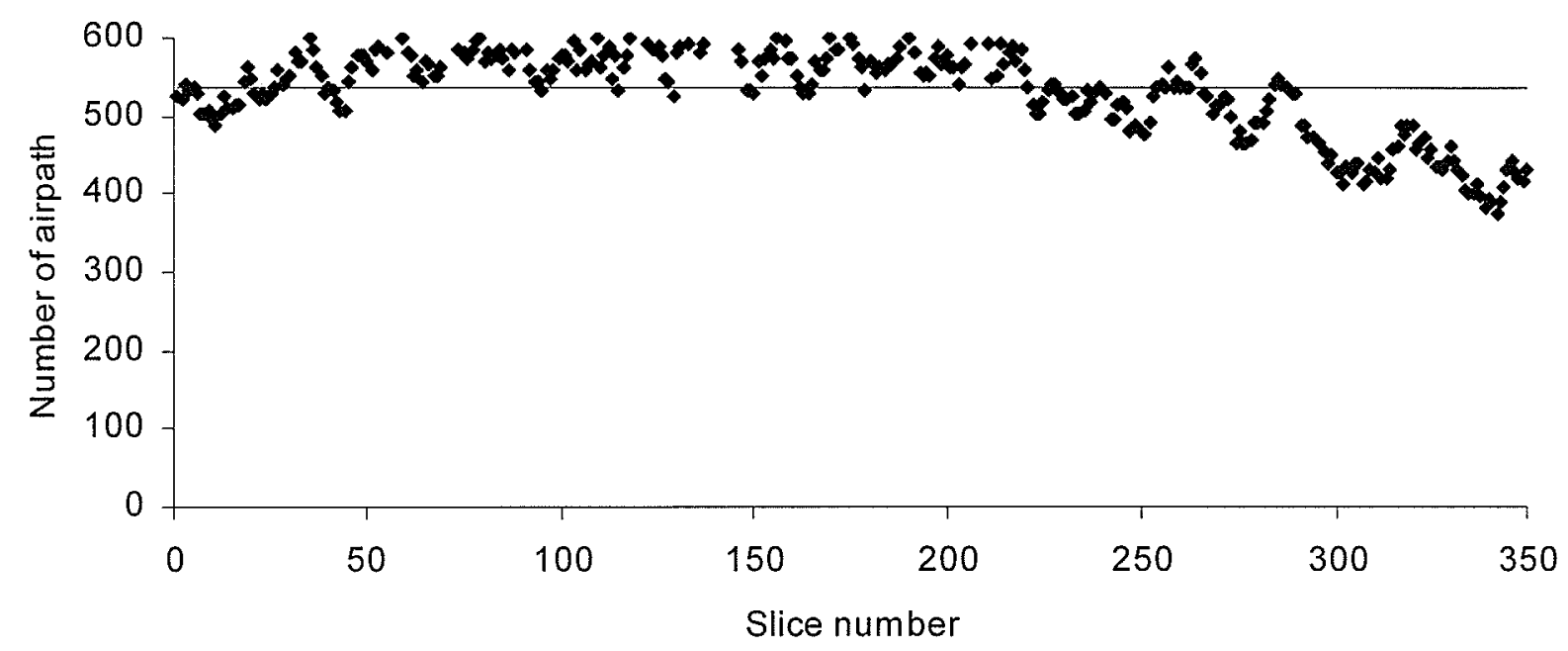

a)

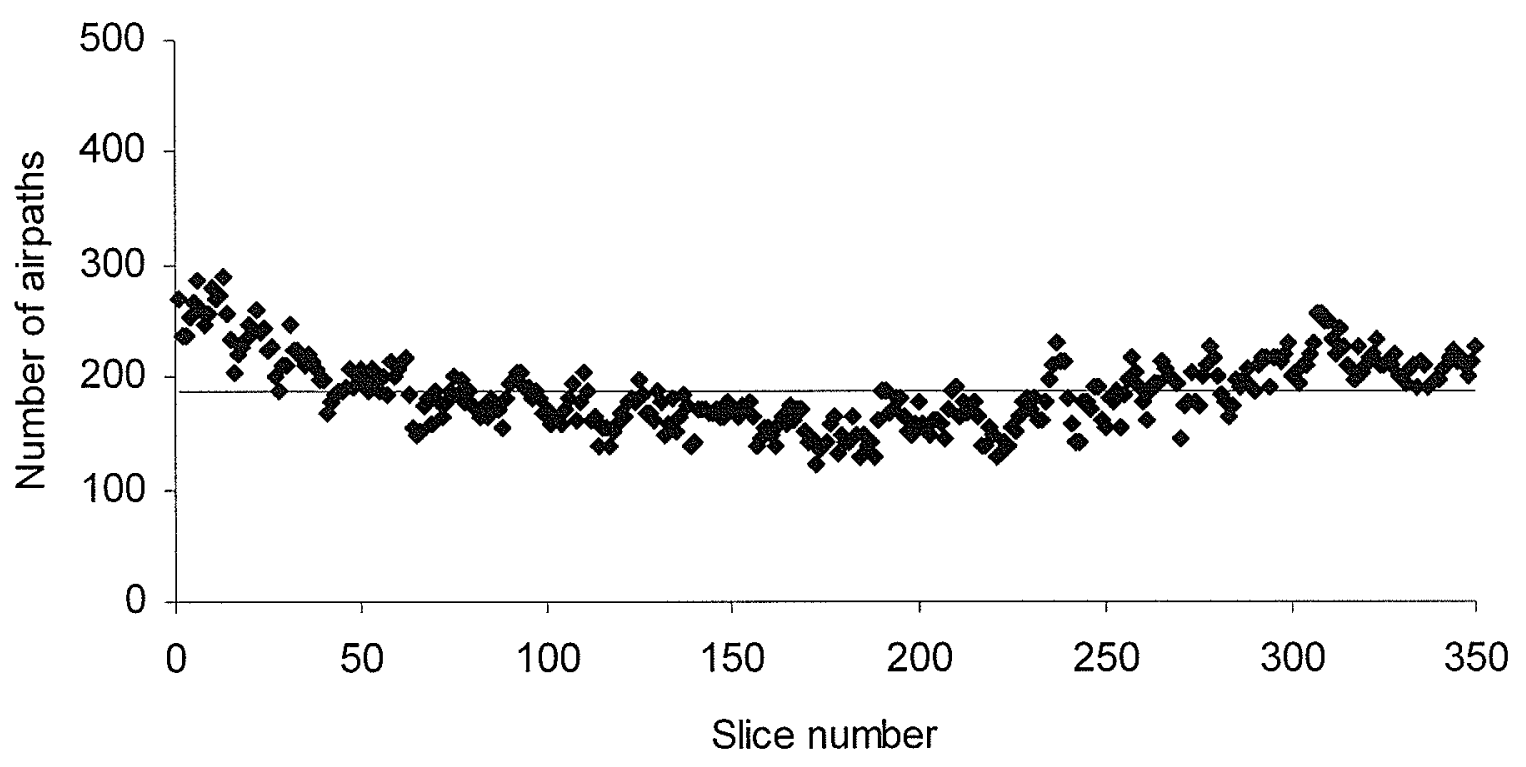

b)

Fig 4.14. Number of airpaths in a) horizontal airspace b) vertical airspace of flax seed bulk images. 


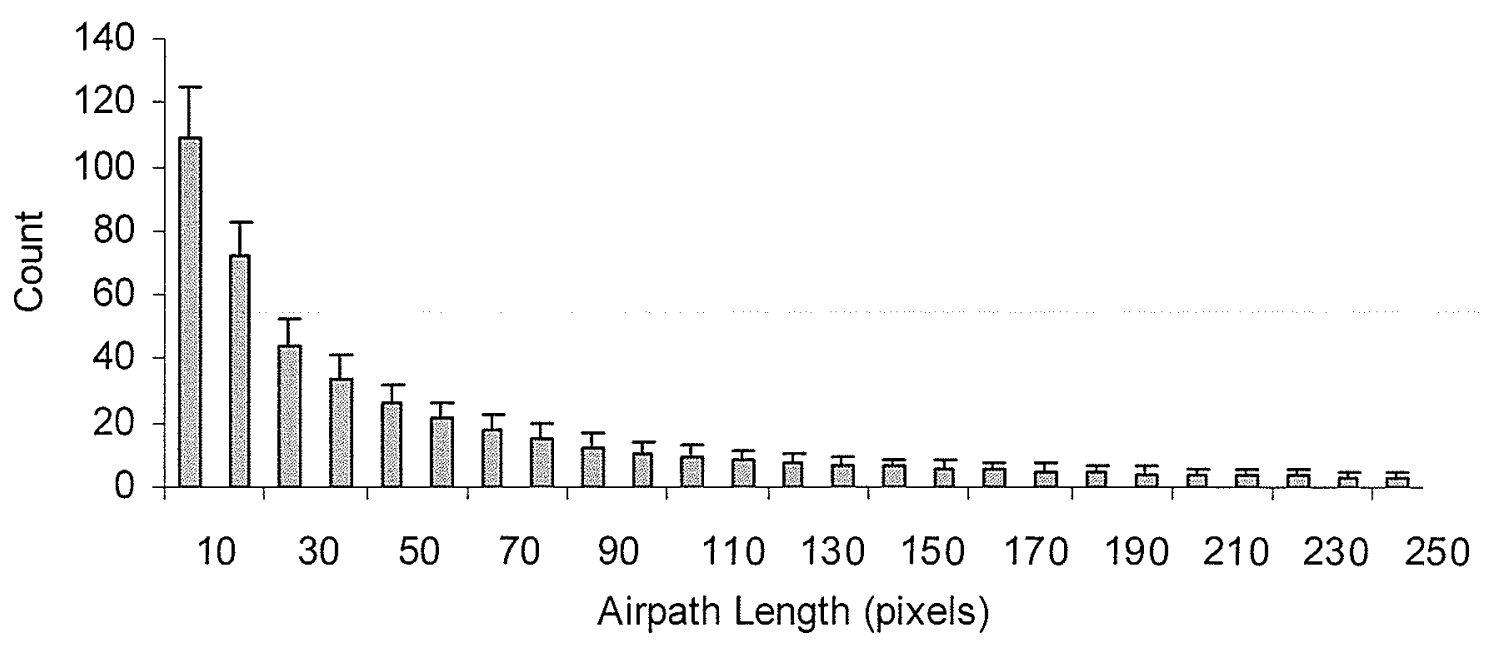

a)

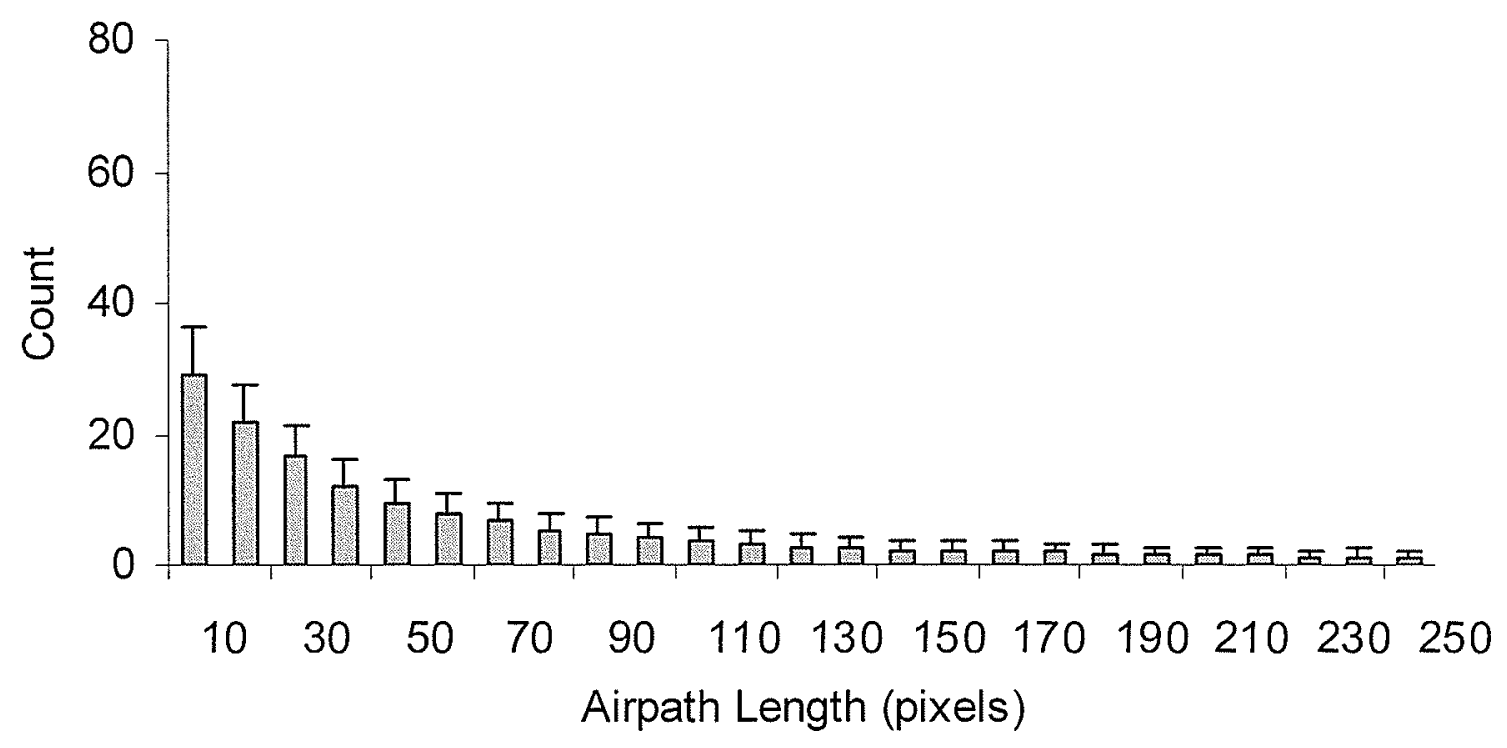

b)

Fig 4.15. Frequency distribution of the length of airpaths in a) horizontal airspace b) vertical airspace of flax seed bulk images. 


\subsubsection{Peas image}

Peas are almost spherical in shape. The cropped horizontal and vertical images of peas grain bulk are shown in Figure 4.16.

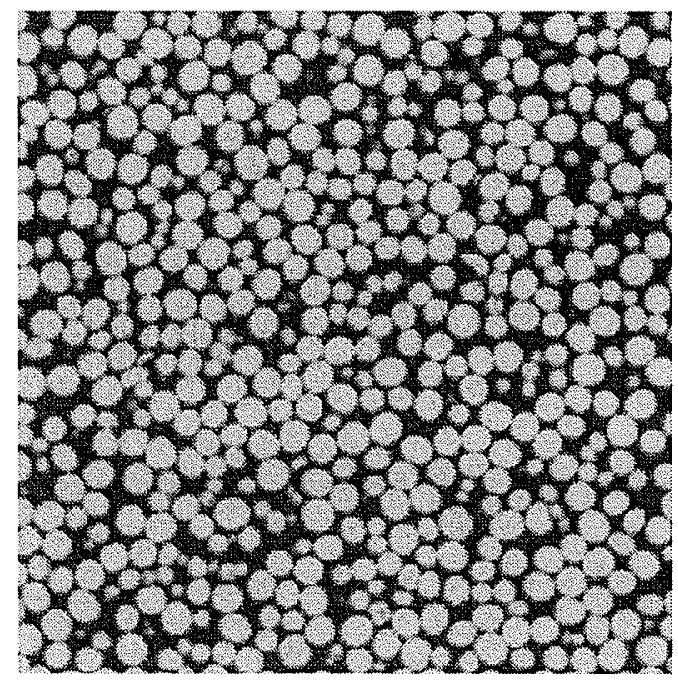

a)

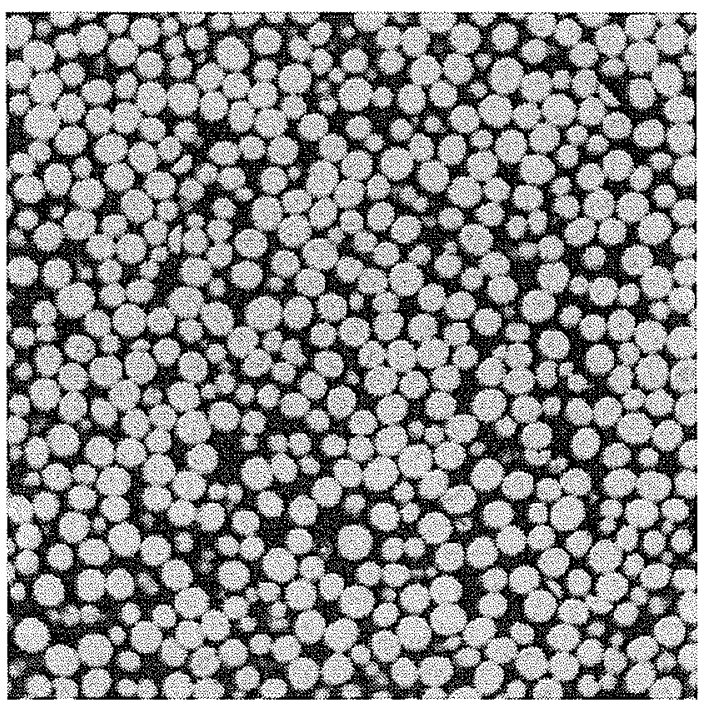

b)

4.16. X-ray $\mathrm{CT}$ images of bulk peas a) horizontal image:

b) vertical image. 
The blob coloured horizontal and vertical pea bulk images are shown in Figure 4.17. The blob coloured image shows that the number of airflow paths are more common in the vertical image (horizontal airspace) than in the horizontal image (vertical airspace). This is opposite to the results for the barley, wheat and flax seed images.

The distribution of horizontal and vertical airspace in a pea bulk is shown in Figure 4.18. The mean value of the horizontal airspace in a pea bulk is 157000 pixels which is similar to the mean airspace area of 159000 pixels for the vertical airspace. The airspace area varies between 150000 pixels to 165000 pixels in the horizontal airspace while in the vertical airspace, the airspace area varies between 155000 pixels to 165000 pixels.

The distribution of airspace area in a pea bulk is almost the same in both the horizontal and vertical airspaces. This can be seen from the distribution pattern in Figure 4.18. It is also clear from Figure 4.18 (b) that there is no compaction of grains from slice 1 to 200 . This means that all the pea grains were almost equally spaced among themselves during packing. Independent group $\mathrm{t}$ - tests between means of airflow path areas between horizontal and vertical airspace of bulk peas showed that they were statistically different at 0.05 level of significance. 


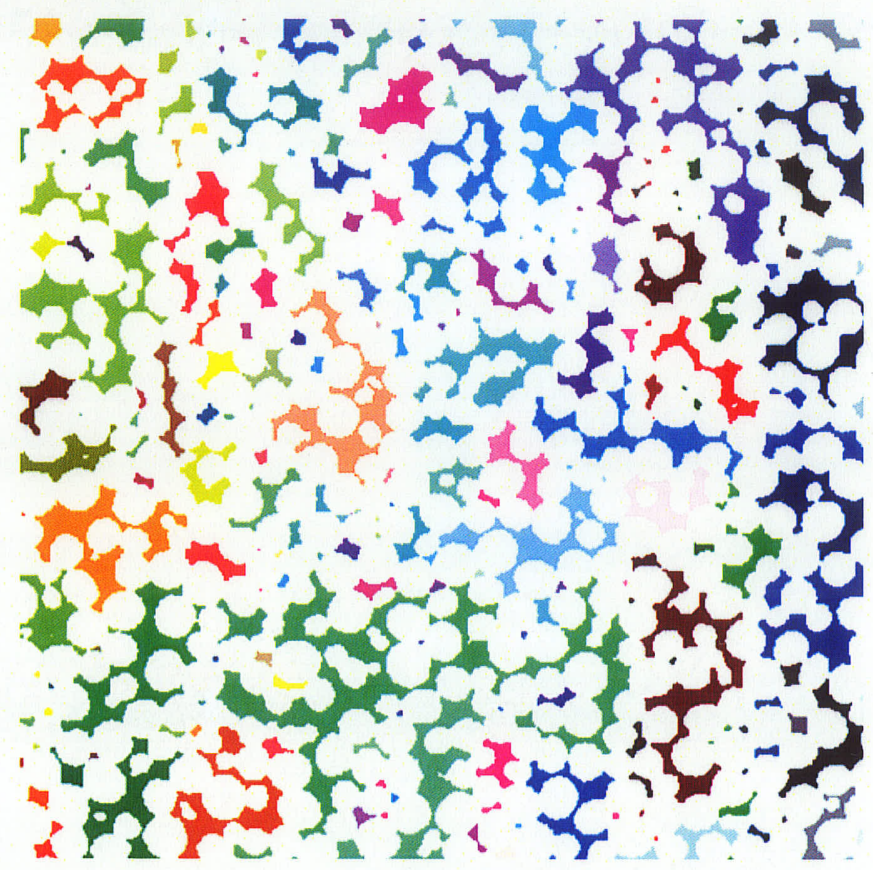

a)

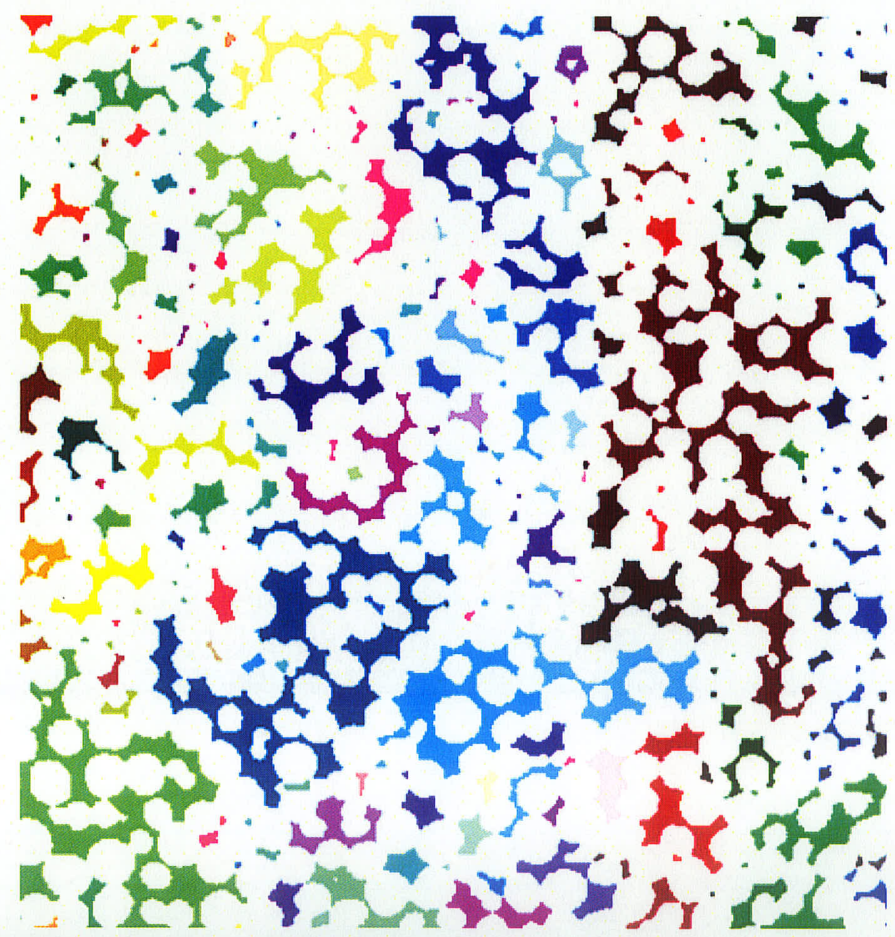

b)

Fig 4.17. Blob coloured X-ray CT images of a pea bulk:

a) horizontal image b) vertical image. 


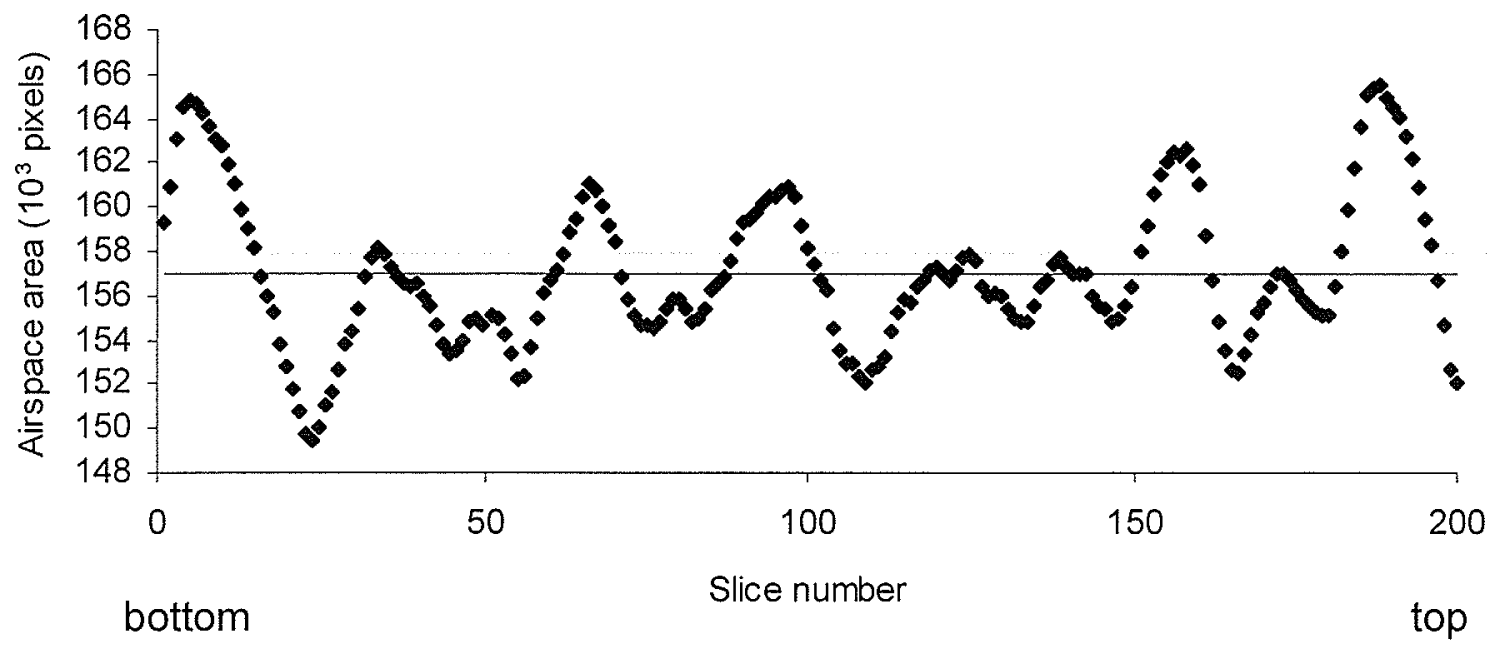

a)

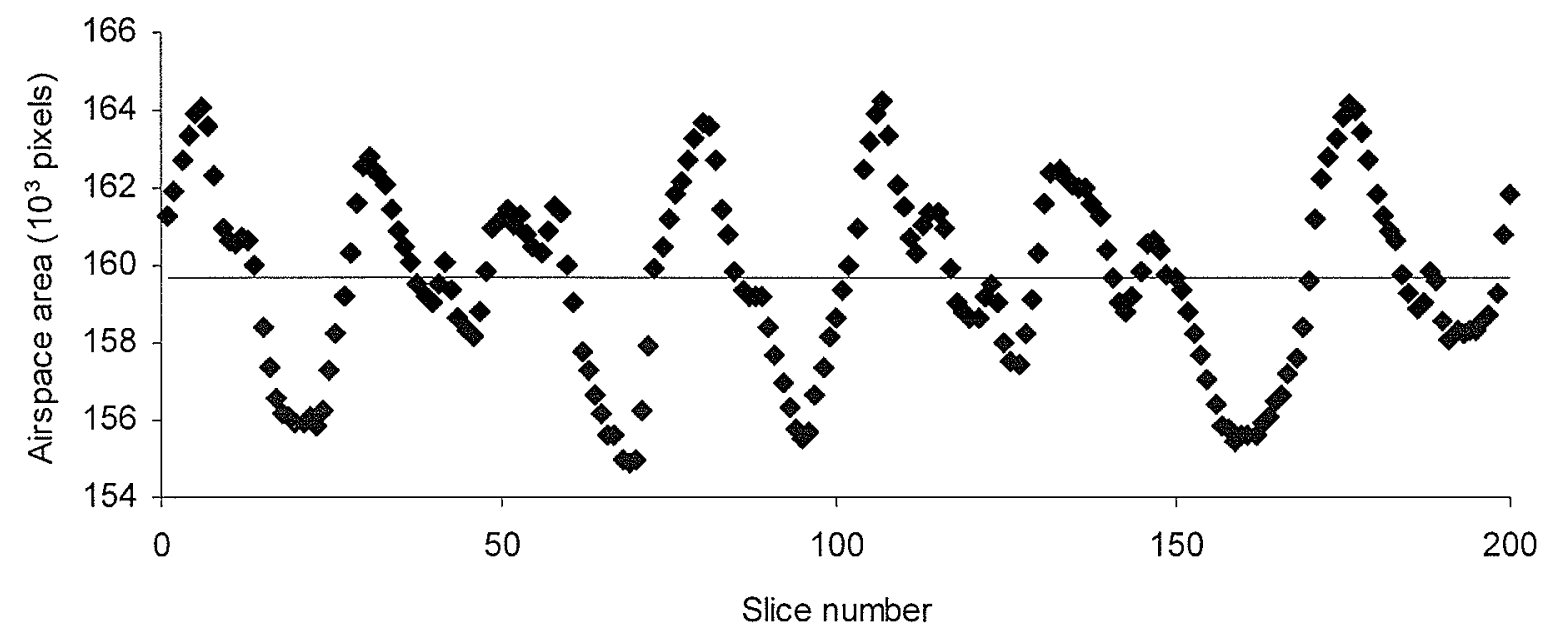

bottom

b) top

Fig 4.18. Distribution of a) horizontal airspace b) vertical airspace in bulk pea images. 0 slice corresponds to bottom of the container.

The number of airpaths in horizontal and vertical airspaces of pea bulk images is shown in Figure 4.19. The number of airpaths is more in the horizontal airspace than in the vertical airspace of bulk peas. The mean value of the 
number of pixels in the airspace in the horizontal airspace was 72 while the mean value in the vertical airspace was 59. However, the difference between the number of airpaths along the horizontal and vertical airspace of bulk peas is small. The number of airpaths is greater while the airspace area is less in the horizontal airspace of the pea bulk. In the vertical airspace of peas, the number of airpaths were less while the airspace area was greater. This is due to the fact that there are fewer large airpaths along the vertical airspace of a pea bulk.

The length of airpaths in horizontal and vertical airspace of bulk peas was also measured (Figure 4.20). The difference in the number of airpaths of the same length along the horizontal airspace and vertical airspace in a pea bulk is small. This can be seen from the pattern of distribution of length of airpaths in the horizontal and the vertical airspace (Figure 4.20). Blob coloured images (Figure 4.17) also show that the distribution of the airpaths along horizontal and vertical airspaces are almost the same. For example, in the horizontal airspace of bulk peas (Figure 4.20, (a)), 10 pixel width of airflow path length were four in number whereas in the vertical airspace of bulk peas (Figure 4.20, (b)), the number was three. Because there are almost the same number of airflow paths in the horizontal airspace and the vertical airspace, air can pass through the grain bulk with the same resistance in both directions of the grain bulk. This is the reason for the same airflow resistance in the horizontal direction as in the vertical direction for the airflow in the pea bulk. There was almost the same number of airpaths, distributed uniformly in both the horizontal and vertical airspace of pea bulk. 
Shorter airpaths are more in wheat bulk than in the pea bulk (Figure 4.5 and Figure 4.20). As the length of airpath increases, there is a decrease in the number of airpaths in wheat bulk. Pea bulk consists of more larger airpaths than in the wheat bulk (Figure 4.20).

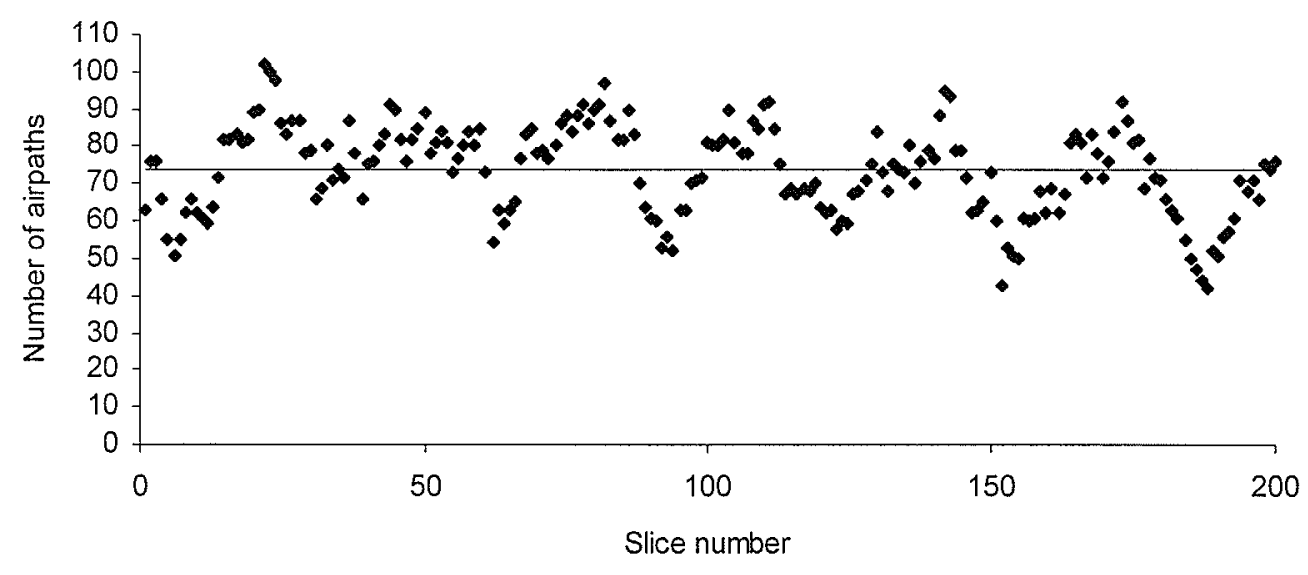

a)

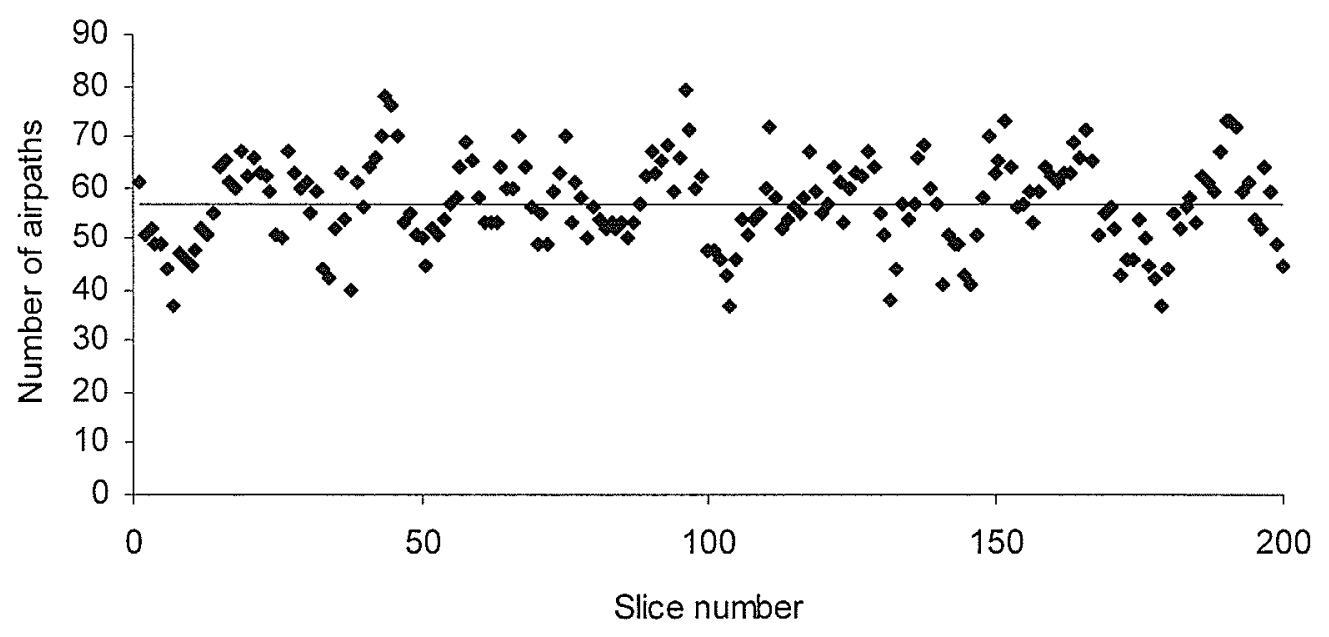

b)

Fig 4.19. Number of airpaths in a) horizontal airspace b) vertical airspace of bulk peas. 


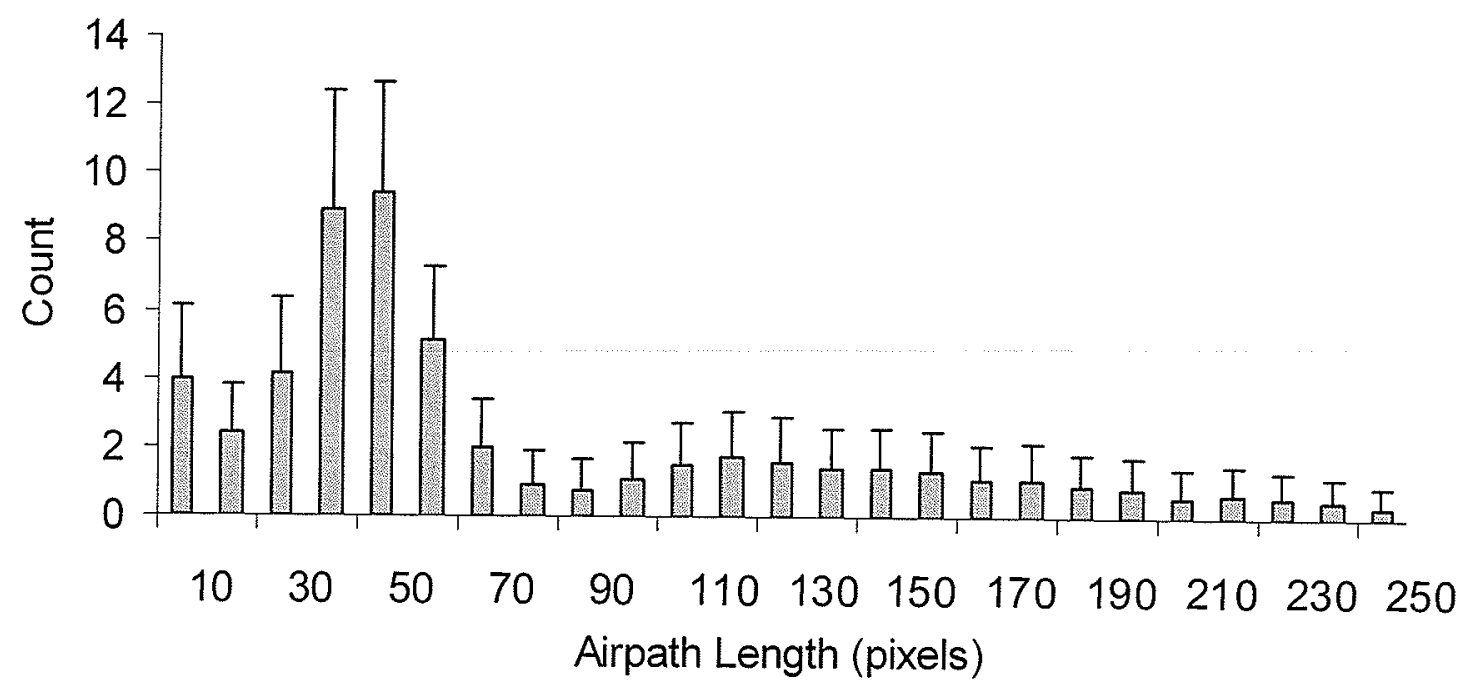

a)

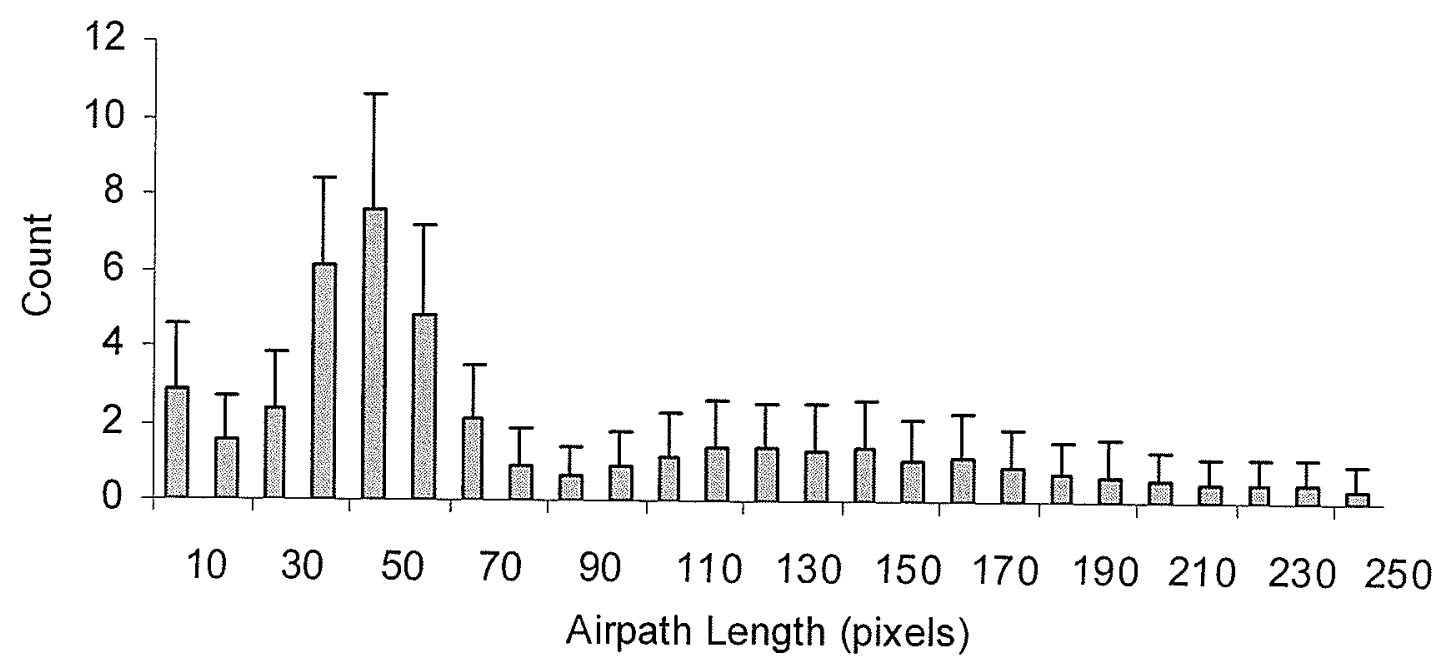

b)

Fig 4.20. Frequency distribution of the length of airpaths in a) horizontal airspace b) vertical airspace of bulk peas images. 


\subsubsection{Mustard images}

The cropped horizontal and vertical images of mustard grain bulk are shown in Figure 4.21.

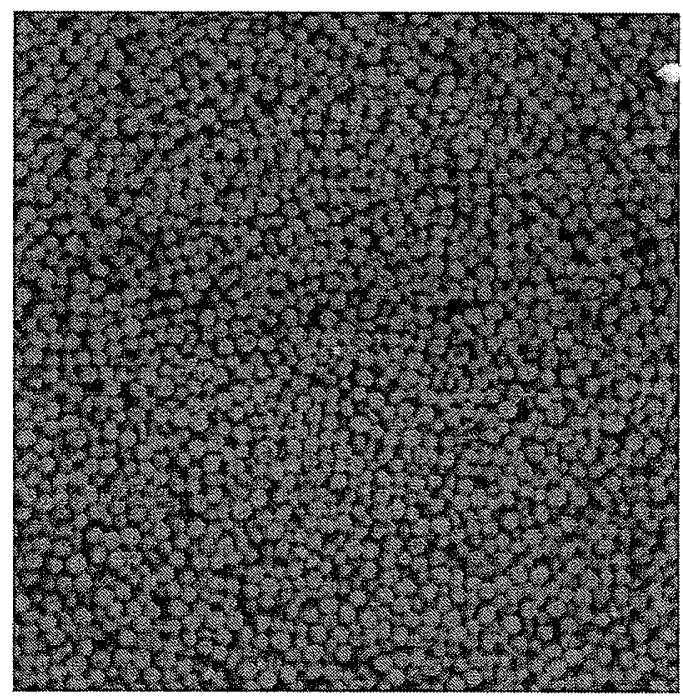

a)

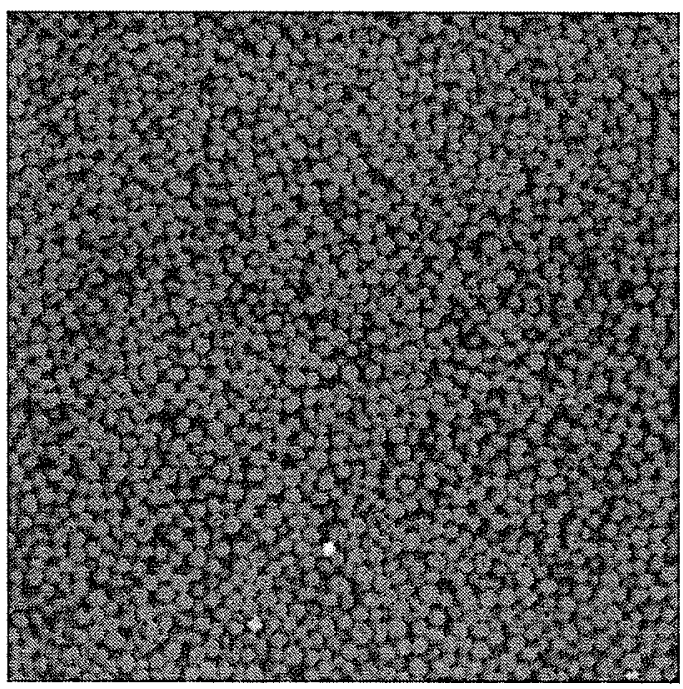

b)

4.21. X-ray CT images of mustard bulk: a) horizontal image b) vertical image. 
The distribution of the airspace area in a mustard bulk is almost the same in both the horizontal and vertical airspaces. This can be seen from the blob coloured bulk mustard image (Figure 4.22). The distribution of horizontal and vertical airspace in a mustard bulk is shown in Figure 4.23.

The mean value of the horizontal airspace and vertical airspace in a mustard bulk is 133000 pixels. But the airspace area varied between 1280000 pixels to 138000 pixels in the horizontal airspace while in the vertical airspace, the airspace area varied between 127000 pixels to 138000 pixels. Independent group $\mathrm{t}$ - test between means of airpath area between horizontal and vertical airspaces of mustard bulk showed that they were statistically different at 0.05 level of significance.

It is also clear from the Figure 4.23 (b) that there is no compaction of grains from slice 1 to 200 . This means that all the mustard grains were almost equally spaced among themselves in packing and the airspace area was uniformly distributed from the bottom to the top of the grain bulk. This behaviour is similar to peas and leads to the conclusion that spherical seeds are packed uniformly in a bulk whereas oblong seeds such as wheat, flaxseed and barley are compacted increasingly from the bottom. 


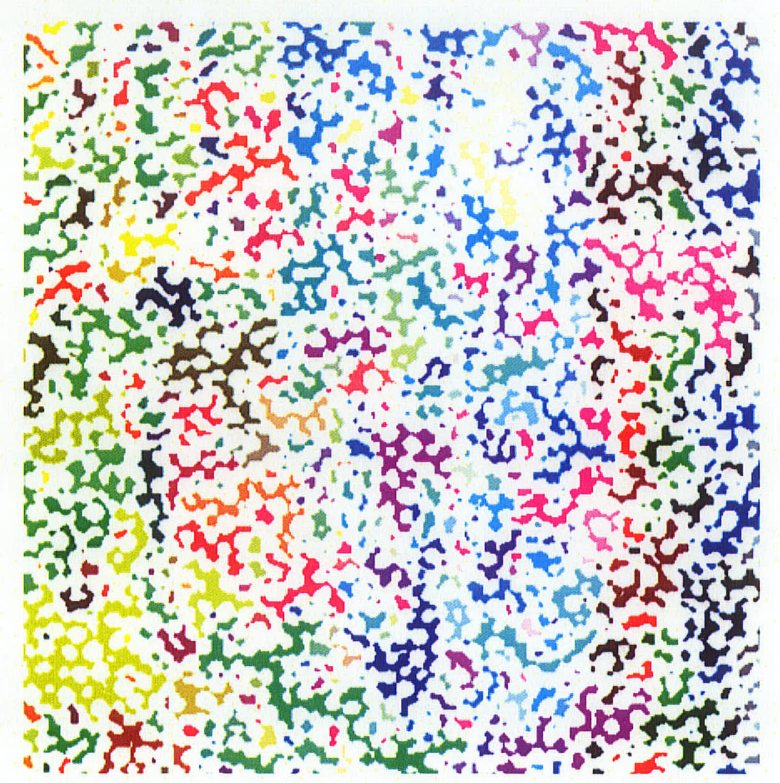

a)

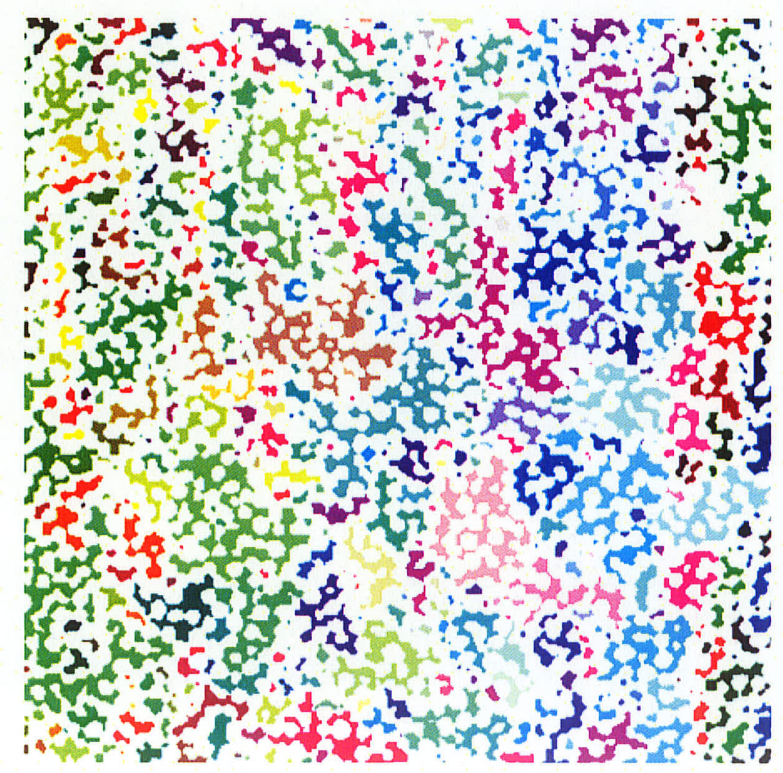

b)

Fig 4.22. Blob coloured X-ray CT images of a mustard bullk:

a) horizontal image b) vertical image. 


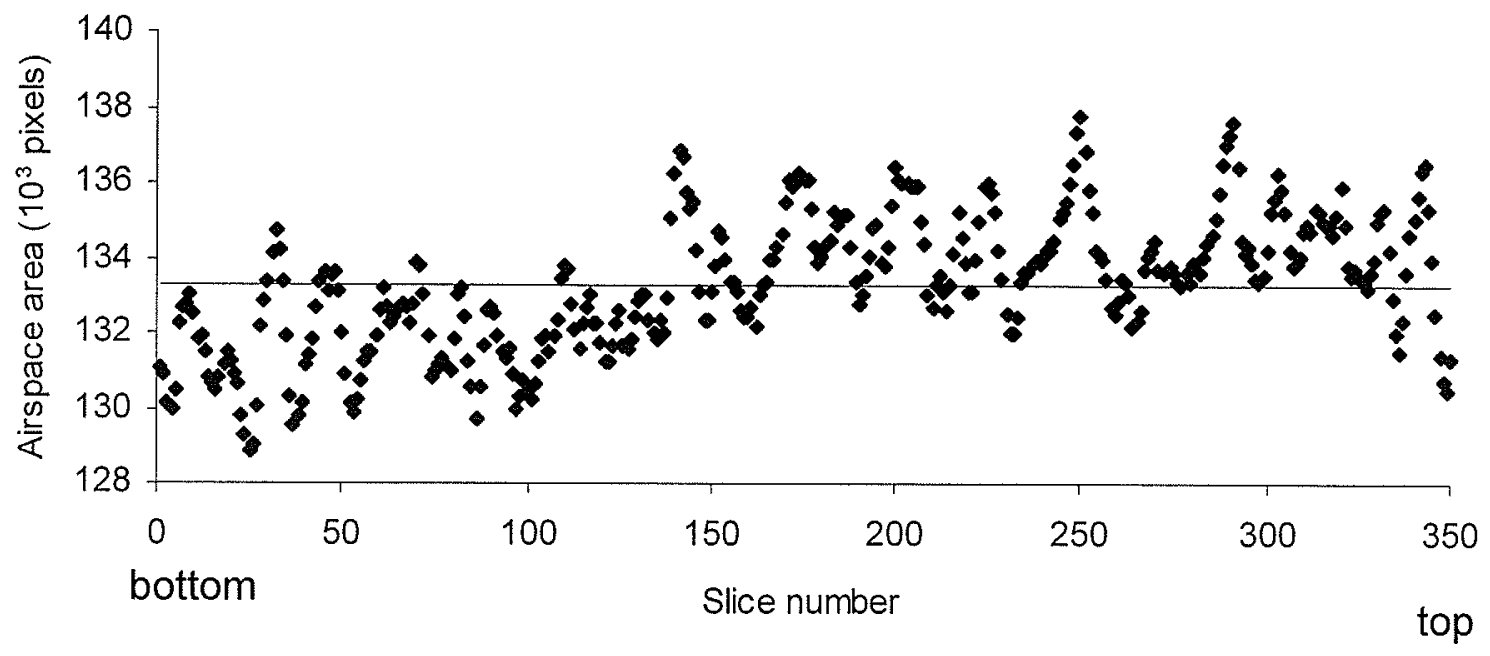

a)

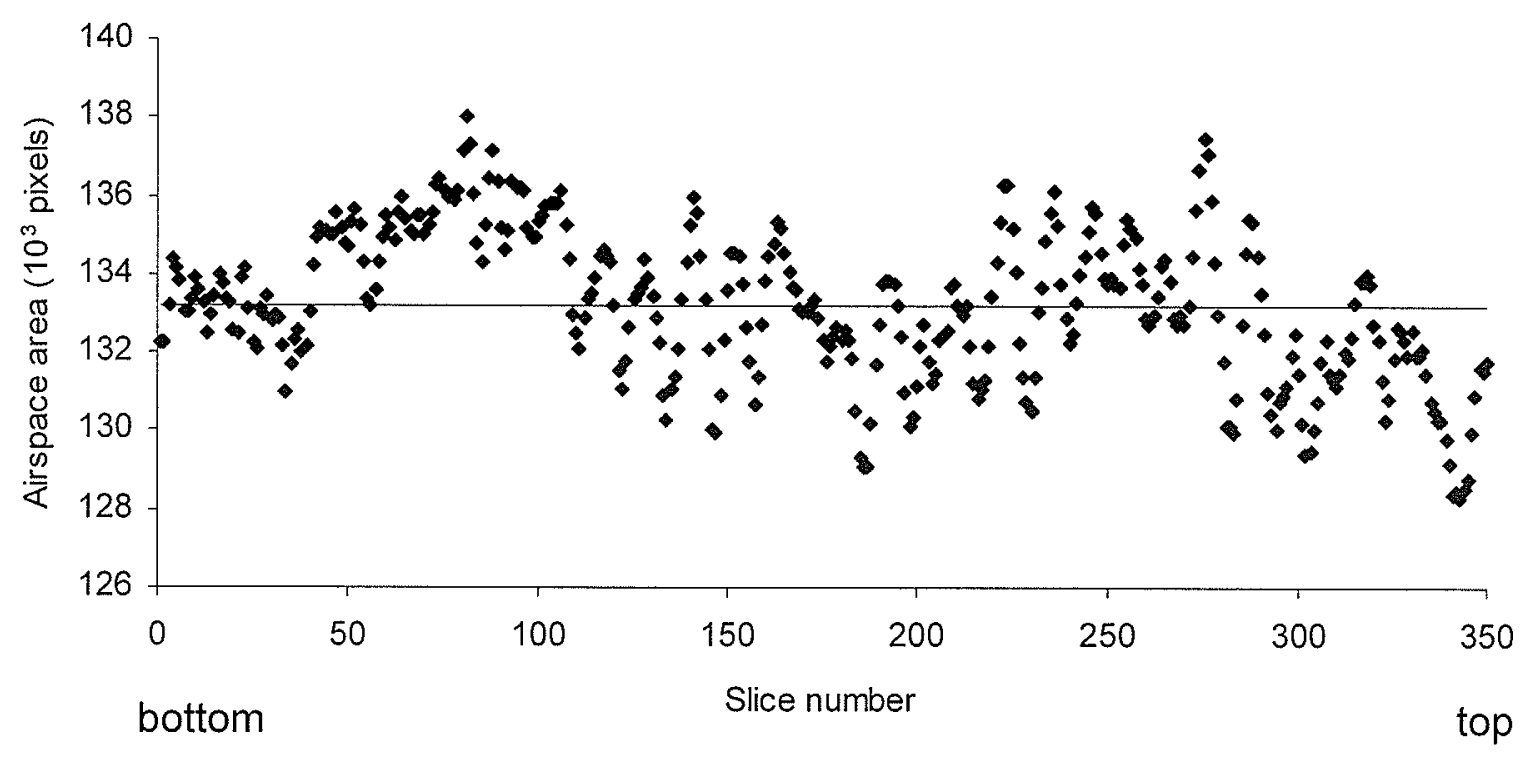

b)

Fig 4.23. Distribution of a) horizontal airspace b) vertical airspace in mustard images. 0 slice corresponds to bottom of the container. 
The number of airpaths in horizontal and vertical airspaces of a mustard bulk is shown in Figure 4.24. The number of airpaths was more in the horizontal airspace than in the vertical airspace of a mustard bulk. The mean value of the number of airpaths in the horizontal airspace was 471 while in the vertical airspace it was 400 . The difference between the number of airpaths along the horizontal and the vertical airspace of a mustard bulk was small.

The length of airpaths in horizontal and vertical airspaces of mustard was also measured (Figure 4.25). The difference in the number of airpaths of same length along the horizontal airspace and the vertical airspace in a mustard bulk was small. There was similar pattern of distribution of lengths of airpaths along the horizontal and the vertical airspace of a mustard bulk (Figure 4.25). Blob coloured images (Figure 4.25) also showed that the distribution of the airpaths along the horizontal and the vertical airspaces was almost the same. For example, in the horizontal airspace of bulk mustard (Figure 4.25, (a)), a 10 pixel width of airflow path length were 140 in number whereas in the vertical airspace of bulk peas (Figure 4.25b), the number was 117. The number of airflow paths in the horizontal airspace is more than in the vertical airspace. So, air will pass the through horizontal airspace more easily than in the vertical airspace. This is the reason for the higher airflow resistance in the vertical direction compared to the horizontal direction of the airflow in a mustard bulk. 


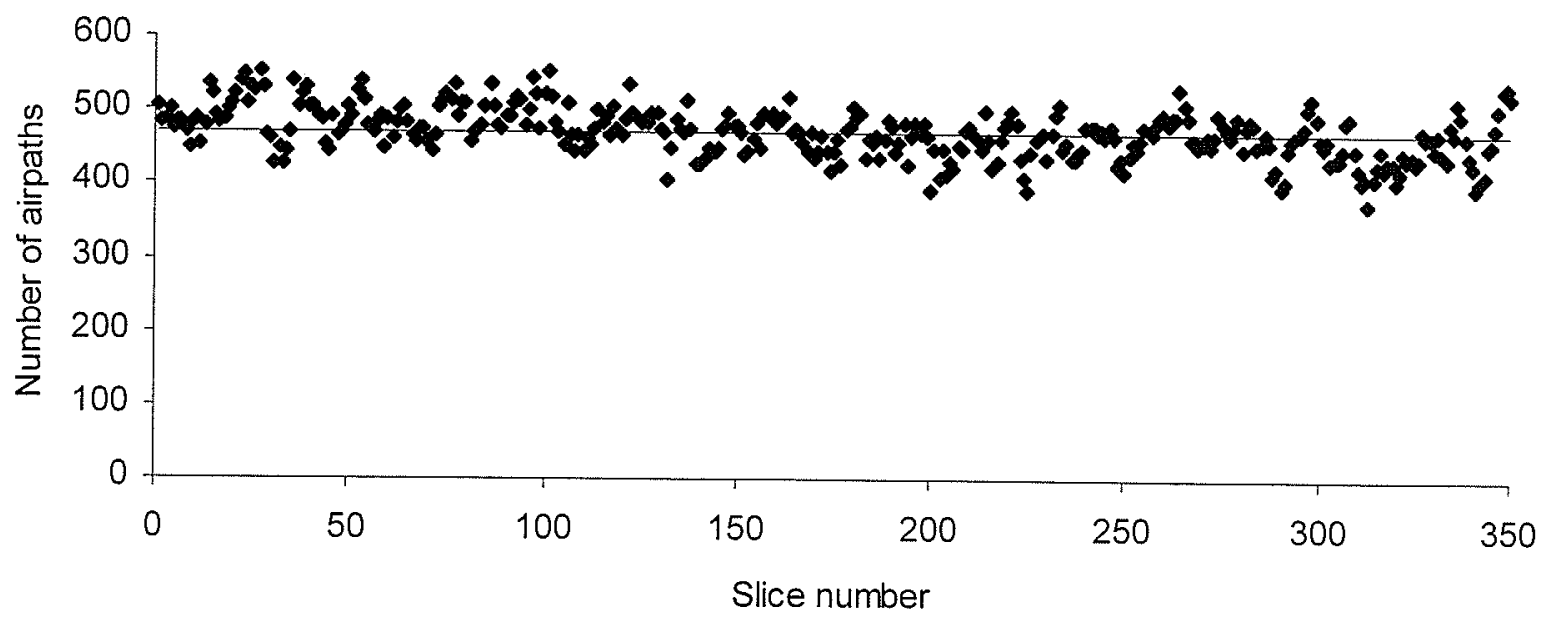

a)

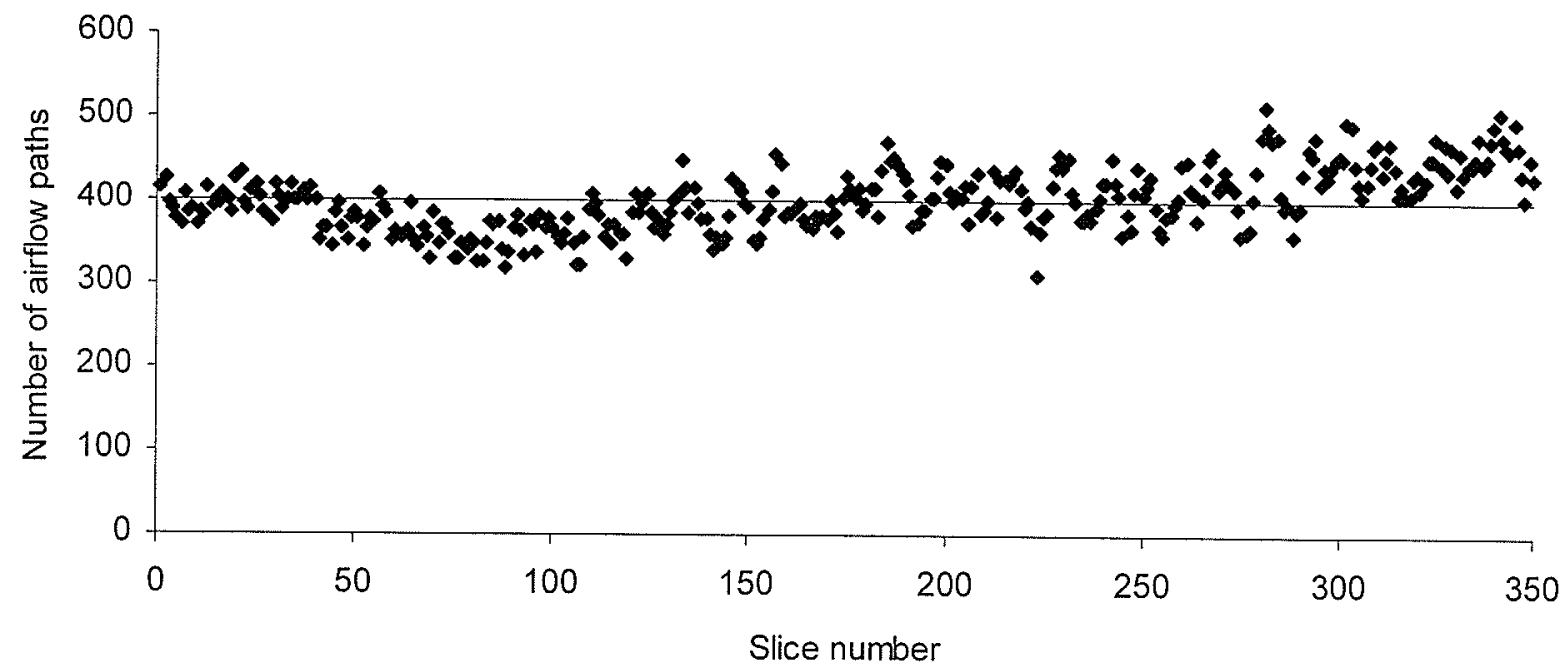

b)

Fig 4.24. Number of airpaths in a) horizontal airspace b) vertical airspace of a mustard bulk image. 


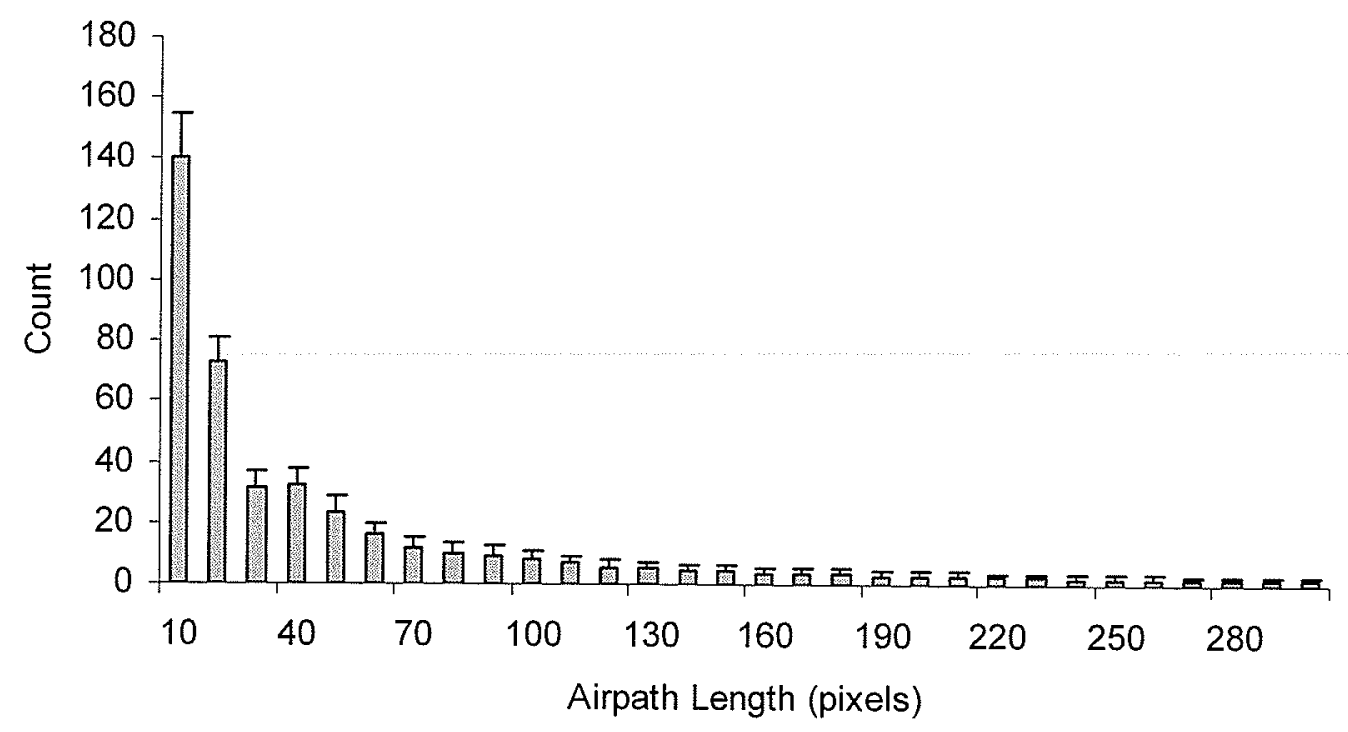

a)

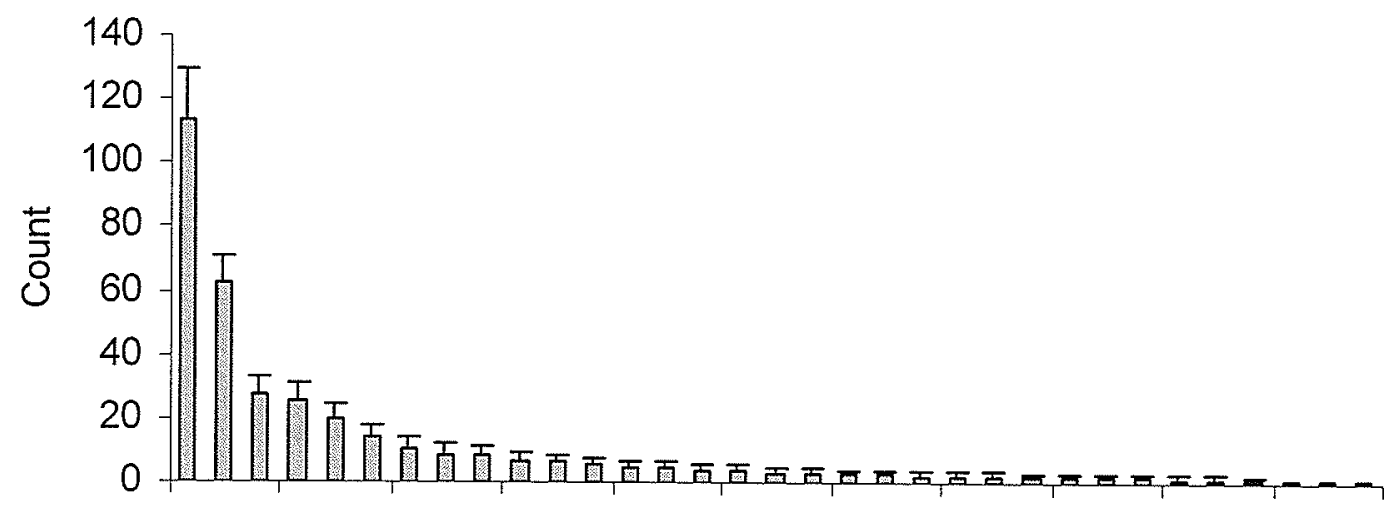

$\begin{array}{llllllllll}10 & 40 & 70 & 100 & 130 & 160 & 190 & 220 & 250 & 280\end{array}$

Airpath Length (pixels)

b)

Fig 4.25. Frequency distribution of the length of airpaths in a) horizontal airspace b) vertical airspace of a mustard bulk image.

\subsection{Comparison of airflow resistance of different grains.}

The reported airflow resistance between vertical and horizontal direction of different grain bulks were compared with the image features such as the 
airspace area and the number of airpaths (Table 4.2). The ratio of vertical airspace area to the horizontal airspace area was similar in all grains. This ratio did not explain the difference in reported airflow resistance in grain bulks. But the ratio of number of airpaths from the vertical to the horizontal direction of the grain bulk is similar to that of the reported airflow resistance.

This clearly explains that the number of airpaths is the main cause for the the airflow resistance difference along horizontal and vertical directions in grain bulks. The airpaths are distributed non uniformly in vertical airspace (compaction) than in the horizontal airspace for the oblong kernels. But for the spherical kernels, the airpaths are distributed uniformly in both the horizontal and vertical airspace. Non-uniform distribution of airpaths inside the grain bulks is also the reason for the airflow resistance difference along horizontal and vertical directions of grain bulks.

The numbers of airpaths along the horizontal and vertical airspace for the grains were statistically analysed. The t values and the difference between the mean along the horizontal and vertical direction are tabulated in Table 4.3. In wheat, barley and flax seed there is a significant difference between the numbers of airpaths along the horizontal and vertical airspace $(P<0.0001)$. But in mustard and peas, the difference between the number of airpaths along horizontal and vertical airspace of grains is less $(P<0.0001)$. 
Table 4.2. Comparison of airflow resistance of reported data with the image features.

\begin{tabular}{|c|c|c|c|c|}
\hline $\begin{array}{l}\text { Grain } \\
\text { Type }\end{array}$ & $\begin{array}{l}\text { Airflow } \\
\text { resistance } \\
(\mathrm{V} / \mathrm{H})\end{array}$ & Reference & $\begin{array}{l}\text { Area of } \\
\text { airspace } \\
(\mathrm{V} / \mathrm{H})\end{array}$ & $\begin{array}{l}\text { Number of } \\
\text { airpaths } \\
(\mathrm{V} / \mathrm{H})\end{array}$ \\
\hline Barley & 0.47 & Kumar and Muir (1986) & 1.03 & 0.40 \\
\hline Wheat & 0.63 & Kumar and Muir (1986) & 1.04 & 0.52 \\
\hline Peas & 1 & $\begin{array}{l}\text { Alagusundaram et al. } \\
\text { (1986) }\end{array}$ & 1.09 & 0.76 \\
\hline Flax seed & 0.38 & Irvine (1989) & 1.02 & 0.34 \\
\hline Mustard & 0.72 & Velasco (1998) & 1.00 & 0.85 \\
\hline
\end{tabular}

Table 4.3. Statistical analysis on the number of airpaths along the horizontal and vertical airspace of grains.

\begin{tabular}{|c|c|c|c|c|}
\hline \multirow[t]{2}{*}{ Grain } & \multicolumn{2}{|c|}{ Mean number of airpaths } & \multirow{2}{*}{$\begin{array}{c}\text { Difference between } \\
\text { the horizontal and } \\
\text { vertical mean } \\
\text { airspace }\end{array}$} & \multirow[t]{2}{*}{$\mathrm{t}$-value } \\
\hline & $\begin{array}{l}\text { Vertical } \\
\text { airspace }\end{array}$ & $\begin{array}{c}\text { Horizontal } \\
\text { airspace }\end{array}$ & & \\
\hline Wheat & $249 \pm 22$ & $477 \pm 30.9$ & 228.22 & $84.96(P<0.0001)$ \\
\hline Barley & $205 \pm 22.4$ & $504 \pm 30.1$ & 299.32 & $112.53(P<0.0001)$ \\
\hline Flax seed & $193 \pm 33.1$ & $568 \pm 35.6$ & 375.52 & $144.52(P<0.0001)$ \\
\hline Peas & $56 \pm 8.2$ & $75 \pm 10.9$ & 19.22 & $171.7(P<0.0001)$ \\
\hline Mustard & $401 \pm 38$ & $471 \pm 31.3$ & 70.4 & $26.4(P<0.0001)$ \\
\hline
\end{tabular}




\section{CONCLUSIONS}

1. For wheat, barley and flax seed

i) airspace area along the horizontal direction of bulk grain was statistically smaller than that of the vertical direction.

ii) number of airpaths along the horizontal direction of bulk grain was almost double that in the vertical direction.

iii) individual airpaths with shorter length were more common in horizontal direction in bulk grain than in the vertical direction.

2. For peas and mustard

i) airspace area along the horizontal direction of bulk grain was similar to that in the vertical direction.

ii) number of airpaths along the horizontal direction of bulk grain was equal to that of the vertical direction.

iii) individual airpaths with almost the same length and were present in both the horizontal and vertical directions in the bulk grain.

3. There was significant compaction of grains at the bottom than at the top of the wheat, barley and flax seed bulks. 
4. Airspace area was uniformly distributed along the horizontal and the vertical directions for pea and mustard bulk grain.

5. There were more shorter airpaths in horizontal direction than in the vertical direction for wheat, barley and flax seed bulks.

6. There were fewer airpaths with larger area along the vertical direction resulting in more airspace area along the vertical direction than in the horizontal direction in the grain bulks. 


\section{IMPACT OF RESEARCH}

This study explains the reason for the difference in airflow resistance along the horizontal and vertical direction of grain bulks. This study shows that the airflow resistance along the horizontal direction is either lower (for oblong kernels) or almost equal (for nearly spherical kernels) to the vertical direction.

This research gives a clear understanding on the packing of grains in a grain bulk. There is compaction of grain kernels from the bottom of the bulk to the top for elongated kernels. This compaction of grains at the bottom offers more resistance to the airflow in the vertical direction in a grain bulk.

The understanding of the airpath configuration inside the grain bulks can be used for predicting pressure and airflow patterns in the stored grain mass. This research also helps to understand the relation between pressure drop and superficial velocity of air for an anisotropic medium. Aeration systems designed to force air horizontally rather than vertically will save energy during aeration and drying. 


\section{REFERENCES}

Abbott, J.A.1999. Quality measurement of fruits and vegetables. Post Harvest Biology and Technology 15:207-225.

Adderley, W.P., I.A. Simpson and G.W. Macheod. 2001. Testing high resolution $X$-ray computed tomography for the micromorphological analyses of archaeological soils and sediments. Archaeological Prospection 8:107112.

Agriculture and Agri-Food Canada. 2004. Canada:Grains and Oilseeds Outlook. 2004.http://www.agr.gc.ca/madam/e/sd1e/2004e/jan2004_e.html (2004/01/20).

Alagusundaram, K. and D.S. Jayas.1990. Airflow resistance of grains and oilseeds. Post Harvest News and Information 1(4):279-283.

Alagusundaram, K., D.S.Jayas, F.Chotard and N.D.G.White.1992. Airflow pressure drop relationships of some specialty seeds. Sciences des Aliments 12:101-116.

Anderson, S.H., R.L.Peyton and C.J. Gantzer. 1990. Evaluation of constructed and natural soil macropores using $X$-ray computed tomography. Geoderma 46(1-3):13-29.

Anderson, S.H., C.J., Gantzer, J.M., Boone and R.J Tully. 1988. Rapid nondestructive bulk density and soil water content determination by computed tomography. Soil Science Society of American Journal 52:35-40.

Asseng, S., L.A.G., Aylmore, J.S., MacFall, J.W., Hopmans and P.J. Gregory. 1999. Computer assisted tomography and magnetic resonance imaging. In Root Methods A Handbook, ed. A.L. Smit, 343-363. Berlin: SpringerVerlag.

Aylmore, L.A.G., 1993. Use of computer- assisted tomography in studying the water movement around roots. Advanced Agronomy 49:1-54.

Barcelon, E.G., S. Tojo and K. Watanabe. 1999a. Relating X-ray absorption and some quality characteristics of mango fruit (Mangifera indica L.). Journal of Agricultural Food Chemistry 47:3822-3825.

Barcelon, E.G., S. Tojo and K. Watanabe. 1999b. X-ray computed tomography for internal quality evaluation of peaches. Journal of Agricultural Engineerig Research 73:323-330. 
Benson-Cooper, D.M., R.L., Knowles, F.J., Thompson and D.J. Cown. 1982. Computed tomographic Scanning for the Detection of Defects within logs. Bull.No.8 .P.9. Rotorua, NZ. Forest Research Institute, Newzealand Forest Service.

Brecht, J.K., R.L., Shewft, J.C., Garner and E.W. Tollner. 1991. Using X-ray computed tomography to non-destructively determine maturity of green tomatoes. Horticultural Science 26:45-47.

Brink, A.D. 1992. Thresholding of digital images using 2-D entropies. Pattern Recognition 25(8):803-808.

Brooker, D.B., F.W. Bakker-Arkema and C.W.Hall. 1974. Drying Cereal Grains. AVI Pub. Co., Inc., Westport, CT.

Brooker, M.J. 1986. Computed Tomography for Radiographers, Lancaster, UK: MTP Press Limited.

Bull, C.R.,1993. A review of sensitive techniques which could be used to generate images of agricultural and food materials. Computers and Electronics in Agriculture 8(1):1 -29.

CGC. 1998. Canadian Grains Industry Statistical Handbook 98. Winnipeg, MB: Canada Grains Council. 259 p. 6

Chang, C.S., H.H. Converse, and C.R. Martin. 1983. Bulk properties of grain as affected by self propelled rotational type grain spreaders. Transactions of the ASAE 26:1543-1550.

Chuma, Y., S. Uchida, and K.H.H. Shemsanga. 1983. Airflow resistance through a packed bed of selected grains. Journal of the faculty of the Agriculture, Kyushu University 27(3.4):115-125.

Crestana, S, R. Cesareo and S. Mascarenhas.1986. Using a computed tomography miniscanner in soil science. Soil Science 142:56-61.

Cruvinel, P.E., R. Cesareo, S. Crestana and S. Mascarenhas. 1990. X- and $\gamma$-ray computerized minitomograph scanner for soil science. IEEE Transactions on Instrumentation and Measurement 39:745-750. 
Cruvinel, P.E., J.M., Naime, M. Borges, A. Macedo and A.Zhang. 2003. Detection of beetle damage in forests by $\mathrm{X}$-ray $\mathrm{CT}$ image processing. $R$. Árvore, Viçosa-MG 27(5):747-752

Dull, G. 1986. Non destructive evaluation of quality of stored fruits and vegetables. Food Technology 40(5):106-110.

Farber, L., G. Tardos and J.N. Michaels. 2003. Use of X-ray tomography to study the porosity and morphology of granules. Powder Technology 132:57-63.

Food and Drugs Act. 2004. Food and Drugs Act and the Food and Drug Regulations, Canada. Available at: http://www.hc-sc.gc.ca/foodaliment/friia-raaii/food_druBgs-aliments_drogues/act-loi/e_index.html (2004/09/11).

Friesen, O.H. and D.N.Huminicki. 1987. Grain Aeration and Unheated Airdrying. Winnipeg, MB: Manitoba Agriculture.

Foster, G.H., and J.Tuite. 1992. Aeration and stored grain management. In Storage of Cereal Grains and Their Products, 4th ed. Ed. D.B.Sauer, 219247. St.paul, MN: American Association of Cereal Chemists.

Fromm, J. H., I. Sauttier, D. Matthies, J. Kremer, P. Schumacher and C. Ganter. 2001. Xylem water content and wood density in spruce and oak trees detected by high-resolution computed tomography. Plant Physics 127:416-425.

Froystein, T., O. Sorheim, S.A., Berg and K. Dalen. 1989. Salt distribution in cured hams, studied by computer x-ray tomography. Fleischwirtschaft 69(2):220-222.

Fuji, M. and K. Uyama.1994. X-ray computer tomography for industrial use (In Japanese). Hihakaikensa 43(5):275-281.

Gonzalez, R. and O. Wintz. 1991. Digital Image Processing. 3rd ed., AddisonWesley Publishing Co, Massachusetts.

Gonzalez, R.C. and R.E.Woods. 2003. Digital Image Processing. AddisonWesley Publishing Co, Massachusetts.

Greenkorn, R.A. 1983. Flow Phenemona in Porous Media. New York, NY: Marcel Dekker Inc. 
Halloran, N., M.U. Kasim and R. Cagiran. 1999. Determination of mechanical injury and effects of bruising on the postharvest quality of cantaloupes. Proceeding of the Ist international Symposium on Cucurbits. Eds. K. Abak and B.Buyukalacha, Acta Horticultura. 492.

Hodges, D.G., W.C., Anderson and C.W. McMillin. 1990. The economic potential of CT scanners for hardwood sawmills. Forest Products Journal 40(3):65-69.

Hopmans J.W, T. Vogel, and P.D. Koblik. 1992. X-ray tomography of soil water distribution in one-step outflow experiments. Soil Science Society of America 56:355-363.

Hopmans, J.W, M. Cislerova and T. Vogel. 1994. X-ray tomography of soil properties. In Tomography of soil-water-Root Processes, ed. S.H.Anderson and J.W.Hopmans. SSSA special Pub. No.36. Madison, WI: American Society of Agronomy -Soil Science Society of America.

Hounsfield, G.N. 1972. A method of and Apparatus for Examination of a body by radiation such as X- or Gamma-Radiation. British Patent No.1283915. British Patent Office, London.

Irvine D.A., 1989. Resistance to airflow through samples of seed. Unpublished B.Sc. thesis, Department of Agricultural Engineering. University of Manitoba, Winniepg, MB.

Jayas, D.S. and S. Sokhansanj. 1986. Effect of foreign material on resistance to airflow of canola. ASAE Paper No. 86-6572. St. Joseph, MI: ASAE.

Jayas, D.S., S.Sokhansanj, E.B.Moysey and E.M. Barber. 1987. The effect of airflow direction on the resistance of canola (rapeseed) to airflow. Canadian Agricultural Engineering 29:189-192.

Jayas, D.S. 1988. Resistance of airflow through granular products - a review. ASAE Paper No. 88 -6534. St.Jospeh, MI: ASAE.

Jayas, D.S., S. Sokhansanj, E.B. Moysey, E.M. Barber. 1990. Predicting pressure patterns in canola bins. Canadian Agricultural Engineering $32: 249-254$.

Jayas, D.S. and W.E.Muir. 1991. Airflow-pressure drop data for modeling fluid flow in anisotropic bulks. Transactions of the ASAE 34(1):251-254. 
Jenneson, P.M., W.B., Gilboya, E.J., Mortona and P.J. Gregory.2003. An X-ray micro-tomography system optimised for the low-dose study of living organisms. Applied Radiation and Isotopes 58:177-181.

Kay, R.L., C.J.Bern and C.R.Hurburgh, Jr.1989. Horiozontal and vertical airflow resistance of shelled corn at various bulk densities. Transactions of the ASAE 32(2):733-736.

Ketcham, R.A and W.D. Carlson. 2001. Acquisition, optimization and interpretation of X-ray computed tomographic images: applications to the geosciences. Computational Geosciences 27:381-400.

Kolstad, K., N.B., Jopson and O. Vangen. 1996. Breed and sex differences in fat distribution and mobilisation in growing pigs fed at maintenance. Livestock Production Science 47:33-41.

Kolstad, K. 2001. Fat deposition and distribution measured by computer tomography in three genetic groups of pigs. Livestock Production Science 67:281-292.

Kumar, A. and W.E. Muir.1986. Airflow resistance of wheat and barley affected by airflow direction, filling method and dockage. Transactions of the ASAE 29:1423-1426.

Lai, F.S. 1980. Three-dimensional flow of air through non uniform grain beds. ASAE Paper No. 76-3529. St.Jospeh, MI:ASAE.

Lammertyn,J., T. Dressalaers, P. Van Hecke, P. Jancsok, M. Wevers and B.M. Nicolai. 2003a. MRI and X-ray CT study of spatial distribution of core breakdown in 'conference' pears. Magnetic Resonance Imaging 21(7):805-15.

Lammertyn,J., T. Dressalaers, P. Van Hecke, P. Jancsok, M. Wevers and B.M. Nicolai.2003b. Analysis of the time course of core breakdown in 'conference' pears by means of MRI and X-ray CT. Postharvest Biotechnology 29:19-28.

Lamond, W.J. and E.A. Smith. 1982. Modeling low temperature drying of grain in an isotropic beds. Third International Drying Symposium. Birmingham.UK.

Lim, K.S., and M. Barigou. 2004. X-ray Computed tomography of cellular food products. Food Research International 37:1001-1012. 
Lindgren, L.O. 1991. Medical CAT-scanning: x-ray absorption coefficients, CTnumbers and their relation to wood density. Wood Science Technology $25: 341-349$.

Matthies, H.J. and H. Peterson. 1974. New data for calculating the resistance to airflow of stored granular material. Transactions of the ASAE 17:11141149.

Morita, K., S. Tanaka, Y. Ogawa, M. Setoguchi and C.N. Thao. 1996. Application of Xray CT for detection of physical foreign materials in food. ASAE Paper No. 96-6059. St. Joseph, MI: ASAE.

Oberle M., F.J. Schwarz and M. Kirchgessner. 1997. Growth and carcass quality of carp (Cyprinus carpio L.) fed different cereals, lupin seed or zooplankton. Archives of Animal Nutrition 50:75-86.

Oceana, L. G. 1991. Computer integrated manufacturing issues related to the hardwood log sawmill. Journal of Forest Engineering 3(1):39-45.

Ogawa,Y., K. Morita, S. Tanaka, M. Setoguchi and C.N. Thai. 1998. Application of X-ray CT for Detection of Physical Foreign Materials in Foods. ASAE. Paper No. 98-6058. St. Joseph, Ml: ASAE

Onoe, M., J. W. Tsao, H. Yamada, H. Nakamura, J. Kogura, H. Kawamura and M. Yoshimatsu. 1984. Computed tomography for measuring the annual rings of a live tree. Nuclear Instruments and Methods in Physics Research 221(1):213-220.

Petrovic A.M., J.E., Siebert and P.E. Rieke. 1982. Soil bulk density analysis in three dimensions by computed tomographic scanning. Soil Science Society of America Journal 46:445-450.

Peyton, R.L., B.A. Haeffner, S.H. Anderson and C.J. Gantzer. 1992. Applying Xray $C T$ to measure macropore diameters in undisturbed soil cores. Geoderma 53:329-340.

Peyton, R.L., C.J. Gantzer, S.H. Anderson, B.A. Haeffner and P. Pfeiffer. 1994. Fractal dimension to describe soil macropore structure using $x$-ray computed tomography. Water Resources Research 30:691-700.

Pierret, A., Y. Capowiez, L. Belzunces and C.J. Moran. 2002. 3D reconstruction and quantification of macropores using $X$-ray computed tomography and image analysis. Geoderma 106:247-271.

Ringrose-Voase, A.J. 1996. Measurement of soil macropore geometry by image analysis of sections through impregnated soil. Plant Science 183:27-47. 
Romvári,R., C.S., Hancz, Z.S., Petrási, T. Molnár and P. Horn. 2002. Noninvasive measurement of fillet composition of four freshwater fish species by computer tomography. Aquaculture International 10:231-240.

Sahasrabudhe, S.C. and K.S. Gupta. 1992. A valley-seeking threshold selection method. In Computer Vision and Image Processing, ed. L. Shapiro and A. Rosenfeld, 55-65. San Diego, CA: Academic Press.

Sahoo, P.K., D.W. Slaff and T.A.Albert. 1997. threshold Selection using a minimal histogram entropy difference. Optical Engineering 36(7):19761981.

Sakou, J.1989. Automatic detection of foreign material in food (In Japanese). Shokuhin - kogya 32(18):28-33.

Sarig Y., P. Chen, A. Gayer and P. Bendel. 1992. Evaluating non-destructive techniques for the detection of seed in pomelo fruit and of internal tissue breakdown in melon. In Proceedings of the International Congress of Agricultural Engineering, Beijing, China,

Schatzki, T.F., R.P. Haff, R. Young, I. Can, L.C., Le and N. Toyofuku. 1997. Defect detection in apples by means of $\mathrm{X}$-ray imaging. Transactions of the ASAE 40:1407-1415.

Schwarz F.J. and M. Kirchgessner. 1993. Didestibility, growth and carcass composition of carp (Cyprinus carpio L.) fed different starches. Archives of Animal Nutrition 43:275-282.

Seeram, E. 1982. Computed Tomography Technology. Philadelhphia, PA: W.B.Saunders Company.

Self, G., H. Wainwright and M. Povey. 1993. Non-destructive quality determination for fruit and vegetables. Postharvest News and Information 4(1):18-20.

Shinohara, H.1995. KD901G X-ray system to reject contaminants (In Japanese). Reitou 70(817):27-32.

Skerjvold, H., K. Grosneth, O. Vangen and A. Evenson. 1981. In vivo estimation of body composition by computerized tomography. Zeitschrift fur Tierzuchtung Zuchtungsbiologic 98:77-79. 
Som, S., P. Wells and J. Davis. 1992. Automated feature extraction of wood from tomographic images. In: Proceedings of the second International Conference on Automation. Robotics and Computer Vision, Singapore.

Sonego, L., R. Ben-Arie, J. Raynal and J.C. Pech. 1995. Biochemical and physical evaluation of textural characteristics of nectarines exhibiting woolly breakdown: NMR imaging, X-ray computed tomography and pectin composition. Postharvest Biology and Technology 5:187-198.

Sorenson, M.T.1992. In vivo prediction of goat body composition by computer Tomography. Animal Production 54:67-73.

Stephens, L.E., and G.H.Foster. 1976. Grain Bulk properties as affected by mechanical grain spreaders. Transactions of the ASAE 19: 354-358.

Suetens, P.,2002. Fundamentals of Medical Imaging. Massachusetts, MS: Cambridge University Press.

Suzuki, K., T. Tajima, S. Takano, T. Asano and T. Hasegawa. 1994. Nondestructive methods for identifying injury to vapour heat-treated papaya. Journal of Food Science 59(4):855-857.

Thieme, J., G. Schneider and C. Knochel. 2003. X-ray tomography of a microhabitat of bacteria and other soil colloids with sub- $100 \mathrm{~nm}$ resolution. Micron 34:339-344.

Thomas, P., S.C., Saxena, R. Chandra, R. Rao and C.R. Bhatia. 1993. X-ray imaging for detecting spongy tissue, an internal disorder in fruits of 'Alphonso' mango (Mangifera Indica L.). Journal of Horticultural Science 68:803-806.

Tollner, E.W., B.P., Verma and J. M. Cheshire. 1987. Observing soil-tool interactions and soil organisms using $\mathrm{x}$-ray computer tomography. Transactions of the ASAE 30(6):1605-1610.

Tollner, E.W., J.W., Davis and B.P. Verma. 1989. Managing errors with X-ray computed tomography (X-ray CT) when measuring physical properties. Transactions of the ASAE. 32:1090-1096.

Tollner, E.W., R. Harrison and C. Murphy.1991.Interpreting the pixel standard deviation statistic from an X-ray topographic scanner. Transactions of the ASAE 34(3):1054-1059.

Tollner, E.W., Y.C., Hung, B.L., Upchurch and E.E. Prussia. 1992. Relating X-ray absorption to density and water content in apples. Transactions of the. ASAE 35(66):1921-1928. 
Tollner, E.W. 1993. X-ray technology for detecting physical quality attributes in agricultural product. Postharvest News and Information 4(6):149-155.

Tollner, E.W., C. Murphy and E. L. Ramseur. 1993. Applications of Computed Tomography in Agriculture, Madison, WI: Soil Science Society of America Publications.

U.S.Food and Drug Administration. 2003. Radiation Risks. http:// www.fda.gov/cdrh/ct/risks.html. (14/10/2003).

Vangen, O., E. Sehested and N. Standal. 1985. Protein and fat changes in boars during fasting and performance testing estimated by Computerized tomography. $36^{\text {th }}$ Annual Meeting European Association of Animal Production, Halkidiki, Greece. 2:266-267.

Vangen, $\mathrm{O}$ and N. Kolstad. 1986. Genetic control of growth, composition, appetite and feed utilization in pigs and poultry. 3rd World Congr. Gen. Appl. Livestock Prod. XI, 367. Lincoln. Nebraska.

Vangen, $\mathrm{O}$ and J.Thompson. 1992. The use of CAT scanning to measure maintenance efficiency in genetic lines of sheep. In: Commission on Sheep and Goat Production, Session 5, 43 rd meeting of the European Association for Animal Production. Madrid, Spain.

Velasco, L., Martinez, Jose M, Haro, A. 1998. Application of Near-Infrared Reflectanec spectroscopy to Estimate the Bulk density of Ethiopian Mustard seeds. Journal of the Science of Food and the Agriculture 77:. 312-318.

Vladimirov, L.V., and B.M. Kanter. 2002. Analysis of the dose load on patients and medical personnel exerted by the FSTs-U-01 photoroentgenograph with X-ray image intensifier. Biomedical Engineering 36:140-144.

Wagner, F.G., F.W., Taylor, D.S., Ladd, C.W., McMillin and F.L., Roder. 1989. Ultrafast CT scanning of an oak log for internal defects. Forest Production Journal 39(11/12):62-64.

Warner G.S., J.L., Nieber, I.D., Moore and R.A. Geise. 1989. Characterizing macropores in soil by computed tomography. Soil Science Society of America Journal 53:653-660.

Yamashita T, Y. Nabeshima and M. Noda. 2000. High-resolution microcomputed tomography analyses of the abnormal trabecular bone structures in klotho gene mutant mice. Journal of Endocrinology 164:239-245. 
Yang, C., P. Chung and C.Chang. 1996. Hierarchial fast two-dimensional entropy thresholding algorithm using a histogram pyramid. Optical Engineering 35(11):3227-3241.

Zwiggelaar R., Bull, C.R., Mooney and M.J., Czarnes.1997. The detection of soft materials by selective energy $\mathrm{X}$-ray transmission imaging and computer tomography. Journal of Agricultural Engineering Research 66(3):203-212. 